\title{
Trauma, life events and PTSD : a challenge for patients and family doctors
}

Citation for published version (APA):

Mol, S. S. L. (2002). Trauma, life events and PTSD : a challenge for patients and family doctors. [Doctoral Thesis, Maastricht University]. Universiteit Maastricht. https://doi.org/10.26481/dis.20020920sm

Document status and date:

Published: 01/01/2002

DOI:

10.26481/dis.20020920sm

Document Version:

Publisher's PDF, also known as Version of record

\section{Please check the document version of this publication:}

- A submitted manuscript is the version of the article upon submission and before peer-review. There can be important differences between the submitted version and the official published version of record.

People interested in the research are advised to contact the author for the final version of the publication, or visit the DOI to the publisher's website.

- The final author version and the galley proof are versions of the publication after peer review.

- The final published version features the final layout of the paper including the volume, issue and page numbers.

Link to publication

\footnotetext{
General rights rights.

- You may freely distribute the URL identifying the publication in the public portal. please follow below link for the End User Agreement:

www.umlib.nl/taverne-license

Take down policy

If you believe that this document breaches copyright please contact us at:

repository@maastrichtuniversity.nl

providing details and we will investigate your claim.
}

Copyright and moral rights for the publications made accessible in the public portal are retained by the authors and/or other copyright owners and it is a condition of accessing publications that users recognise and abide by the legal requirements associated with these

- Users may download and print one copy of any publication from the public portal for the purpose of private study or research.

- You may not further distribute the material or use it for any profit-making activity or commercial gain

If the publication is distributed under the terms of Article $25 \mathrm{fa}$ of the Dutch Copyright Act, indicated by the "Taverne" license above, 
Trauma, life events and PTSD:

Saskia S.L. Mol 
The study presented in this thesis was conducted at the Research Institute for Extramural and Transmural Health Care (ExTra), which participates in the Netherlands School of Primary Care Research (CaRe), acknowledged in 1995 by the Royal Dutch Academy of Science (KNAW).

ISBN 90-6464-873-5

Cover Design: Painting "Transparant oranje” by Petra Mol, lay-out by Petra Mol and Frank Boesveld

Design and lay-out: MTM Grafische Studio, UMC Utrecht

Printer: Unigraphic, Maastricht, The Netherlands

The study presented in this thesis was supported by a grant from the Stichting Achmea Slachtoffer en Samenleving" (Achmea Foundation "Victim ii and Society", Joke.Verhoeven@Achmea.nl) 


\section{Trauma, life events and PTSD: a challenge for patients and family doctors}

proefschrift

ter verkrijging van de graad van doctor aan de Universiteit Maastricht, op gezag van de Rector Magnificus, Prof.dr. A.C Nieuwenhuijzen Kruseman volgens het besluit van het College van Decanen, in het openbaar te verdedigen op vrijdag 20 september 2002 om 14.00 uur

door 
Promotores:

Prof. dr. J.A. Knottnerus

Prof. dr. G.J. Dinant

Co-promotor:

Dr. J.F.M. Metsemakers

Beoordelingscommissie:

Prof. dr. A. Appels (voorzitter)

Prof. dr. F. Buntinx

Prof. dr. B.P.R. Gersons (Universiteit van Amsterdam)

Prof. dr. A.L. Lagro-Janssen (Katholieke Universiteit Nijmegen)

Dr. T. van der Weijden 
To the African child 


\section{Contents}

Chapter 1

Introduction

Chapter 2

Traumatic events in the Netherlands: comparison of data from national registration systems, population enquiries and studies in general practices - a literature review

\section{Chapter 3}

Traumatic events in a general practice population: the patient's perspective

\section{Chapter 4}

Barriers in the care for patients who have experienced a traumatic event: the perspective of the general practitioner

\section{Chapter 5}

Exploring the iceberg: general practitioners long-term awareness of their patients' exposure to traumatic events

\section{Chapter 6}

Symptoms of post-traumatic stress disorder are not specific to traumatic events: evidence from the open population

\section{Chapter 7}

Determinants of a high PTSD symptom score after stressful events: a population-based study

\section{Chapter 8}

General discussion and conclusions 
Summary

121

Samenvatting

125

Dankwoord

131

Curriculum vitae

135

Appendix 1

137

Report of the expert meeting

Appendix 2

149

Translation of relevant parts of the patient questionnaire

Verantwoording citaten

164 



\section{Introduction}

Chapter 1

Chopter 2

Chopter 3

Chopter 4

Chapter 5

Chopter 6

Chopter 7

Chopter 8

Summory

Somenvatr

Dankwoor

Curriculum

Appendix

Appendix 


\section{Background}

We all see reports of traumatic events in the papers and on the news everyday. They range from large scale terrorist attacks and wars fought in faraway countries, to the recent disasters in the Netherlands due to a big fireworks explosion in a residential area and a fierce blaze in a pub on new years' eve, and finally to events such as robberies and accidents in our own hometowns. Sometimes our family or friends, or we ourselves, are confronted with injury or loss of loved ones. In one way or another, traumatic events are part of our daily lives.

People try to come to terms with traumatic experiences in various ways. Social support plays an important role in this process, as do caregivers such as clergy, social workers and volunteers from victim organisations. Another professional expected to provide care in this area is the general practitioner (GP). Several characteristics of general practice contribute to it's potentially central role in the care of victims in the aftermath of a traumatic event. To begin with, the easy accessibility and the patients' familiarity with their GP is likely to ease presentation of problems around victimisation. Secondly, as the GP is in contact with both the patient and his or her social context, as well as with the professionals to whom the patient can be referred, the GP is in a good position to advise care that is appropriate in terms of timing and content. In the third place, the continuity of care in general practice enables long-term follow-up. In case of referral there remains a task for the GP in supporting the family and making sure secondary care is not fragmented. Once secondary care has been terminated the GP is in a good position for follow-up of the patient.

Although there are no exact data on the frequency with which the Dutch GP is confronted with trauma victims, statistics on the incidence of traumatic events from questionnaires held in the open population give an idea of how often the doctor could be confronted with trauma victims. A rough estimate from such questionnaires shows that, per year, some $10 \%$ of the population experience one of the following: accidents, robbery, adult physical or sexual abuse ${ }^{1-3}$. Of the patients that consult the GP in a given year (approximately $70 \%$ of the average practice population of 2350 ) some 160 patients will have experienced a traumatic event, a considerable amount ${ }^{4.5}$.

There is at present no systematic insight into the way general practitioners in the Netherlands fulfil the task of caring for this potentially large group of patients. Little is known about which help is sought by patients in the aftermath of traumatic events, and how they appreciate the care given by their GP, as well as about problems GPs themselves encounter in caring for this group of patients. Greater insight in these matters is useful for the enhancement of the present care. 
Another topic under study is the distress traumatic events give rise to. On the short term people are likely to re-experience the event, to experience palpitations and other physiological equivalents of fear when they are reminded of the event, sensations that are alternated by avoidance and numbing. Such reactions are considered normal, and probably help one integrate the experience in one's life ${ }^{6}$. Only if the distress surpasses a certain threshold, is it considered a disorder: the acute stress disorder ${ }^{7}$.

Usually, the acute reactions to a traumatic event will subside. Some persons, however, experience sequelae on the long term, including sleep disorders, depression, somatisation, anxiety disorders, as well as a great variety of physical problems, explained or unexplained ${ }^{7-9}$. Pre-event characteristics such as previously experienced traumatic events and personality, characteristics of the event itself and the care and support given after the event influence the type and intensity of the reaction.

A long term sequel considered to be specific to traumatic events, is chronic post-traumatic stress disorder (PTSD) ${ }^{7}$. When symptoms of re-experiencing, hyperarousal and numbing or avoidance last longer than three months, this psychiatric diagnosis must be considered. It can be the consequence of acute events such as a car accident or disaster, but it can also ensue from domestic violence or captivity, events with a repetitive or chronic character. In the latter case a more complex response pattern may follow, including changes in character, affective arousal, attention and consciousness; the diagnostic label suggested for this type of PTSD is complex PTSD $^{10,11}$, or "Disorder of Extreme Stress Not Otherwise Specified" (DESNOS) ${ }^{7}$.

An area into which little research has been done, is the extent to which various types of events experienced by the general population give rise to symptoms of PTSD. Characteristics of persons with high PTSD symptom scores form another area of interest. This knowledge may serve to improve trauma care by alerting the GP to the diagnosis of PTSD.

\section{Aim}

The aim of our study is to give insight in the challenges for general practice in the Netherlands, regarding the care for patients who have experienced traumatic and other stressful events, from the perspectives of both the patient and the doctor. The ultimate aim is to provide recommendations for the enhancement of the GP's care in this field. 


\section{Traumatic events, life events, stressful events: definitions}

In this thesis we have chosen to group the various traumata according to the following definitions. We have called the events that form a threat to one's physical integrity, and therefore can give rise to post-traumatic stress disorder, traumata ${ }^{7}$. Other events that have an impact on one's life, but in a less direct and physical manner, we have chosen to call life events. Stressful events is the name we use for both types together.

In the studies described in the chapters 2 through 5 , about the incidence of traumatic events and about the doctor's and the patients' perspective on trauma care, we have included the most prevalent of the traumatic events experienced by patients personally. These are serious accidents, burglary, robbery, physical and sexual abuse as an adult and in childhood, disaster and war experiences.

In chapters 6 and 7, ahout spmptoms of post-traumatic stress, we heve extended the listed range of events. We have included sudden death of loved ones, another group of traumatic events that according to the DSM-IV definition can give rise to PTSD. Besides, we have included life events such as chronic illnesses, problems with relationships, employment and finances.

\section{Research questions and design}

The research questions and their respective study designs will be discussed in the order of the chapters.

\section{Incidence}

\section{Research question}

1. What is the incidence of traumatic events in the general population in the Netherlands?

To get an impression of the frequency with which people are confronted with traumatic events we started our study with a literature review (Chapter 2). This was followed up by a study in the open population, asking about lifetime experience with traumatic events (Chapter 3). The following events were covered: serious accidents, burglary/ robbery, physical abuse as an adult, sexual abuse as an adult, physical or sexual abuse in childhood, disaster and war. 
Incidence: population and instruments

Literature review:

Electronic databases and catalogues were searched for studies on incidences and cumulative incidences published between 1986-1998. From these publications more references were searched bock to 1984.

Patient questionnaire:

The patient questionnaire (see box below: Patients' perspective: population and instruments), sent to 2997 patients in Limburg, contained a checklist with traumatic experiences. Patients had to indicate the frequency with which they had been confronted with these in their lifetime.

\section{The patient's perspective of general practice care after traumatic events}

\section{Research questions}

2. Which role do patients who have experienced traumatic events assign their GPs?

3. How is the care they receive appreciated by these patients?

The second and third research questions of this study, to be answered in chapter 3, aim at gaining insight in the patients' perspective of the care. Do they want professional help, in particular GP help, after traumatic events, or do they prefer to work things out with family and friends? What do they expect from their general practitioner, and how do they appreciate the care they receive? Does the perception they have of the GPs' task influence their choice of consulting or not consulting? The results can be used to enhance patient education and GP training.

\section{Patients' perspective: population and instruments}

A written questionnaire (see Appendix 2) was posted to a random sample of patients obtained from the Maastricht Registration Network of Family Practices, consisting of - at the time - $16 \mathrm{GP}$ practices in the province of Limburg. The population in the network is similar to the Dutch population as regards age and sex, education, medical insurance and type of household ${ }^{12}$.

Twelve of the practices, with 32 doctors, consented to participate. Of the 3200 patients sampled, 203 were excluded because of dementia, acute psychosis, illiteracy, being too fragile to participate, and having moved away or died. The 2997 questionnaires, which were posted via the GPs, could be returned anonymously. Those who had not yet responded after four weeks - identified by a code number - received a written reminder.

The patient questionnaire consisted of the following parts:

a. personal characteristics, use of medical care in the past year (GP, hospital admission, specialist outpatient clinic, community nurse, physiotherapist, social worker, ambulatory mental health care), handicap due to any of the events, use of sedatives, alcohol, drugs 
b. checklist of traumatic events:

- serious accidents

- burglary/ robbery

- chronic illness or sudden-death of loved one

- physical abuse as an adult

- sexual abuse as an adult

- physical or sexual abuse in childhood

- disaster

- war experience

c. a chapter, per event category, on characteristics of the most recent event (frequency, dates, injury, impact on one's life), non-professional and professional help wanted and sought, appreciation of GP care, reasons for not seeking care

d. other events experienced, not covered by checklist

e. PSS-SR checklist ${ }^{13}$ on symptoms of post-traumatic stress, to be filled out with the worst event in mind

\section{Barriers in the care for traumatized patients: the GP's perspective}

\section{Research questions}

4. Which barriers do GPs encounter in the care of patients who experience a traumatic event?

5. Are there GP characteristics that determine the number of barriers a GP experiences?

6. To what extent are general practitioners aware of their patients' exposure to traumatic events?

7. Are there patient, event or GP characteristics that determine this awareness?

Besides gaining insight in what is felt by patients as good GP care after traumatic events, we were interested to know how GPs themselves view this topic (chapter 4). We asked them which problems they encounter in taking care of these patients. The aim of this exercise was threefold. The literature on adult learning shows the importance of linking on to the learning needs of the "students", when planning curricula ${ }^{14}$. Knowledge of the barriers would therefore enable us to give advice on relevant learning objectives for vocational training and continuous medical education. Secondly, to be able to direct further training on trauma care more efficiently, we were interested to know whether doctors with certain characteristics experience more barriers than others. The third goal was to gain insight in problems with the collaboration with other caregivers in this field. This could give rise to recommendations on the organizational level. 
GP Barriers: population and instruments

Data collection for the study on barriers was done with a telephone interview amongst a random sample of 500 Dutch doctors, male and female doctors being equally represented. For the sake of brevity only four types of trauma were studied: accidents as a representative of an acute type of trauma, incest in the past as an example of a repetitive type of trauma which has stopped, and present violence in the family involving adults or children as two examples of events that are ongoing.

The doctors were asked about barriers experienced in the following areas:

- recognition of signs and symptoms

- verification of the traumatic event

- treotment

- referral

- the need for guidelines and refresher courses on this topic.

The following characteristics of the doctors and their practices were collected: doctor's sex, age, years of experience as a GP, type of practice and the estimated incidence in the practice.

A lack of awareness of patients' past experiences - on the doctor's part - was postulated to be another barrier in caring for patients with health problems related to a trauma. As a matter of course, asking GPs how aware they think they are would give no insight into this matter. There being no studies on this topic in the Netherlands, we used the data from our literature study (chapter 2). We compared incidences found in surveys held in the open population to those from GP registration studies. As the evidence from the literature was lacunal and the available data showed a wide range of results, we performed a study of the iceberg phenomenon in a general practice population. We asked the doctors of the patients included in the first part of our study what they knew about events their patients had experienced, and compared this with what the patients had reported to us (chapter 5).

As it was one of our aims to give practical recommendations, we also collected characteristics of patients and events related to a low awareness. This would enable us to advise GPs in which cases to be specially alert. Furthermore, as awareness could also be a characteristic of the doctor, certain types of doctors being more aware than others, the relation between several GP characteristics and awareness was studied.

The iceberg phenomenon: Population and instruments

The 32 doctors, whose patients we had studied in the first part of our study, received questionnaires of all patients who had reported the experience of one or more events to us, as well as of a random sample of patients who had reported no events. The GPs were blinded for victimisation state. The questionnaires were about the type and date (year) of each patient's traumatic experiences, using the list of traumatic events from the patient questionnaire. The GPs received a single questionnaire about their own demographics, training and interest in the topic as well as personal experience with traumatic events. 


\section{Symptoms of PTSD after traumatic and other stressful events}

\section{Research questions}

8. Do life events give rise to as many PTSD symptoms as traumatic events?

9. Which personal and health characteristics are determinants of PTSD symptoms in persons who have suffered a stressful event?

Traumatic events - as described under the heading of PTSD in the psychiatric literature - are extreme stressors involving actual or threatened death or serious injury, or other threat to one's physical integrity ${ }^{7}$. Examples of these events are accidents, abuse and combat. GPs are certainly confronted with victims of these typical traumatic events, but they much more frequently encounter patients who have experienced other types of events that are stressful, such as chronic illness of the patient and their relatives, divorce and unemployment (life events). As there is evidence in the literature, that some of these life events give rise to PTSD-symptoms, we were interested to know to what extent this would be the case for a larger range of life events in a general population. This study is described in chapter 6 .

The last research question, which is answered in chapter 7, aims at advising the general practitioner in whom to be alert about symptoms of PTSD. Determinants of PTSD have been studied in the United States, Canada and Australia, mostly in selected groups who had experienced a communal event such as a fire or hurricane. Studies in the open population, looking at a variety of events, are scarce; none were found in the European literature. We focused our study on indicators to which the GP has easy access: personal and health characteristics. We looked at both traumatic events and life events.

\section{PTSD: population and instruments}

The data about personal and health characteristics, the events the subjects experienced and the PTSD symptom scores (PSS-SR) were collected vio the patient questionnaire described under the heading "Patient's perspective: population and instruments". 


\section{Guide to the reader}

The main body of this thesis comprises a series of six articles (Chapters 27). As each article must be comprehensible by itself, some repetition is inevitable - especially in the "Methods" sections. The articles are followed by a final chapter in which the main findings, the methodology, as well as the implications for further study and for daily practice are discussed. This is followed by a summary in English and in Dutch.

The first appendix is a report of an expert meeting in which the recommendations ensuing from this study were discussed. The 14 experts were from the fields of trauma care, education, research, policy-making and implementation strategies, all within general practice.

The second appendix contains the most relevant parts of the patient questionnaire in English, and the Dutch version of the PTSD symptom checklist (PSS-SR).

As an attachment to the back cover of this thesis the reader will find an educational booklet, written by the author, on communicating with patients who have experienced traumatic events. It has been published by the Dutch College of General Practitioners, which has distributed it to all its GP members. 


\section{References}

1. Mulder S, Bloemhoff A, Harris S, Kampen LTB van, Schoots W. Ongevallen in Nederland. TSG 1996; 4:140-45.

2. Ploeg HM van der, Buuren ET, Wöstmann M, Hulshof RE, Huisman SJ, Kleijn WC. Psychologisch onderzoek naar (het ontbreken van) de hulpvraag van slachtoffers van geweld. Deel I: Het meten van de omvang van enkele vormen van geweld en het in kontakt komen met slachtoffers. Lisse: Swets en Zeitlinger, 1985.

3. Mayhew P, Dijk JJM van. Criminal Victimization in eleven industrialised coutries. Key findings from the 1996 international crime victims survey. Den Hoag: Ministerie van Justitie/WODC, 1997.

4. Lamberts $\mathrm{H}$. Morbidity in general practice. Diagnosis related information from the Monitoring Project. Utrecht: Huisartsenpers, 1984.

5. Veltman MTM. Huisartsengeneeskundige zorgepisoden. Analyse van een zevenjaars bestand [proefschrift]. Lelystod: Meditekst, 1995.

6. Horowitz M. Stress response syndromes. New York: Jason Aronson, 1986.

7. American Psychiatric Association APA. Diagnostic and statistical manual of mental disorders. Woshington DC: APA, 1994.

8. Portegijs PJ, Jeuken FM, Horst FG van der, Kraan HF, Knottnerus JA. A troubled youth: relations with somatization, depression and anxiety in adulthood. Fam Pract 1996;13(1):1-11.

9. Resnick HS, Acierno R, Kilpatrick DG. Health impact of interpersonal violence: II. Medical and mental health outcomes. Behavioral Medicine 1997:65-78.

10. Herman J. Trauma and recovery. New York: Basic Books, 1992.

11. Dickinson LM, deGruy FV, Dickinson WP, Candib LM. Complex posttraumatic stress disorder: evidence from the primary care setting. Gen Hosp Psychiotry 1998;20(4):214-24.

12. Metsemakers JFM, Höppener $P$, Knottnerus JA, Kocken RJJ. Computerized health information in the Netherlands: a registration network of family practices. Br J Gen Pract 1992;42:102106.

13. Foa BE, Riggs SD, Dancu CV, Rothbaum BO. Reliability and validity of a brief instrument for assessing post-traumatic stress disorder. J Trauma Stress 1993;6(4):459-473.

14. Hodges B, Inch C, Silver I. Improving the psychiatric knowledge, skills, and attitudes of primary care physicians, 1950-2000: A review. Am J Psychiatry 2001;158(10):1579-86. 
Traumatic events in the

Netherlands:

comparison of data from national

registration systems, population

surveys and studies in general

practices - a literature review 


\section{Abstract \\ Object}

Comparison of (cumulative) incidences of traumatic events from population surveys and registration systems as well as from studies in general practice.

\section{Design}

Literature study.

\section{Method}

Literature searches were done about the frequencies of accidents, fires, murder, robbery, physical and sexual abuse listed in electronic databases and relevant catologues covering 1986-1998, after which more references were searched via the references found, going back to 1984 .

\section{Results}

There were large discrepancies between frequencies found in the various studies, such as surveys in the open population $(\mathrm{n}=10)$, national registration systems $(n=4)$ and studies in general practice $(n=4)$. The incidences (per 1000 persons per year) of physical abuse were $66,2.7$ and 1-3 for surveys in the open population, police and general practitioners' registration systems respectively. For sexual abuse the figures were $21,0.025$ and $0.2-2.9$ respectively. Different definitions and methods were used in the studies.

\section{Conclusion}

Considering the variation in the data from various sources, incidences of traumatic events must be approached with care. Regarding physical and sexual abuse: general practitioners are aware of only a fraction of the abuse that their patients have experienced. 


\section{Introduction}

Violent robbery, car accidents, sexual and physical abuse, are some of the stressful events from a range of events that people may have to face during their lifetime. General practitioners can play a key role in the process of coping with such events. GPs are in a good position to detect any signals that may refer to continuing traumatising situations or to traumas from the past that have not yet been dealt with. In addition, the tasks of general practitioners include guidance and, if necessary, referral of these patients ${ }^{1}$. To do so, general practitioners need to be able to recognise early indicators of traumatisation, have the skills to bring up the topic, and be familiar with the organisations to which they can refer patients. A primary condition for performing these tasks, is that GPs are aware that events can cause distress and illness. This requires insight in the incidence of victimisation and the chances that such events lead to psychological or psychosomatic complaints ${ }^{2}$. A general practitioner who believes that physical abuse is a very rare phenomenon, is not likely to enquire about such experiences.

Stressful events can be looked at from various angles. Firstly, there are the so-called life events, events that upset the daily pattern and require an individual to make far-reaching adjustment. These events may lead to adjustment disorders and depressions ${ }^{3.4}$. Another category of events, as defined in Diagnostic State Manual of Mental Disorders IV (DSM-IV), concerns personally experienced or witnessed events that are life-threatening or involve a large risk of serious personal injury, and which are accompanied by feelings of fear, helplessness or horror. Reliving the event and avoidance behaviour as a result of such events prompt victims to turn to a GP or other care providers for help. This also applies to event-related disorders, such as anxiety disorders, amongst which posttraumatic stress disorders and depressions ${ }^{5}$. In this overview, we focus on the category of traumatic events as meant in DSM-IV.

This article contains an overview of the literature on the incidence of such events in the Netherlands. A comparison is made of figures from surveys among the general population, from various registration systems, and data from general practitioners. These figures will also be used to get an impression of the degree to which GPs are aware of such events.

\section{Method}

The following electronic catalogues were consulted: Nederlands Tijdschrift voor Geneeskunde (from 1986); Huisarts en Wetenschap (from 1986); Nederlandse Centrale Catalogus (from 1989); the catalogues of the Maastricht University, Aletta Centrum voor Vrouwengezondheidszorg (Aletta Centre for Women's Health Care) (from 1987), Trimbos Institute, Buro Vertrouwensarts inzake Kindermishandeling (Social Services Register for 
Child Abuse) in Maastricht, Transact: Centre for Gender issues in health care and prevention of sexual violence (from 1989). To find relevant literature, the Dutch key words 'slachtoffer' (and 'hulpverlening'), 'misbruik' and 'mishandeling' were used ('victim', 'care', 'sexual abuse' and 'physical abuse'). For the English catalogues (Medline and Psychlit from 1992), we used the key word 'victim*' in combination with 'general practice', 'family medicine', and 'family practice'. We consulted experts on victims of child abuse, sexual abuse, traffic accidents and crime. In addition, we used relevant reports (Ministry of Justice, National Child Protection Agency).

Earlier literature was retrieved, back to 1984 , on the basis of the references found. Our study took place in 1998.

The overview contains publications that matched the following criteria: (a) data on the population of the Netherlands; (b) relating to at least one of the following traumatic events: accident in which someone sustained injuries (at home, at work, on the road); murder; fire (at home or at work); violent robbery; (threat of) physical abuse, by known or unknown person; sexual abuse, by known or unknown person; (c) the research method concerned registration through a national registration system, or a survey among a sample of individuals from the open population, or a study in general practices; (d) the data could be converted into figures of (cumulative) incidence.

To provide insight in the possibility of generalizing the results, we have reported the research method, and the nature and size of the studied population (including the response) for each publication.

\section{Results}

Publications were found on four national registration systems, ten surveys among the open population and four registration studies from general practice (tables 1-3). In most studies, the focus is on the incidence during the previous year. However, where data relate to ever having experienced an event, cumulative incidences are reported (in italics).

The extent of the discrepancy between the results of data from registration systems and surveys in open populations is striking. The number of traffic casualties (table 1) - according to the police - is 3.23 per 1000 per year, while the figure is 22 according to a survey among the population. For sexual abuse (table 3), the differences are even greater. For rape and "indecent assault", the police have registered an incidence of 0.025 per 1000 persons, whereas victim surveys give figures between 7 and 90 per 1000 persons per year; the difference is by a factor 280-3600.

Data collected by general practitioners also differ greatly from those in surveys among the open population. Case note research carried out in a GP 
to 3.1 reported physical abuse (table 2) ${ }^{17}$. The Chronic Morbidity Registration in the Netherlands reported an incidence of 0.9 for $1997^{18}$. A survey among an open population showed that the figure was between 23 and 73 per 1000 per year $^{12}$.

A special group concerns studies in which individuals were asked whether they had experienced something 'at any time in their lives', as was the case in large-scale studies on physical and sexual abuse (tables 2 and 3 , Römkens, van Dijk, numbers in italics) ${ }^{15,16,20}$. These cumulative incidence figures can only be compared indirectly with the incidence figures from the registration studies and surveys with data on 'events in the past year'. In general, the findings reported by Römkens, Van Dijk and Draijer ${ }^{15,16,20}$ match those from other surveys among the open population, but differ considerably from the figures known to GPs ${ }^{12,13,16,22}$. To illustrate this: a general practitioner will see $70 \%$ of the patients registered in his or her practice in any one year ${ }^{25.26}$. In a standard practice (2350 patients, of whom 940 are adult women), the GP will see about 670 women each year. Of these, $7.4 \%$ (50 women) at some point in life is raped or forced to have sex within a relationship ${ }^{15}$. Assuming that the chance of experiencing this is similar in all age groups, GPs will see 25 women per year who were forced by their partner to have sex or who were raped. This contrasts sharply with the figure of 0.79 of adult women and men (0.48/1000 x 1645 adults) seen yearly by the GP according to the GP registration systems, which not only registered abuse within the relationship, but also outside $\mathrm{it}^{24}$.

Ordering events by their frequency depends on the method of data collection used. Judging by the most common method - surveys among the open population - accidents in the home that require medical treatment, are the most common category, followed by physical threat and abuse, traffic accidents with injuries, and then burglary and sexual abuse. The list is closed by bag snatching and homicide.

In three of the cited studies, long term psychological effects were studied $^{15,20,27}$. Of all women who were sexually abused by relatives when they were girls, $56 \%$ and $48 \%$, respectively, scored higher than average on the questionnaires on depression and $\mathrm{fear}^{20}$. In her study of physical abuse, Römkens mentions a positive correlation between depression and psychosomatic complaints, and the severity of the violence ${ }^{15}$. Also, women who reported to have experienced serious violence, indicated five times more often that they had 'considered suicide' than women who had not experienced violence.

Crimes against property (robbery et cetera), appeared to have caused psychological complaints in $9 \%$ of all men and $17 \%$ of all women within the first two years after the event (complaints including sleeping problems, nightmares, tiredness, stress, worrying and nervousness) ${ }^{27}$. Physical or sexual abuse by unknown persons led to such complaints in $25 \%$ to $32 \%$ of all 
Table 1 Accidents, fire, murder and robbery; incidence according to studies published between 1984-1997

\begin{tabular}{|c|c|c|c|c|}
\hline Author; & Population; & Response\%; & Incidence (per 1000/year) & \\
\hline & & & & \\
\hline (traffic, home and occupational) & & & & \\
\hline Central bureau of statistics (CBS) & total Dutch population in 1992; & NA; ${ }^{*}$ & traffic accidents & 0.75 \\
\hline Department of traffic statistics ${ }^{6}$ & police registration & $N=15,129,150$ & deaths & 0.09 \\
\hline 1992 & & & injured, admitted to hospital & 0.77 \\
\hline & & & injured, not admitted to hospital & 2.46 \\
\hline Den Hertog' ${ }^{7}$ & three hospital based prospective & NA & treated at A\&E department & \\
\hline $1990-94$ & registration systems, covering most & & traffic accidents & 3.6 \\
\hline & Dutch hospitals (VIPORS, PORS, LMR) & & home occidents & 34 \\
\hline & & & odmitted to hospital & \\
\hline & & & traffic accidents & 1.3 \\
\hline & & & home occidents & 3.8 \\
\hline Mulder 8 & Random Digital Dialing; & $71 \% ;$ & Traffic accidents & 22 \\
\hline $1992-93$ & Questionnaire & $N=25,284$ & Occupational accidents & 15 \\
\hline & & households with 67000 persons & Home accidents & \\
\hline & & & (all medically treated) ${ }^{\star \star}$ & 106 \\
\hline Fires and burn victims & & & & \\
\hline CBS Yearbook of statistics? & Total population of the Netherlands & NA & Fire in the home ${ }^{\star * \star}$ & 1.2 \\
\hline 1994 & & $N=15,341,600$ & & \\
\hline Den Hertog7 & 13 hospitals; & NA & Treated at A\&E Department & 0.80 \\
\hline $1990-94$ & prospective registration system & & Treated at burn centre & 0.02 \\
\hline
\end{tabular}


Table 1 Continued

\begin{tabular}{|c|c|c|c|c|}
\hline $\begin{array}{l}\text { Author; } \\
\text { Year of study }\end{array}$ & $\begin{array}{l}\text { Population; } \\
\text { Methodology }\end{array}$ & $\begin{array}{l}\text { Response\%; } \\
\text { Number }\end{array}$ & Incidence (per 1000/year) & \\
\hline \multicolumn{5}{|l|}{ Murder } \\
\hline CBS Yearbook of statistics ${ }^{10}$ & Total population of the Netherlands; & NA & $\delta$ & 0.016 \\
\hline 1995 & prospective registration system & $\mathrm{N}=7,662,300$ and $7,831,600$ ? & Q & 0.007 \\
\hline \multicolumn{5}{|l|}{ Robbery } \\
\hline $\begin{array}{l}\text { CBS Yearbook of statistics } 11 \\
1985\end{array}$ & $\begin{array}{l}\text { Total population of the Netherlands; } \\
\text { police registration system }\end{array}$ & NA & $\delta$ and $?$ & 0.0054 \\
\hline Van der Ploeg ${ }^{12}$ & Random selection of inhabitants of large cities; & $37 \%$ & Bag snatching & \\
\hline \multirow[t]{2}{*}{1985} & tel/written questionnaire & $N=2957$ & $\delta$ & 2 \\
\hline & & & १ & 11 \\
\hline Mayhew ${ }^{13}$ & Random selection open population; & $66 \%$; & $\delta$ and $?$ & 6 \\
\hline 1996 & telephone questionnaire & $N=2000$ & & \\
\hline
\end{tabular}

* NA: response\% not applicable

' when a response percentage is given, the number given refers to the number of respondents

** all categories together: $2 \%$ admission to hospital

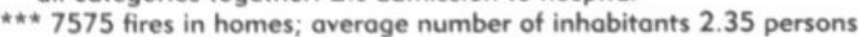




\section{Table 2 Physical abuse}

$\begin{array}{lllll}\text { Author; } & \text { Population; } & \text { Response } \% * ; & \text { Victim knew perpetrator before } & \text { Incidence (per 1000/year); } \\ \text { Year of study } & \text { Research methodology } & \text { Numbers } & \text { abuse took place: yes/no; once } & \text { Cumulative incidences, per 1000 }\end{array}$

Year of study

Research methodology Numbers abuse took place: yes/no; once

Cumulative incidences, per 1000

NATIONAL REGISTRATION

CBS Yearbook of statistics

Total population of the only or repeated

$1995^{10}$

Netherlands; $\quad N=15,424,100$

Not specified

Threat of physical abuse

0.66

police registration system

Physical abuse

1.80

(procès-verbal)

Annual report of the National Child Population of the Netherlands

Life-threatening physical abuse

0.23

neglect

0.44

Protection Agency (LSVBK) ${ }^{14}$

up to 20 years;

$N=3,754,560$

NA;

Perpetrator known; Physical abuse or physical

1995

prospective records of Social

Services Register for Child

Abuse

\section{POPULATION SURVEY}

Van der Ploeg '?

1984

Random selection of large

city dwellers:

$37 \%$;

tel/written questionnaire

$\mathrm{N}=2,957$

Perpetrator known or unknown;

once only or repeated

Perpetrator known:

ठ

Perpetrator unknown:

Random selection ? 20-60 35\%;

years, open population,

$N=1,016$

Perpetrator known;

repeated
Römkens's

1986 telephone interviews
Unilateral abuse within partner

relationship **: total

$43 \%$ slight

$23 \%$ moderate

$19 \%$ severe

$12 \%$ very severe

$3 \%$ severity unknown 


\begin{tabular}{|c|c|c|c|c|c|}
\hline $\begin{array}{l}\text { Author; } \\
\text { Year of study }\end{array}$ & $\begin{array}{l}\text { Population; } \\
\text { Research methodology }\end{array}$ & $\begin{array}{l}\text { Response \% *; } \\
\text { Numbers }\end{array}$ & $\begin{array}{l}\text { Victim knew perpetrator before } \\
\text { abuse took place: yes/no; once } \\
\text { only or repeated }\end{array}$ & $\begin{array}{l}\text { Incidence (per 1000/year); } \\
\text { Cumulative incidences, per } 1000\end{array}$ & \\
\hline CBS Yearbook of statistics ${ }^{10}$ & Random selection of open & NA; & Not specified & Threat of physical abuse & 35 \\
\hline 1995 & population $>15$ years & $N=5,396$ & & Physical abuse & 21 \\
\hline $\begin{array}{l}\text { Mayhew } 13 \\
1996\end{array}$ & $\begin{array}{l}\text { Random selection open } \\
\text { population; } \\
\text { telephone questionnaire }\end{array}$ & $\begin{array}{l}66 \% \\
N=2,000\end{array}$ & Not specified & Physical abuse (threats included) & 40 \\
\hline Van Dijk 16 & Random selection $18-70$ & $44 \%$ & Family members and housemotes; & ** & \\
\hline \multirow[t]{3}{*}{1997} & years open population; & $N=1,005$ & repeated & Beaten & 230 \\
\hline & telephone interviews & & & Kicked & 130 \\
\hline & & & & Injured with knife etc. & 16 \\
\hline \multicolumn{6}{|l|}{ GP REGISTRATION } \\
\hline $\begin{array}{l}\text { Van Griethuysen }{ }^{17} \\
1985-1990\end{array}$ & \multicolumn{2}{|c|}{$\begin{array}{l}6 \text { general practitioners }{ }^{* \star *} ; \mathrm{NA} ; \\
\text { retrospective cose-notes study }\end{array}$} & $\begin{array}{l}\text { Perpetrator known or unknown; } \\
7,000-9,000\end{array}$ & $\begin{array}{l}\text { Physical abuse (threats included) } \\
\text { once only or repeated } \\
\delta \\
\oint\end{array}$ & $\begin{array}{l}0.6-1.7 \\
1.3-3.1\end{array}$ \\
\hline $\begin{array}{l}\text { NIVEL } \\
1997\end{array}$ & $\begin{array}{l}63 \text { general practices; } \\
\text { prospective registration }\end{array}$ & $\begin{array}{l}N A_{;} \\
N=126,943\end{array}$ & $\begin{array}{l}\text { Perpetrator known or unknown; } \\
\text { once only or repeated }\end{array}$ & $\begin{array}{l}\text { Unilateral violence } \\
\delta \\
\varnothing\end{array}$ & $\begin{array}{l}2.8 \\
1.0\end{array}$ \\
\hline
\end{tabular}

NA: response\% not applicable

'when a response percentage is given, the number given refers to the number of respondents

** cumulative incidence (per 1000)

*** student practices: $85 \%$ of patients $20-39$ years 
Table 3 Sexual abuse

\begin{tabular}{|c|c|c|c|c|c|}
\hline $\begin{array}{l}\text { Author; } \\
\text { Year of study }\end{array}$ & $\begin{array}{l}\text { Population; } \\
\text { Research methodology }\end{array}$ & $\begin{array}{l}\text { Response\% ; } \\
\text { Numbers }\end{array}$ & Once only or repeated & $\begin{array}{l}\text { Incidence (per 1000/year); } \\
\text { Cumulative incidences, per 1000/year }\end{array}$ & \\
\hline \multicolumn{6}{|l|}{ NATIONAL REGISTRATION } \\
\hline CBS Yearbook of statistics; ${ }^{10}$ & Total population of the & $N A ; *$ & Once only & Rape & 0.009 \\
\hline 1995 & $\begin{array}{l}\text { Netherlands; } \\
\text { police registration system } \\
\text { (proces-verbal) }\end{array}$ & $N=15,424,100$ & & Indecent assault & 0.016 \\
\hline $\begin{array}{l}\text { Annual report of the National } \\
\text { Child } \\
\text { Protection Agency (LSVBK); }{ }^{14} \\
1995\end{array}$ & $\begin{array}{l}\text { Population of the } \\
\text { Netherlands up to } 20 \text { years; } \\
\text { prospective records Social } \\
\text { Services Register for Child } \\
\text { Abuse }\end{array}$ & $\begin{array}{l}\text { NA; } \\
N=3,754,560\end{array}$ & Repeated & $\begin{array}{l}\text { Sexual acts in presence of or with child, } \\
\text { not appropriate for age or developmental } \\
\text { stage }\end{array}$ & 0.342 \\
\hline \multicolumn{6}{|l|}{ POPULATION SURVEY } \\
\hline Vennix; ${ }^{19}$ & $\begin{array}{l}\text { Random selection middle } \\
\text { class population }\end{array}$ & $\begin{array}{l}\text { Response\%; } \\
\text { unknown }\end{array}$ & Once or repeated & $\begin{array}{l}<20 \text { years, both relatives } \\
\text { and non-relatives } * * \star\end{array}$ & \\
\hline \multirow[t]{2}{*}{1981} & & $\begin{array}{l}N=529 \\
(\delta=257, Q=272)\end{array}$ & & $\begin{array}{l}\delta \\
\text { perpetrator } \delta \\
\text { perpetrator } q \\
q\end{array}$ & $\begin{array}{l}50 \\
70\end{array}$ \\
\hline & & & & $\begin{array}{l}\text { perpetrator } \delta \\
\text { perpetrator } q\end{array}$ & $\begin{array}{r}150 \\
10\end{array}$ \\
\hline $\begin{array}{l}\text { Van der Ploeg: }{ }^{\prime 2} \\
1984\end{array}$ & $\begin{array}{l}\text { Random selection of large } \\
\text { city dwellers; }\end{array}$ & $\begin{array}{l}37 \% \\
N=2957\end{array}$ & Not specified & $\begin{array}{l}\text { Sexual abuse ** } \\
\text { Perpetrator known: }\end{array}$ & \\
\hline \multirow{6}{*}{1984} & tel/written questionnaire & & & 8 & 16 \\
\hline & about past year & & & \& & 30 \\
\hline & & & & Perpetrator unknown: & \\
\hline & & & & $\delta$ & 18 \\
\hline & & & & \& & 90 \\
\hline & & & & $\begin{array}{l}\text { Partner is perpetrator: } \\
q\end{array}$ & \\
\hline
\end{tabular}


Table 3 Continued

\begin{tabular}{|c|c|c|c|c|c|}
\hline $\begin{array}{l}\text { Author; } \\
\text { Year of study }\end{array}$ & $\begin{array}{l}\text { Population; } \\
\text { Research methodology }\end{array}$ & $\begin{array}{l}\text { Response\% ; } \\
\text { Numbers }\end{array}$ & Once only or repeated & $\begin{array}{l}\text { Incidence (per 1000/year); } \\
\text { Cumulative incidences, per } 1000 / \text { year }\end{array}$ & \\
\hline $\begin{array}{l}\text { Mayhew; } \\
1996\end{array}$ & $\begin{array}{l}\text { Random selection open } \\
\text { population; } \\
\text { telephone questionnaire }\end{array}$ & $\begin{array}{l}66 \% \\
N=2000\end{array}$ & Once or repeated & $\delta$ and ? & 38 \\
\hline $\begin{array}{l}\text { Draijer; }{ }^{20} \\
1986\end{array}$ & $\begin{array}{l}\text { Random selection } \\
\text { 20-40 yr open } \\
\text { population; interviews }\end{array}$ & $\begin{array}{l}50.7 \% \\
N=1054\end{array}$ & Once or repeated " & $\begin{array}{l}\text { Perpetrator is relative; victim experienced } \\
\text { event at }<16 \text { years } \\
\text { total }{ }^{* * *} \text { : } \\
18 \% \text { petting over clothes; } \\
35 \% \text { petting under clothes; } \\
21 \% \text { attempt at penetration; } \\
27 \% \text { penetration }\end{array}$ & 156 \\
\hline $\begin{array}{l}\text { Römkens; }^{15} \\
1986\end{array}$ & $\begin{array}{l}\text { Random selection } \$ 20-60 \\
\text { years, open population; } \\
\text { Interviews }\end{array}$ & $\begin{array}{l}35 \% \\
N=1016\end{array}$ & Once or repeated & $\begin{array}{l}\text { Forced sex or rape within partner relationship } \\
\text { (sex under pressure excluded)***}\end{array}$ & 74 \\
\hline $\begin{array}{l}\text { Langeland; }{ }^{21} \\
1986\end{array}$ & $\begin{array}{l}\text { Random selection \& 20-40 } \\
\text { years, open population; } \\
\text { interviews }\end{array}$ & $\begin{array}{l}50.7 \% \\
N=1054\end{array}$ & Once or repeated & $\begin{array}{l}\text { Perpetrator is not a relative ; victim } \\
\text { experienced event ot }<16 \text { years } \\
\text { Total*** } \\
25 \% \text { kissing or petting of breasts or } \\
\text { genitals over clothes } \\
31 \% \text { petting under clothes } \\
20 \% \text { attempt at penetrotion } \\
24 \% \text { penetrotion }\end{array}$ & 232 \\
\hline Eijken; 22 & Random selection open & Response\% unknown; & Not specified & Indecent ossault & \\
\hline 1992 & $\begin{array}{l}\text { population >15 years; } \\
\text { questionnaire }\end{array}$ & $N=4448$ & & $\begin{array}{l}\text { At home } \\
\text { Outside the home }\end{array}$ & $\begin{array}{r}7 \\
14\end{array}$ \\
\hline
\end{tabular}


Table 3 Continued

\begin{tabular}{|c|c|c|c|c|c|}
\hline $\begin{array}{l}\text { Author; } \\
\text { Year of study }\end{array}$ & $\begin{array}{l}\text { Population; } \\
\text { Research methodology }\end{array}$ & $\begin{array}{l}\text { Response\%; } \\
\text { Numbers }\end{array}$ & Once only or repeated & $\begin{array}{l}\text { Incidence (per 1000/year); } \\
\text { Cumulative incidences, per 1000/year }\end{array}$ & \\
\hline Van Dijk:' & Random selection $18-70$ & $44 \%$ & Repeoted & $* *$ & \\
\hline \multirow[t]{3}{*}{1997} & years, open population; & $N=1005$ & & unwanted caresses with sexual intent & 105 \\
\hline & Telephone interviews & & & forced sex (without penetration) & 76 \\
\hline & & & & rape & 40 \\
\hline \multicolumn{6}{|l|}{ GP REGISTRATION } \\
\hline Van Griethuysen; ${ }^{17}$ & 6 general practitioners' & NA; & Once or repeated & $\delta$ & $0-0.2$ \\
\hline $1985-90$ & retrospective case-notes & $7,000-9,000$ & & १ & $0.8-2.9$ \\
\hline \multirow[t]{3}{*}{ Mourits in Meyboom-De Jong 23} & 10 general practices & NA & Once or repeated & & 3 \\
\hline & Groningen-city; & & & & \\
\hline & method not indicated & & & & \\
\hline Ter Braak; ${ }^{24}$ & 11 general practices; & NA & Once or repeated & Child+ & 0.37 \\
\hline \multirow[t]{3}{*}{$1990-91$} & prospective registration & & & Adult consulting about abuse as an adult ${ }^{+}$ & 0.48 \\
\hline & & & & Adult consulting about abuse as a child & 0.85 \\
\hline & & & & Child or adult consulting about current abuse & 0 \\
\hline
\end{tabular}

* NA: response\% not applicable; when a response percentage is given, the number refers to the number of respondents

*t definition: from indecent looks to rape

*** cumulative incidence (per 1000)

- repeated abuse in $63 \%$

Student practices: $85 \%$ of patients 20-39 years

t victims consulting about abuse in the past 
cases, respectively; if the offender was known to the victim, this figure was $50 \%$ (for both sexes) ${ }^{27}$.

\section{Discussion}

As an initial exploration showed that journals and books would yield insufficient data, reports were also included. Data on war and disasters have not been included, because there were so few data available that a comparison between the various sources was difficult.

Standard data from the customary GP registration systems in the Netherlands were unavailable, because both the International Classification of Primary Care (ICPC) and the so-called E list of the Chronic Morbidity Registration (CMR) register on the basis of effect rather than cause (i.e. 'broken nose' instead of 'physical abuse') ${ }^{28}$.

The differences between data from national registration systems, victim surveys in the open population, and studies by general practitioners, are remarkable. For almost all types of events, the frequencies found in victim surveys were many times higher than those from national registration systems and GP studies. Part of the discrepancies can be explained by differences in the definition of the concepts used. The Römkens study, for example, deals with actual physical abuse, while the Griethuysen study also included the threat of violence ${ }^{15,17}$.

Furthermore, the differences in the frequencies found, can be explained by the data collection methods. In the case of the registration of reports by victims - for example to the police - the confidence in the organisation or person concerned, the trouble experienced and the degree to which the victim expects to gain from reporting the event, all play a role. In surveys among victims, the numbers are influenced by the effect of 'telescoping': the phenomenon that - when asked - those involved feel that the events took place more recently than was actually the case ${ }^{29}$. This leads to overreporting when being asked about events experienced during for example "the last twelve months". Also, those who did experience something, may be more inclined to respond to a victim survey than those who did not experience anything at all.

Comparison of the frequencies found is complicated by the differences in duration and time of occurrence of the event. Did the event take place repeatedly or only once, during one's youth or later? In some studies, the different categories are reported together, while other studies looked at only one sub-category.

The studies on the different categories of events were collected in different years (between 1981 and 1997). This does not explain the differences in incidences found; even in sources from a single year, there are great discrepancies between the victim surveys and the registration systems (see, for 
example, physical abuse in table 2). This may be explained in part by the difference in methodology and definitions.

No data are available on the degree to which general practitioners are aware of accidents, fires, violent robbery, and murder. On the basis of the data on physical and sexual abuse, we could conclude that only a small number of GPs are aware of these. Considering the restrictions listed with regard to comparison of reported frequencies, it is not possible to use the currently available data to establish the exact scope of the "iceberg phenomenon". This would require a study in which general practitioners and their patients, independently of one another but using the same definitions, are asked about events experienced by the patients. One could also include other types of events, which have not been studied in GP populations before. Such a study is reported in chapter 5 .

The psychological and psychosomatic effects of experiencing traumatic events are considerable, and make effective primary care important ${ }^{15,20,27}$. The question is whether, and if so, to what extent, the iceberg phenomenon impedes the provision of care. Does a patient refrain from reporting an event to the GP because he or she has dealt with the event adequately with the support from family and friends? Or does a patient, who does need help, hesitate to tell the GP because the latter failed to respond adequately on previous occasions? The question whether the discrepancy mentioned between what patients experience and what the GP knows about this - constitutes an impediment for effective care, deserves further investigation. 


\section{References}

1. Anonymus. Basistakenpakket van de huisarts. Deel III. Utrecht: Landelijke Huisartsen Vereniging, 1987.

2. Knottnerus JA. Diagnostische hypothesen en a priori kansen in de huisortsgeneeskunde. Huisarts Wet 1986;29:269-73.

3. Brown GW, Harris TO. Life events and illness. Londen: Unwin Hyman, 1989.

4. Gersons BPR. Acute Psychiotrie. Houten: Bohn Stafleu Van Loghum, 1995.

5. Anonymus. DSM IV Patiēntenzorg: diagnostiek en classificatie van psychische stoornissen voor de geneeskunde. Lisse: Swetz \&Zeitlinger, 1996.

6. CBS HSvVeV. Statistiek van de verkeersongevallen op de openbare weg 1992. Den Hoog: Sdu, 1993.

7. Hertog PC den, Toet H, Driel HF van, Schoots W, Ommeren PJ van. Kerncijfers. Letsels door ongevallen en geweld. Een overzicht van sterfte en letsel door verkeers-, bedrijfs,- en priveongevallen, sportblessures en geweld. Amsterdam: Stichting Consument en Veiligheid, 1997.

8. Mulder S, Bloemhoff A, Harris S, Kampen LTB van, Schoots W. Ongevallen in Nederland. TSG $1996 ; 4: 140-45$.

9. CBS. Statistisch jaarboek 1996. Heerlen: Centraal Bureau voor Statistiek, 1996.

10. CBS. Statistisch jaarboek 1997. Heerlen: Centraal Bureau voor Statistiek, 1997.

11. CBS. Statistisch jaarboek 1985. Heerlen: Centraal Bureau voor Statistiek, 1985.

12. Ploeg HM van der, Buuren ET, Wöstmann M, Hulshof RE, Huisman SJ, Kleijn WC. Psychologisch onderzoek naar (het ontbreken van) de hulpvraag van slachtoffers van geweld. Deel I: Het meten van de omvang van enkele vormen van geweld en het in kontakt komen met slachtoffers. Lisse: Swets en Zeitlinger, 1985.

13. Mayhew P, Dijk JJM van. Criminal Victimization in eleven industrialised coutries. Key findings from the 1996 international crime victims survey. Den Hoag: Ministerie van Justitie/WODC, 1997.

14. Anonymus. Jaarverslag 1995 Landelijke Stichting Bureaus Vertrouwensarts inzake Kindermishandeling. Utrecht: LSVBK, 1996.

15. Römkens RG. Gewoon geweld? Omvang, aard, gevolgen en achtergronden van geweld tegen vrouwen in heteroseksuele relaties [Ordinary Violence?]: Amsterdam, Lisse: Swets \& Zeitlinger, 1992.

16. Dijk T van, Flight S, Oppenhuis E, Düssmann B. Huiselijk geweld; aard, omvang en hulpverlening: Den Hoog: Ministerie van Justitie, 1997.

17. Griethuysen J van. Geregistreerd seksueel en fysiek geweld in een huisartspraktijk. Huisarts Wet $1992 ; 35(6): 240-242$.

18. Bartels AIM. Continue morbiditeitsregistratie peilstations Nederland 1997. Utrecht: NIVEL, 1998.

19. Vennix P. Symposium: Incestueus of niet, wat maakt het uit. In J. Frenken en $C$. van Lichtenburcht (red.): Incest, feiten achtergronden en hulpverlening - een symposium. UtrechtZeist: Ned. Vereniging voor Seksuologie, 1984:129-140. 
20. Draijer N. Seksueel misbruik van meisjes door verwanten. Een landelijk onderzoek naar de omvang, de aard, de achtergronden, de emotionele betekenis en de psychische en psychosomatische gevolgen. [Sexual abuse of girls by relatives. A national study on occurence, nature, background, emotional, psychological and psychosomatic sequelea]. Den Hoag: Ministerie van Sociale Zaken en Werkgelegenheid, 1988.

21. Langeland W, Dijkstra S, Swets-Gronert F. Kindermishandeling: van signaal naar hulp. Deel I. Signaleren en melden. Utrecht: Nederlands Centrum Geestelijke Volksgezondheid, 1990.

22. Eijken AWM. Criminaliteitsbeeld van Nederland. Aard, omvang, preventie, bestraffing en zorg voor slachtoffers van criminaliteit in de periode 1980-1993. Den Haag: Stafafdeling Informatievoorziening. Directie Criminaliteitspreventie, Ministerie van Justitie, 1994.

23. Meyboom-de Jong B. Seksueel geweld, incest en SOA in de huisartspraktijk. Bussum: Medicom, 1990.

24. Braok EM ter. Seksueel geweld woargenomen in de huisartspraktijk. Ned. Tijdschr Geneeskd 1992;136(nr. 50):2467-2471.

25. Lamberts $\mathrm{H}$. Morbidity in general proctice. Diagnosis related information from the Monitoring Project. Utrecht: Huisortsenpers, 1984.

26. Veltman MTM. Huisartsengeneeskundige zorgepisoden. Analyse van een zevenjaars bestand [proefschrift]. Lelystod: Meditekst, 1995.

27. Ploeg HM van der, Buuren ET, Wöstman M, Hulshof RE, Huisman SJ, Kleijn WC, et al. Psychologisch onderzoek naar (het ontbreken van) de hulpvraag van slachtoffers van geweld. Deel 2: gevolgen, hulpvraog en hulpverlening. Lisse: Swets en Zeitlinger, 1985.

28. Hart HE, Wouden JC van der, Höppener P, Schendel GJ van, Metsemakers JFM, Knottnerus JA. Huisartsgeneeskundige registraties in Nederland. Rotterdam, Maastricht: Instituut Huisartsgeneeskunde Erasmus Universiteit Rotterdam/Nakgroep Huisartsgeneeskunde Rijksuniversiteit Limburg, 1996.

29. Thompson CP, Skowronski JJ, Lee DJ. Telescoping in dating naturally occurring events. Mem Cognit 1988;16(5):461-8. 
Worldpress foto 1972

haar naam is

Phan Kim Phué - 9 jaar

Vietnam

\section{Foto van het jaar}

Er was een man in een vliegtuig

die in opdracht van zijn chef

iedereen verminkte

haar-zichzelf en ons

onder zijn voeten vlucht

het geschroeide meisje - naakt

zo onschuldig aangerand

niet begrijpend in paniek

pril - te teer om te vervloeken

gilt zij haar angst uit

naar niemand

zo vluchten is niet bescherming halen

(is moeder hier)

veilig bestaat niet

er is niets meer vertrouwd

geen huis - geen borg

er is een man in een viegtuig.

\section{Pieter Mol}




\section{Traumatic events in a general practice population:}




\section{Abstract \\ Objective}

To describe the patient's perspective on the general practitioner's care after violent events: which role is the GP assigned and how is the care appreciated. Events studied were serious accidents, burglary, robbery, physical and sexual abuse, disasters and war.

\section{Method}

A postal questionnaire was sent to a random sample of 2997 patients (20 years and over) from the practice population of 32 GPs (67,500 patients).

\section{Results}

The response was $50 \%$. Forty-two per cent of the respondents had experienced one or more events. Twenty-eight percent of the victims desired some kind of professional help; more than half of them desired that care from their GP, three-quarters actually seeking it. Most frequently sought care was sympathy, "a number of good talks" and care for physical complaints. Overall contentment with the GPs contribution was high; dissatisfaction was felt in the areas of sympathy and support, as well as in showing initiative in commencing and pursuing care.

Of those who felt no need for professional help, three-quarters found they could cope with the traumatic event well enough, with or without the help of family and friends. For those who did not seek help, although they did desire it, the main reasons were that they considered their problems insufficiently medical or felt that their GP lacked the time. In the case of physical and sexual abuse feelings of guilt and issues of patient confidentiality played a role for some patients.

\section{Conclusion}

The number of events experienced by our respondents is lower than in previous studies for burglary, robbery, physical and sexual abuse (adults and children); the occurrence of accidents is similar.

The majority of the people who experience traumatic events cope with them well enough without professional help. For those seeking help the GP plays an important role. Care could be improved as follows: the GP should make it clear to patients that he/she can play a role in caring for them in the aftermath of a traumatic event and should stress the confidential nature of the consultation. On the whole GPs should be more supportive and attentive when being consulted about this topic; also patients would like their doctors to be more active in bringing it up, as well as in initiating followup. 


\section{Introduction}

Partners, relatives and friends can play an important part in helping someone cope with a traumatic event. In addition, victim organisations, psychologists, psychiatrists, refuge homes and social workers can provide assistance. As a consequence of their central position in the health-care system, caring for patients after traumatic events, as a matter of course, is a task for the GP. First, GPs can raise topics that patients may not raise spontaneously, such as abuse by relatives. Secondly, in the case of acute events, GPs - being part of the community - will often have heard about them at an early stage and finally, GPs are able to provide patient education, help patients come to terms with what has happened or refer patients when necessary.

Which role do patients who have experienced traumatic events assign their GPs? And how is the care they receive appreciated by these patients? Studies on traumatic events supply insufficient answers to these questions or are irrelevant to the situation in the Netherlands ${ }^{1-4}$. We studied the topic in a primary care population, concentrating on events that may lead to posttraumatic stress disorder (PTSD) as defined in DSM-IV (threatening a person's physical integrity, accompanied by feelings of fear, helplessness or horror $)^{5}$. We investigated serious accidents, burglary, robbery, physical and sexual abuse, disasters and war, excluding witnessing of events for the sake of brevity ${ }^{6}$.

\section{Method}

The study population was recruited from the Maastricht Registration Network of Family Practices (RNH), consisting of 16 GP-practices in the province of Limburg. The Netherlands ${ }^{7}$. The population in this network is representative of the Dutch population as regards age and sex, level of education, medical insurance and type of household ${ }^{8}$. Of the 47 GP's taking part in the network, 32 (covering 4 rural and 8 urban practices and a registered population of 67,500 patients of all ages) participated in the study. A random sample of 3200 patients aged 20 years or over was taken from the register. Patients suffering from dementia or acute psychosis $(\mathrm{N}=23)$ and those unable to read or write Dutch $(\mathrm{N}=46)$ were excluded, as were patients considered by their GPs to be too fragile to participate (terminal cancer, etc., $\mathrm{N}=15$ ). A further 119 had recently moved or died.

A total of 2997 questionnaires was mailed to the patients' homes, by the GP (see Appendix 2). The questionnaire could be returned anonymously. After 4 weeks, those who had not yet responded, identified by a code number, received a written reminder. The questionnaire asked for demographic data and the types of events experienced, including their frequency. To ensure a representative cross-section of all degrees of severity, patients had to refer to the most recent event within that category in answering further 
questions. These concerned the desire for help from professionals (including the GP), whether care was actually sought and how it was appreciated. Those who did not desire or seek care were asked for their reasons. There were additional questions about PTSD symptoms and health correlates; these are reported on in chapters 6 and 7 .

As no previous questionnaires on help-seeking after traumatic events were found, we constructed our own set of questions on the basis of brainstorm sessions with colleagues. The questionnaire was piloted in a group of 30 patients recruited in general practice. On the basis of the results appropriate changes were made. Special attention was paid in the lay-out to the fact that patients had to fill out certain parts of the questionnaire only, namely the parts regarding the events they had experienced.

Differences between respondents and non-respondents in demographic characteristics were tested with chi-square tests (dichotomous variables) and t-tests (continuous variables). Relative risks were used to calculate the role of sex in lifetime experience of events. No statistical analyses could be performed on differences between the various event types regarding preferences for and appraisal of GP care, because a third of the study population had experienced more than one event, implying that the findings are probably not independent. Nevertheless, where we considered this to be justified in terms of cell size, we highlighted trends.

\section{Results}

\section{Response}

Of the 2997 questionnaires, 1498 were returned (50\% response). Of the respondents, $43 \%$ were male. The mean age was 50 years (SD 16). Eightyfive percent lived with family/partner, $14 \%$ alone and $1 \%$ otherwise (e.g. student hostel). Thirty three percent had private health insurance and $67 \%$ had national health insurance, $44 \%$ had a low level of education, $43 \%$ had completed secondary education, $13 \%$ had completed higher education.

Regarding all demographics, except for insurance type, respondents differed from non-respondents $(p<0.05)$. Only several of these differences were large enough to be relevant. Of the respondents $43 \%$ were male, while for the non-respondents this was $52 \%$ (chi-square). There were more people with a secondary or higher education among respondents than among non-respondents ( $56 \%$ versus $44 \%$, chi-square). On average the respondents were 2 years older than the non-respondents, due to an under-representation of 20-30 year olds and an over-representation of 60-70 year olds among respondents (ANOVA).

As 27 questionnaires were filled out insufficiently, further analyses were performed on 1471 questionnaires ( 844 women, 627 men). 


\section{Table 1 Lifetime prevalence of event types (1471 respondents)}

Event type

$\begin{array}{cccc}\text { Yes, } & \% \text { of } & \text { Relative } & 0.95 \\ \text { I suffered this } & \text { women } & \text { Risk } & \begin{array}{c}\text { Confidence } \\ \text { Interval }\end{array} \\ \text { type of event } & \text { amongst } & \text { Men/ } & \text { Interval } \\ \text { at least once' } & \text { the victims } & \text { Women } & \end{array}$

No. \%

Serious accident

Burglary/robbery

209

14.2

234

65

Physical abuse as an adult

Sexual abuse as an adult

Physical or sexual abuse as a child

Disaster (natural or manmade)

Wor

Total

Subjects can be included in more than one category

${ }^{2}$ Significant differences in bold

\section{Table 2 Number of incidents}

Event type

Number of

Number of times this event event was suffered respondents who suffered

this type of

event once

or more

\begin{tabular}{|c|c|c|c|c|c|c|}
\hline & & Unknown & 1 & $2-5$ & $5+$ & Total \\
\hline Serious accident & 209 & 10 & 166 & 33 & N.A. ${ }^{2}$ & 240 \\
\hline Burglary & 210 & 4 & 162 & 44 & N.A. & 270 \\
\hline Robbery & 30 & 0 & 27 & 3 & N.A. & 34 \\
\hline Disaster & 109 & 11 & 55 & 43 & N.A. & 150 \\
\hline War & 144 & 10 & 127 & 7 & N.A. & 141 \\
\hline Physical abuse as an adult & 65 & 10 & & & & \\
\hline By a stranger & & & 15 & 5 & 0 & $\#$ \\
\hline By a non-stranger & & & 11 & 8 & 24 & $\#$ \\
\hline Sexual abuse as an adult & 29 & 2 & & & & \\
\hline By a stranger & & & 12 & 2 & 0 & $\#$ \\
\hline \multirow[t]{2}{*}{ By a non-stranger } & & & 5 & 3 & 5 & \# \\
\hline & & & $\begin{array}{l}\text { Once/ } \\
\text { a few } \\
\text { times }\end{array}$ & $\begin{array}{c}\text { Once } \\
\text { a month }\end{array}$ & $\begin{array}{c}\text { At least } \\
\text { once a } \\
\text { week }\end{array}$ & \\
\hline Physical abuse as a child & 23 & 1 & 4 & 7 & 11 & $\#$ \\
\hline Sexual abuse as a child & 44 & 6 & & & & \\
\hline By a stranger & & & 10 & 0 & 1 & $\#$ \\
\hline By a non-stranger & & & 15 & 6 & 9 & $\#$ \\
\hline
\end{tabular}

Subjects can be included in more than one category

${ }^{2}$ N.A. not applicable

\# Exact number cannot be calculated 


\section{Event types and number of incidents experienced}

Of the respondents, $42 \%$ had experienced one or more of the types of events; of them $70 \%$ had experienced only one, $21 \%$ had experienced two and $8 \%$ had experienced three or more. There was no significant relation between gender and the number of event types experienced (chi-square test). However, those who had experienced many event types were significantly older than those who had experienced few or none. Average ages ranged from 46 for no events to 53 for three or more types of events.

Burglary and serious accidents were reported most frequently, while sexual abuse as an adult was least reported (table 1). Men were found to have a significantly higher risk of accidents and war experiences, while women proved to be at a significantly higher risk of physical and sexual abuse as adults and of sexual abuse as a child.

Robbery and war as well as physical or sexual abuse by a stranger were mostly once-in-a-lifetime experiences (table 2). Abuse by persons known to the victim had often been experienced repeatedly. Of those who had experienced war (mostly World War II), 73 \% had undergone one of the following: injury, camps, being in hiding, and witnessing or hearing about death of loved ones.

\section{Care seeking}

Tables 3-7 list the responses to questions about the most recent event experienced within a particular event type. Table 3 shows care seeking behaviour. Professional care was desired for $28 \%$ of the 854 events (column 2); in $64 \%$ of these $(18 \% / 28 \%)$ the respondent wished help from the GP, sometimes in combination with other sources of care. Of those desiring help from their GP, $74 \%$ had actually requested it (column 4 ). The GP was thus consulted for an average of $13 \%(74 \% \times 18 \%)$ of the events. The flowchart (figure 1) illustrates the choices of care.

The greatest desire for any assistance resulted from sexual and physical abuse. Not seeking the GP's assistance even though the desire for such assistance was felt, occurred most frequently after burglary/robbery and after childhood physical or sexual abuse.

Of all the events for which assistance from the GP was desired, sympathy was sought in $67 \%$, while care for physical complaints was sought in $55 \%$ (particularly after accidents and war experiences), and "a number of good talks" in $43 \%$ (especially after physical or sexual abuse). Referral was desired after $39 \%$ of events (especially after physical or sexual abuse as a child), medication in $22 \%$ of cases, a legal statement in $10 \%$, and other types of assistance after $6 \%$ of events (results not shown). The wish for mental health care (social worker included) - expressed by half of the 54 respondents wanting a referral - came mostly from those abused physically or sexually. 
Table 3 Care desired for the most recent event experienced within an event type (854 events)

Event type

Number of events

Respondents from column 1 who wanted any professional care

\begin{tabular}{lccr}
\hline & 1 & \multicolumn{2}{c}{2} \\
\hline Serious accident & No. & No. & $\%$ \\
\hline & 209 & $67 / 198$ & 34
\end{tabular}

Serious accident

Burglary/robbery

234

65

29

64

109

144

854 (including GP)

Respondents from column 1 who wanted this care from their GP

$40 / 220$

$39 / 53$

$20 / 27$

$33 / 61$

$10 / 96$

$12 / 121$

$221 / 776$

their GP

\begin{tabular}{cc} 
& 3 \\
\hline & No. \\
\hline 4 & $58 / 198$
\end{tabular}

74

$12 / 220$

24/52

$10 / 27$

$20 / 60$

$3 / 96$

$9 / 121$

$136 / 774$
Respondents from column 3 who asked for help from their GP

\begin{tabular}{rr} 
& 4 \\
No. & $\%$ \\
\hline $46 / 56$ & 82 \\
$7 / 12$ & 58 \\
$17 / 24$ & 71 \\
$9 / 10$ & 90 \\
$13 / 20$ & 65 \\
0 & - \\
$7 / 9$ & 78 \\
$9 / 134$ & 74
\end{tabular}

Due to missing data there is a loss of respondents from one column to the next (see Figure 1) 


\section{Figure 1 Choices of care (854 events)}

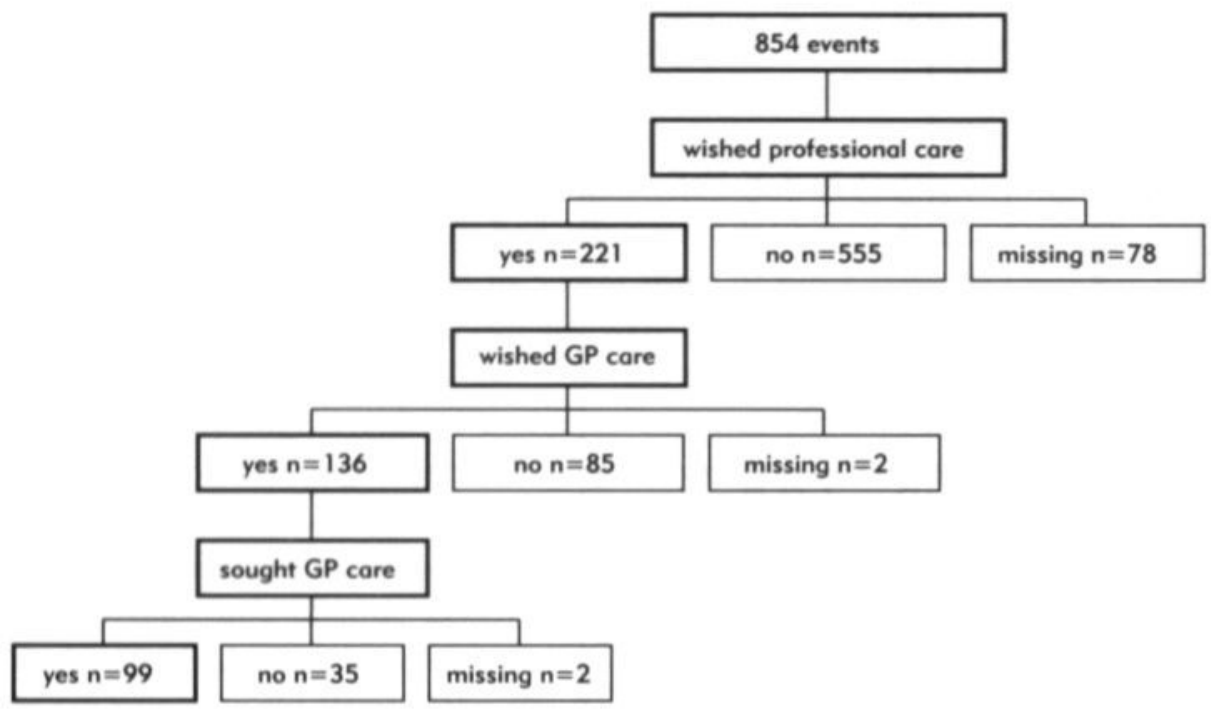

\section{Impact of the event}

The most negative impact was attached to sexual and physical abuse (table 4). The more negative the impact of the event, the greater the wish for professional help. For accidents, sexual abuse as a child and disasters, this relationship was significant (odds ratios and 95\% confidence intervals: accidents 1.75 (CI 1.2-2.6), sexual abuse as a child 4.7 (CI 1.4-16.3), disaster 2.2 (CI $1.0-4.8)$, corrected for age and sex). The relationship was positive for all other events, though not significant - due in part to small numbers.

The wish for help from the GP, rather than from other professionals, increased significantly for victims of accidents and adult physical abuse as they rated the impact of the experience more negatively (odds ratios 7.6 (CI 1.1-53.4) and 5.1 (CI 1.3 -19.4) respectively, corrected for age and sex). Once again, the relationship - though not significant - pointed in the same direction for the other events, except for disasters.

\section{Appraisal of general practitioners' care}

Respondents' appraisal of the GP's care was on the whole favourable (table 5; statements 1, 2 and 3 are stated negatively, whereas the other statements are stated positively). Opinions on the GP's invitation to express emotions and on the extent to which the consultation had helped the patient along were least positive. The most striking difference between the various events was for raising the subject: those who had been physically or sexually abused found it particularly difficult to do this (not shown in table). 
Table 4 Impact of the most recent event experienced within an event type (854 events)

Event type

All events

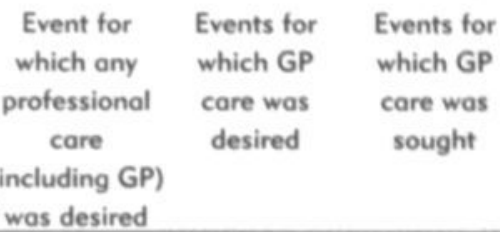

\begin{tabular}{lcccc}
\hline & Impact' & Impact & Impact & Impact \\
\hline Serious accident $(\mathrm{N}=209)$ & 3.3 & 3.6 & 3.7 & 3.7 \\
Burglary/robbery $(\mathrm{N}=234)$ & 3.7 & 3.9 & 4.3 & 4.3 \\
Physical abuse as an adult $(\mathrm{N}=65)$ & 4.2 & 4.3 & 4.6 & 4.6 \\
Sexual abuse as an adult $(\mathrm{N}=29)$ & 4.5 & 4.6 & 4.5 & 4.4 \\
Physical or sexual* abuse as a child $(\mathrm{N}=64) 4.1$ & $4.4^{*}$ & 4.1 & 4.4 & $\mathrm{~N} . \mathrm{A}^{2}$ \\
& 3.3 & $3.6^{*}$ & $4.7^{*}$ & $5.0^{*}$ \\
Disaster (natural or manmade) $(\mathrm{N}=109)$ & 3.4 & 3.5 & 3.3 & $\mathrm{~N} . \mathrm{A}$. \\
War $(\mathrm{N}=144)$ & 3.7 & 4.0 & 4.6 & 3.3 \\
\hline Total & & & 4.1 & 4.0 \\
\hline
\end{tabular}

1 Mean impact on Likert scale 1 to 5 : very positive to very negative impact

${ }^{2}$ N.A.: not applicable (no valid data in cell)

Due to missing data there is a loss of respondents from one column to the next (see Figure 1 )

\section{Table 5 Mean appraisal of GP care for all types of events'}

Mean score

$\left(91\right.$ events $\left.^{2}\right)$

1. I had difficulty raising the subject

1.98

2. The doctor put the blame on me

1.10

3. The doctor said I should try and get over it

1.29

4. The doctor was attentive

5. The doctor took my symptoms/complaints seriously

3.19

6. The doctor had sympathy for my problems

7. The doctor invited me to show my feelings

8. The consultations helped me along

2.49

9. Altogether, I was satisfied with the help I got from the doctor

2.88

'Items scaled 1 (not al all) to 4 (a lot); statements 1, 2, 3, are stated negatively, whereas the other statements are stated positively

${ }^{2}$ Data for eight events missing; total number of events 99

Respondents reported shortcomings in the GP's care for one-third of the 99 events for which they sought care. The top three shortcomings they volunteered in this open-ended question were a lack of initiative on the part of the doctor in raising the subject or reverting to it in later consultations $(n=9)$, lack of sympathy and support $(n=8)$ and not being taken seriously $(n=5)$. Similar topics were mentioned in answer to a question in the same 
section about the advice they would give a young GP on how to deal with patients like themselves. Almost half of the 108 pieces of advice given had to do with support and attentiveness: taking the patient seriously, providing support and comfort, listening attentively and questioning the patient thoroughly. In $11 \%$ the wish was expressed for the GP to take more initiative in raising the subject and initiating follow-up. The remaining suggestions were related to taking sufficient time, referring, caring for physical complaints and improving expertise.

\section{Reasons for not seeking help}

As the reasons for not seeking help from the GP among respondents preferring help from a professional other than the GP, and the respondents who did not consult their GP even though the GP was their preferred caregiver, were similar, the answers of both groups are summarised in one table (table 6). The most frequent reason for not asking the GP's help was that the patient thought the problem was not really a medical one (after burglary/robbery, disaster or war mostly). Lack of time was mentioned in one-fifth of the events. The items "I'm afraid my GP will tell someone else" and "my GP knows the person guilty of the event" were ticked almost exclusively by those who had been sexually or physically abused. Of the 64 reasons under the heading 'other', 26 fell under the GPs influence: lack of trust in the GP, feelings of shame, etc.

\section{Table 6 Reasons for not seeking the GP's help although the respondent did} want some type of professional help (GP help included)'

Total:

for all types of events

$(\mathrm{N}=114)^{2}$

\begin{tabular}{lc} 
& \multicolumn{1}{c}{$\%^{3}$} \\
\hline My GP can't deal with these things & 5.5 \\
My GP knows too little about such matters & 12.7 \\
My GP has no time for such matters & 18.2 \\
This type of experience is not medical enough & 40.5 \\
I'm atraid my GP will tell someone else about this & 10.0 \\
My GP knows the person guilty of the event & 10.0 \\
My GP will wonder why I've taken so long to come and talk with him/her & 12.7 \\
I am afraid my GP will become prejudiced against me & 9.1 \\
Other reasons (got other help, ashamed of going, child: & 56.1 \\
afraid of going, never thought of going, too long ago) & \\
\hline
\end{tabular}

'More than one reason could be given

${ }^{2}$ Data for the remaining 6 events were missing; total number of events: 120 (85 respondents not wishing GP care and 35 wishing but not seeking GP care, see Figure I)

${ }^{3}$ Percentage of respondents with a positive answer to that question 
Table 7 Reasons for not asking help from the GP or another professional 1,2

\begin{tabular}{|c|c|c|c|c|c|c|c|c|}
\hline & $\begin{array}{c}\text { Serious } \\
\text { accident } \\
(\mathrm{N}=123)^{3} \\
\%\end{array}$ & $\begin{array}{c}\text { Burglary/ } \\
\text { Robbery } \\
(\mathrm{N}=175) \\
\%\end{array}$ & $\begin{array}{c}\text { Physical abuse } \\
\text { adult } \\
\left(\begin{array}{c}N=10) \\
\%\end{array}\right.\end{array}$ & $\begin{array}{c}\begin{array}{c}\text { Sexual abuse } \\
\text { adult }\end{array} \\
\begin{array}{c}(\mathrm{N}=7) \\
\%\end{array}\end{array}$ & $\begin{array}{c}\text { Physical/ } \\
\text { Sexual abuse } \\
\text { child } \\
(N=26) \\
\%\end{array}$ & $\begin{array}{c}(\mathrm{N}=82) \\
\%\end{array}$ & $\begin{array}{c}(N=100) \\
\%\end{array}$ & $\begin{array}{c}(\mathrm{N}=523) \\
\%\end{array}$ \\
\hline Got over it without help & 76 & 79 & 60 & 71 & 39 & 88 & 64 & 74 \\
\hline Got over it with help of family and friend & ds 73 & 67 & 60 & 14 & 31 & 76 & 58 & 66 \\
\hline Seeking care will not help me & 47 & 48 & 33 & 43 & 58 & 51 & 39 & 47 \\
\hline I should work it out on my own & 44 & 43 & 56 & 29 & 42 & 50 & 46 & 45 \\
\hline Talking about it makes it worse & 10 & 8 & 22 & 29 & 31 & 12 & 11 & 11 \\
\hline I only worry at night & 6 & 7 & 13 & 14 & 19 & 12 & 4 & 8 \\
\hline I feel guilty & 12 & 2 & 25 & 43 & 35 & 4 & 0 & 7 \\
\hline I feel ashamed to talk about it & 1 & 1 & 38 & 57 & 46 & 1 & 4 & 5 \\
\hline $\begin{array}{l}\text { Other reasons (not neccesary, was too } \\
\text { young, no problems dealing with it) }\end{array}$ & 6 & 4 & 40 & 29 & 31 & 6 & 26 & 11 \\
\hline Missing $N^{4}$ & 8 & 5 & 4 & 0 & 2 & 4 & 9 & 32 \\
\hline
\end{tabular}

'Percentage of respondents with a positive answer to that question

${ }^{2}$ More than one reason could be given

${ }^{3}$ Number of respondents that filled out at least one answer of this section

${ }^{4}$ Number of respondents that should have filled out this section, but did not 
The most common reasons given by respondents for not seeking any professional help, except in cases of child abuse, was having been able to cope well enough without this help (table 7). When combining the two options "got over it without help" and "got over it with help of family or friends", $88 \%$ found they had got over it without professional help. For almost half of the events experienced, respondents indicated that professional care would not help them, or that they thought they should work it out themselves. Although the numbers are small, the trend that emerges from the data is that feelings of guilt and shame are more often the reason for not seeking professional help after abuse than after other types of events.

\section{Discussion}

This is the first Dutch study on the lifetime prevalence of a range of traumatic events in the open population and on the victims' perspective of the role of the GP in their aftermath. The prevalences we found are systematically lower than those found in American, British and Australian studies for burglary, robbery, adult physical and sexual abuse and childhood physical and sexual abuse $e^{6,9,10-16}$. International comparison of war and disaster experiences is not useful, as these events are specific for each country. The numbers we found for accidents are comparable to those found in the USA ${ }^{6.10}$. The sex differences we found per type of event are comparable with those found elsewhere.

The lower prevalences found in our study may be due to selective nonresponse. Our response, at $50 \%$, was reasonable and not unusual, taking into account the taboo surrounding some of the topics and the length and difficulty of the questionnaire?. Our non-respondents were less well educated than the respondents. Although there is conflicting evidence about this, on the whole, lower socio-economic status is considered a risk factor for experiencing traumatic events ${ }^{6,9}, 17$. This may have contributed to the lower prevalences found in our study.

Other Dutch studies on prevalence of sexual abuse of girls and of physical abuse of children show higher prevalences than ours, possibly because the data were collected by interview, rather than by written questionnaire ${ }^{1-}$ 3.18. In an interview one can enhance recall of past experiences by detailed questioning and stepwise cueing ${ }^{19}$. Another benefit of interviewing is that with a complex questionnaire like ours, with many references to questions further on, the number of missing answers can be minimized. However, we felt that the anonymity of a postal questionnaire when studying a sensitive topic outweighed the advantages of interviewing patients.

Of all the events for which no care was sought $(72 \%), 88 \%$ of the respondents felt they were able to cope well enough without professional care - with or without help of family or friends. This means that after some 
$60 \%$ of all events people come to terms with the event without professional help, a considerable amount.

The more negative the experience, the greater the wish for professional help. Of those who wanted professional care, $62 \%$ chose the GP's care. Patients mostly seek understanding, care for physical complaints and "a number of good talks", care that is typical for general practice. Whether or not the GP is able to select patients that need more specialized care or whether there are interventions for patients with PTSD feasible in the general practice setting, are topics for further study.

Although, on the whole, our patients were positive about their GP's help, one-third reported shortcomings. They would appreciate a more listening attitude, more sympathy and support, more initiative in informing how the patient is coping with the trauma and in initiating "a number of good talks". These aspects, related to the GP's attitude and communication skills, would merit extra attention in medical training and continuing medical education (CME) courses. Also, considering the impact experienced, teaching about the care of abused patients deserves priority.

In an international study on GP care in general, not being given sufficient time was found to be the patients' top priority ${ }^{20}$. Of our patients onefifth thought the GP had too little time to help them with coping with traumatic events. Whether GPs have insufficient time or not, it is important to realize that looking busy keeps patients from consulting ${ }^{21}$.

Even though it is considered the GP's task to help people cope with a traumatic experience ${ }^{22}$, patients themselves often perceive their problem as insufficiently medical to consult their GP about. This matter would deserve attention in patient education.

Although the data on sexual and physical abuse, both in childhood and as an adult, should -due to the small numbers- be interpreted with care, they do show a trend. They were the events for which the patients considered their capacity to cope with the aftermath more often insufficient than for other events. This led to a higher desire for care, care that was not always sought. As was found in earlier studies, difficulty raising the topic, feelings of guilt and shame as well as the fact that the GP knows the perpetrator and fears regarding confidentiality were reasons for not seeking care $^{12,23,24}$. Therefore, to enhance the care of patients who have been abused, GPs should be taught how to facilitate disclosure of abuse while patients should be educated about rules of confidentiality.

In summary, patients who want professional care for getting over a traumatic event, assign their GP an important role in helping them cope with its aftermath. Our data provide a basis for improvement in the care of these patients, in both the areas of patient education and the GP's attitude and communication skills. For optimal implementation of the suggested changes, the barriers GPs themselves perceive in bestowing help on this 
group of patients should also be taken into consideration, a topic that is decribed in the next chapter ${ }^{21}$.

\section{References}

1. Dijk T van, Flight S, Oppenhuis E, Düssmann B. Boek: Huiselijk geweld; aard en omvang en hulpverlening [Domestic violence: nature occurence and professional care]: Den Haag: Ministerie van Justitie, 1997.

2. Römkens RG. Gewoon geweld? Omvang, aard, gevolgen en achtergronden van geweld tegen vrouwen in heteroseksuele relaties [Ordinary Violence?]: Amsterdam, Lisse: Swets \& Zeitlinger, 1992.

3. Draijer N. Seksueel misbruik van meisjes door verwanten. Een landelijk onderzoek naar de omvang, de aard, de achtergronden, de emotionele betekenis en de psychische en psychosomatische gevolgen. [Sexual abuse of girls by relatives. A national study on occurence, noture, background, emotional, psychological and psychosomatic sequelea]. Den Haag: Ministerie van Sociale Zaken en Werkgelegenheid, 1988.

4. Ploeg HM van der, Buuren ET, Wöstman M, Hulshof RE, Huisman SJ, Kleijn WC, et al. Psychologisch onderzoek naar (het ontbreken van) de hulpvraag van slachtoffers van geweld. Deel 2: gevolgen, hulpvraog en hulpverlening. Lisse: Swets en Zeitlinger, 1985.

5. American Psychiatric Association. Diagnostic and statistical manual of mental disorder. Washington DC: APA, 1994.

6. Norris FH. Epidemiology of trauma: frequency and impact of different potentially traumatic events on different demographic groups. J Consult Clin Psychol 1992;60(3):409-18.

7. Metsemakers JFM, Höppener $P$, Knottnerus JA, Kocken RJJ. Computerized health information in the Netherlands: a registration network of family practices. Br J Gen Pact 1992;42:102-106.

8. Metsemakers JFM. Unlocking patients' records in general practice for research, medical education and quality assurance: the Registration Network Family Practices [thesis], Amsterdam: Thesis publishers, 1994.

9. Koss MP, Woodruff WJ, Koss PG. Criminal victimization among primary care medical patients: prevalence, incidence, and physicion usage. Behav Sci Law 1991;9:85-96.

10. Kessler RC, Sonnega A, Bromet E, Hughes M, Nelson CB. Posttraumatic stress disorder in the National Comorbidity Survey. Arch Gen Psychiatry 1995;52(12): 1048-60.

11. Gorey KM, Leslie DR. The prevalence of child sexual abuse: integrative review adjustment for potential response and measurement bioses. Child Abuse Negl 1997;21(4):391-8.

12. Mazza D, Dennerstein L, Ryan V. Physical, sexual and emotional violence ogainst women: a general practice-based prevalence study. Med J Aust 1996;164(1):14-7.

13. Finkelhorn D. Early and long-term effect of child sexual abuse: An update. Professial Psychology: Research and Practice 1990;21:325-330.

14. Markowe HL. The frequency of childhood sexual abuse in the UK. Health Trends 1988;20:2-6.

15. Plichta $\mathrm{S}$. The effects of woman abuse on health care utilization and health status: a literature review. Womens Health Issues 1992;2(3):154-63. 
16. Resnick HS, Kilpatrick DG, Dansky BS, Sounders BE, et al. Prevalence of civilian trauma and posttraumatic stress disorder in a representative national sample of women. Journal of Consulting and Clinical Psychology 1993(6):984-991.

17. Breslau N, Kessler RC, Chilcoat HD, Schultz LR, Davis GC, Andreski P. Trauma and posttroumatic stress disorder in the community: the 1996 Detroit Areo Survey of Trauma. Arch Gen Psychiotry 1998;55(7):626-32.

18. Langeland W, Dijkstra S, Swets-Gronert F. Kindermishandeling: van signaal naar hulp. Deel I. Signaleren en melden. Utrecht: Nederlands Centrum Geestelijke Volksgezondheid, 1990.

19. Acierno R, Resnick HS, Kilpatrick DG. Health impoct of interpersonal violence. 1: Prevalence rates, case identification, and risk factors for sexual assault, physical assault, and domestic violence in men and women. Behor Med 1997; 23(2):53-64.

20. Grol R, Wensing M, Mainz J. Patients' priorities with respect to general practice care: an international comparison. Family Practice 1999;16:4-11.

21. Akker M van den, Mol SSL, Metsemakers JFM, Dinant GJ, Knottnerus JA. Barriers in the care for patients who have experienced a traumatic event: the perspective of general practice. Family Practice 2001;18: 214-216.

22. Springer MP. Basic job description for the general practitioner. Utrecht, the Netherlands: National association of general proctitioners, 1987.

23. Rodriguez MA. Breaking the silence. Battered Women's Perspectives on Medical Care. Arch Fam Med 1996;5:153-158.

24. Friedman LS, Samet JH, Roberts MS, Hudlin M, Hans P. Inquiry about victimization experiences. A survey of patient preferences and physician practices. Arch Intern Med 1992; 152(6): 1186-90. 
Behind the wall

Last night I heard the screaming

Loud voices behind the wall

[...]

Last night I heard the screaming

Then a silence that chilled my soul

I prayed that I was dreaming

When I saw the ambulance in the road

[...]

\section{Tracy Chapman}




\section{Barriers in the care for patients who have}

\section{the perspective of the general practitioner}

\section{Chopter 8 \\ Summory}

Samenvottin 


\section{Abstract \\ Background}

Previous research has indicated that GPs encounter barriers in the care for patients who have experienced a traumatic event.

\section{Aims}

To map barriers GPs encounter in the care for patients who have experienced a traumatic event as well as solutions for those barriers. To estimate the influence of GP characteristics on the experienced level of barriers.

\section{Method}

Telephone interviews among a sample of 500 Dutch GPs stratified by sex. Questions focused on the barriers in the care for victims of four types of events: accidents, incest in the past, ongoing physical or sexual abuse of an adult, and ongoing physical or sexual abuse of a child.

\section{Results}

The response rate was $42 \%$. GPs are regularly confronted with patients who have experienced a traumatic event. GPs experience the most barriers in the care for child victims of ongoing physical or sexual abuse, and the least barriers in caring for patients who had difficulties getting over an accident. Most of the GPs recently updated their knowledge of care for victims of traumatic events, but still the majority feels in need of additional expert training.

\section{Conclusion}

GPs experience the greatest number of barriers regarding the care for children who are being abused. GP characteristics were not related to the number of barriers. However, seeing more victims was associated with fewer barriers. To facilitate GP care for victims of traumatic events, GP training and continuous medical education (CME) should especially focus on education regarding the detection and initial counselling of ongoing physical and sexual abuse of both adults and children. 


\section{Introduction}

Estimates of the incidence and prevalence of traumatic events vary, but most reports agree on the fact that primary care workers only identify a small proportion of cases'.

Although $60 \%$ to $80 \%$ of assaulted women reported to seek professional medical care ${ }^{2}$, the abuse was found to be disclosed to the doctor by those who experienced physical abuse and sexual abuse in only $27 \%$ and $9 \%$ respectively ${ }^{3}$. Norwegian general practitioners (GPs) were found to recognise $19 \%$ (prevalence $5.4 \%$ ) of the cases with a history of violence or threats ${ }^{4}$. Yet a large proportion of the GPs state that it is a primary care task to recognise and treat victims of traumatic events ${ }^{5}$. A number of barriers that hinder recognition and counselling of patients who had a traumatic event have been identified, including factors related to both the doctors' knowledge and skills and the patients' presentation ${ }^{6}$.

Barriers for physicians can be classified in four categories: social issues (e.g. societal norms), personal factors (e.g. personal history of abuse), professional factors (e.g. time constraints), and institutional and legal factors (e.g. unclear policies $)^{7-11}$. Improvement of knowledge, training to identify violence and to collaborate with the range of community services involved, comprehensive training in the medical school curricula, curriculum development (curricular guidelines, providing video and slide materials, and annotated reference materials), and improvement of guidelines and protocols are mentioned as tools to overcome barriers ${ }^{10-13}$.

Research on this subject among GPs is scarce in the Netherlands. In 1987, a Dutch study on victims of sexual abuse and the role of the GP showed that about a third knew very few signs and signals of sexual abuse; and a third did not know how to raise the subject when sexual abuse is suspected $^{14}$.

The aim of this study is to get more insight into current knowledge and skills of Dutch GPs with regard to violent traumatic events, the barriers they experience when confronted with these patients, characteristics of GPs that are related to these barriers, and possibilities to improve patient care.

\section{Methods}

Out of the approximately 7,500 GPs registered in the Netherlands, a random sample of 500 , stratified by sex $(1: 1)$, was drawn. One to two weeks prior to the telephone interview, GPs received a letter describing its goal and scope. The interviewer then called the assistant to obtain consent and to plan the interview. In order to stimulate response, the interview was limited to approximately 15 minutes and a small financial compensation was offered. GPs' answers were simultaneously entered in a database. GPs who did not 
want to take part in the interview were asked to fill in a postal questionnaire.

All GPs were interviewed about the estimated incidence of traumatic events in their own practice, and the need for guidelines and refresher courses on the subject. To limit the length of the interview, a random half of the interviewed GPs were asked about barriers in care regarding accidents (exemplary for incidental violent events) and ongoing physical or sexual abuse of a child. The other half were asked about barriers in care regarding incest in the past, and ongoing physical or sexual abuse of an adult. In the postal questionnaire all four types of events were included.

The questionnaire focused on barriers concerning recognition of signs and symptoms, verification of traumatic events, counselling and referral of victims, as well as on attitude towards victims, task definition and need for CME. These topics evolved from semi-structured face-to-face interviews held with four GPs, in which they were invited to take in mind a patient from each of the four categories and freely associate about which barriers they had encountered when caring for these patients.

\section{Analysis}

Non-response was analysed using the chi-square tests and the chi-square test for trend. Sum scores of the barriers listed in table 3 are reported in percentages, per type of event (so-called barrier scores). This enables comparison of barriers between the four types of events. Multiple linear regression analysis was used to establish the relation between the barrier score (dependent variable) and GP characteristics (sex, age group, single handed or duo/group practice/health centre, number of years in practice, number of patients per year with a new event).

\section{Results \\ Response}

Total response was $42 \% ; 161$ GPs $(34 \%)$ took part in the telephone interview, 50 GPs filled in the questionnaire. In total, 134 GPs provided information regarding barriers in the care for patients who had difficulties getting over an accident and ongoing physical or sexual abuse of a child; 127 GPs answered questions about barriers in the care for patients who experienced incest in the past and about ongoing physical or sexual abuse of an adult. There were no significant relations between response and sex, age, years since registration as a GP, type of practice, degree of urbanisation, practice with or without own pharmacy, or socio-economic status of the district.

Background characteristics of the participating GPs are shown in table 1 . Table 2 describes the proportions of GPs reporting no, one or two, or three or more new patients per year. 


\section{Table 1 Background features of the participoting GPs $(N=211)$}

Characteristic

Sex

male

female

Age

$<<40$

40-44

45-49

$\geq 50$

practice type

health centre

group proctice

duo practice

single handed practice percentage

50

50

19

27

27

27

11

15

38

36

\section{Table 2 Percentage of GPs who report no, one or two, and three or more} patients per year with a new traumatic event $(N=211)$

\begin{tabular}{lccc} 
& None & One or two & Three or more \\
\hline Difficulties getting over accident & 7 & 52 & 41 \\
Incest in the past & 3 & 50 & 46 \\
Ongoing abuse of adult & 22 & 63 & 15 \\
Ongoing abuse of child & 21 & 65 & 14
\end{tabular}

\section{Accidents}

GPs reported few barriers in caring for patients who have difficulties getting over an accident (table 3). In answer to an open question, additional problems mentioned by the GPs mainly concerned patient's attitude (GP thinks the patient should take the first step, inability of patients to see the problem etc.), co-ordination of care between the GP and other health care facilities, and problems with insurance and legal settlements.

All GPs agreed it is part of their job to bring up the topic and $93 \%$ thought part of the counselling should be carried out by the GP. Seventy percent experienced problems with either the type or the number of other care providers available. GPs have referred to the regional institute for mental welfare $(69 \%)$, a psychologist $(41 \%)$, the social services $(30 \%)$, and vic- 
Table 3 Percentage of GPs experiencing specific problems in the care for patients who experienced an accident, incest in the past, ongoing sexual or physical abuse of an adult, or ongoing sexual or physical abuse of a child

\begin{tabular}{|c|c|c|c|c|}
\hline & $\begin{array}{l}\text { Accident } \\
\mathrm{N}=134\end{array}$ & $\begin{array}{c}\text { Incest } \\
N=127\end{array}$ & $\begin{array}{c}\text { Abuse adult } \\
\mathrm{N}=127\end{array}$ & $\begin{array}{c}\text { Abuse child } \\
N=134\end{array}$ \\
\hline Insufficient knowledge of signs and symptoms & $21.6^{*}$ & 29.0 & 46.3 & 41.7 \\
\hline Insufficient knowledge of signs of acute danger & n.o. & n.a. & 59.3 & 48.4 \\
\hline Insufficient knowledge of normal coping process & 3.8 & n.a. & n.a. & n.a. \\
\hline Lock of time & 19.4 & 19.7 & 19.8 & 14.3 \\
\hline Insufficient skills to raise the subject & n.a. & 26.8 & 31.2 & 30.2 \\
\hline Insufficient skills to confront parents with suspected abuse & n.a. & n.a. & n.a. & 52.3 \\
\hline Insufficient skills to start counselling & 28.6 & 41.7 & $\star \star \star \star$ & 62.3 \\
\hline \multicolumn{5}{|l|}{ Frustration due to previous experience } \\
\hline (yes vs no) & 6.1 & 8.8 & 7.3 & 4.7 \\
\hline \multicolumn{5}{|c|}{ Reticence of GP because victim and perpetrator are in the same practice } \\
\hline (always/most of the time vs sometimes/never) & n.o. & n.a. & 5.0 & 20.0 \\
\hline \multicolumn{5}{|c|}{ Change of attitude because GP believes patient was accessory to the event(s) } \\
\hline (yes vs no) & $13.7^{\star \star \star}$ & 2.4 & 12.0 & 2.4 \\
\hline \multicolumn{5}{|c|}{ Reticence of GP because of known psychosocial problems of the family } \\
\hline (rather/very much so vs a little/not at all) & n.a. & n.a. & n.a. & 6.9 \\
\hline \multicolumn{5}{|c|}{ Reticence of GP because of fear of unknown consequences confrontation } \\
\hline (always/most of the time vs sometimes/never) & n.a. & n.a. & n.a. & 37.1 \\
\hline \multicolumn{5}{|l|}{ GP hesitates becouse of patient's reticence } \\
\hline (olways/most of the time vs sometimes/never) & n.a. & 22.2 & 15.1 & n.a. \\
\hline
\end{tabular}

n.a. = not applicable

*for accidents: signs and symptoms of difficulties in coping with the accident

**for accident: change of attitude because patient was guilty of the accident

***not available due to technical problems 


\section{Table 4 Level of barriers per topic as experienced by the GPs}

Subject

Level of barriers as

a percentage
Percentage of doctors experiencing one or more barriers
Accident (max. 6)

Incest in the past (max. 7)

Ongoing physical/sexual abuse of an odult ( $\max .8$ )

Ongoing physical/sexual abuse of a child ( $\max .11$ )
10.0

13.0

16.4

19.8
37

41

48

60

The mean barrier score was $10 \%$ (table 4 ), with $63 \%$ of the GPs not experiencing any barriers. Regression analysis revealed that the barrier score was related only to the number of new patients per year reporting problems coping with an accident, an increasing number of patients being related to a decreasing number of barriers experienced. No relation was found with sex, age, years of experience as a GP, and type of practice.

\section{Incest in the past}

GPs are reasonably satisfied with their knowledge about signs and symptoms, skills and time to talk about incest, and GPs generally do not hesitate to raise the subject because of the patients' reticence, nor are they reserved because of previous experiences (table 3). About 40\%, however, thought their skills are insufficient to start counselling, while $80 \%$ considered it to be part of their job. Fifteen GPs sometimes blame victims of incest (in part); five of them stated this influences their attitude towards the patient.

An inadequate type or number of care providers to refer to was experienced by $61 \%$ of the GPs. Most GPs have referred to the regional institute for mental welfare $(83 \%)$ and psychologists $(35 \%)$. Furthermore, patients were referred to psychiatry $(22 \%)$, social services $(20 \%)$ and sometimes to women's health care $(9 \%)$ and victim organisations $(6 \%)$.

In answer to the open questions GPs reported problems regarding the family of the patient, either the fact that the perpetrator is also a patient or the fact that disclosing incest can disrupt the family as a whole. Other problems concerned the patients' attitude (having difficulties talking about it, not willing to cooperate in therapy, or claiming the GP's attention), financial problems for the patient when referring to caregivers not refunded by the insurance, and insufficient knowledge about male victims.

The mean barrier score was 13\% (table 4), 59\% of GPs not experiencing any barriers in the care for patients who experienced incest in the past. As with accidents, only seeing a higher number of victims is related to experiencing fewer barriers. 


\section{Ongoing physical or sexual abuse of an adult}

Table 3 shows that only just over half of the GPs reported sufficient knowledge of signs and symptoms of ongoing adult physical or sexual abuse, a similar proportion said to be attentive to these symptoms. Thirty-one percent find they lack the right skills to raise the subject, and $15 \%$ feel restrained to do this by the patient's reticence. Only $40 \%$ stated they know signals that indicate acute danger because of abuse. In general GPs are not hindered by the experiences of previous cases of abuse, or by the fact that the victim and the perpetrator are patients in the same practice. A quarter of the GPs stated that they sometimes believe that the victim is accessory to the abuse, which in half of these doctors influences treatment.

Almost all GPs (97\%) thought it is part of their task to raise the issue of ongoing abuse when they suspect it, and $85 \%$ stated starting the counselling is the GP's responsibility. For referral $57 \%$ of the GPs found that the number or type of care providers is inadequate. The pattern of referral to caregivers is similar to that for incest.

Problems raised by the GPs themselves concern the willingness and ability of patients to cooperate in treatment, lack of transparency regarding legal procedures, complexity of the problems (often combined with alcohol or drug addiction, psychiatric diseases), patients from other cultures or not speaking Dutch, or inhibitions of the GP because of personal norms and values.

The mean barrier score for care for adults who are physically or sexually abused was $16 \%$ (table 4 ); $52 \%$ of the GPs did not report any barriers. Regression analysis revealed no relationship between the barrier score and the GP characteristics.

\section{Ongoing physical or sexual abuse of a child}

In case of child abuse $42 \%$ of the GPs reported having too little knowledge of signs and symptoms, and 15\% lacked time to explore a suspicion. Sixty percent stated they have too little skills to raise the subject. One quarter is usually not alert to signals that indicate child abuse; half of the GPs lack knowledge of signs that indicate acute danger. Fifty-two percent of GPs feel they have insufficient skills to confront parents with suspected abuse of a child, $62 \%$ lacks skills to start counselling (table 3). An unpredictable family situation hinders $37 \%$ of GPs in confronting the parents; $20 \%$ feel restrained when both the abused child and the perpetrator are patients in their practice.

Over half of the GPs ( $57 \%$ ) stated that the type and/or number of care providers to refer to is insufficient. GPs have referred to the regional institute for mental welfare $(56 \%)$, paediatricians $(24 \%)$, child welfare $(12 \%)$, child psychiatrist (9\%) and the Social Services Register for Child Abuse (Algemeen Meldpunt Kindermishandeling) ( $9 \%$ ). Just over half of the GPs 
have had contact with the latter, or with the Child Welfare Council (Raad voor de Kinderbescherming). Cooperation with these two institutions was valued reasonable to good by $79 \%$ and $63 \%$ respectively.

The attitude towards the child and family is generally not influenced by earlier experiences with child abuse. Ten GPs sometimes partly blame the child for being the victim, 4 of them said this influences their professional behaviour.

Additional problems mentioned by the GPs are coping with uncertainty about whether a child is being abused or not, patients unwilling to cooperate, and, more in general, the societal taboo. Cultural differences make caring more difficult. On a more organisational level GPs mentioned legal procedures, co-ordination of different caregivers and difficulties in longterm care.

The mean barrier score was highest in this category: $20 \%$ (table 4); only $40 \%$ of GPs experienced no barriers. Again, a higher number of new cases was the only variable related to a lower percentage of experienced barriers.

\section{How to improve care?}

GPs stated they should increase their own knowledge and skills for recognition (regarding incest in the past, ongoing abuse of adults, and ongoing abuse of children) and initiation of counselling (regarding all four types of events). For all types of events they recommended more experts and specialised caregivers to refer to, and for ongoing abuse of children and accidents the possibility to consult expert colleagues was mentioned. GPs wanted reduction of waiting lists, better co-ordination between specialist caregivers and GPs, more education and information for patients about the (possible) role of the GP in case of a traumatic event and diminishment of the societal taboo.

\section{Education about traumatic events}

Only a quarter of the GPs said they received moderate to good education on traumatic events during vocational training. Two-thirds updated their knowledge or skills in the last three years (by reading a book or an article on the subject $(63 \%)$, going to a lecture or discussion group $(71 \%)$, refresher course $(44 \%)$, or intervision/supervision group (28\%)). GPs stated they are in need of CME regarding the care of victims of traumatic events ( $54 \%$ for incidental violent events, $70 \%$ for protracted violent events in the past (such as incest), $71 \%$ for ongoing physical or sexual abuse of an adult, and $71 \%$ for ongoing physical or sexual abuse of a child). Although not statistically significant, there was a trend that GPs, who had not updated their knowledge or skills during the last three years, felt more in need of expert training than those who had done some form of CME in this field. 


\section{Discussion}

The objective of this study was to gain insight into barriers experienced by GPs in their care for patients who have experienced a traumatic event and to elicit improvements.

For each of the four categories of events, most GPs were confronted with at least one patient per year who had experienced that event. The number and type of barriers as experienced by the GPs differed for the various types of events, with most barriers being experienced in the care for children who are presently being abused, sexually or physically. Combining the results it seemed that for events with less taboo (like accidents) barriers are fewer. Furthermore, those barriers are of a more organisational and financial nature, whereas for events with more taboo more emotional and attitudinal barriers were mentioned.

It is remarkable that the number of barriers, as reported by the GPs, is not related to socio-demographic characteristics of the GPs. Some previous studies reported differences in knowledge and attitudes towards victims between male and female doctors, between long-serving and short-serving doctors, and between trained and untrained doctors ${ }^{4,6.7}$. This was not confirmed in our study. Males and females, GPs of different ages and GPs just starting practice and those with many years of experience, either working single handed or in groups, report similar numbers of barriers. The only characteristic related to experiencing fewer barriers is a higher number of new victims per year.

In order to increase response rates, telephone interviews were performed, a financial incentive was given, and GPs not willing to participate in the telephone interview were asked to fill in a postal questionnaire ${ }^{15.16}$. In total $42 \%$ of the sampled GPs took part in our study. Main reasons for nonresponse were similar to those in other GP studies: lack of time and interest $^{17}$. We found that two-thirds of our respondents had updated their knowledge on this topic in the past three years, which seems a very high fraction. Both findings suggest that our respondents are more acquainted with the topic than are average GPs, implying that we may have underestimated GPs' barriers.

In this study we did not measure the actual care given by the GPs in case of a traumatic event, nor the patient satisfaction with GP care. In order to improve the care for patients who experienced a traumatic event, it would be useful to relate barriers, actual care and patient satisfaction in future research.

GPs state that the care for these patients is part of their job. Our figures, however, showed that helping people to cope with the aftermath of traumatic events is difficult for GPs. Although two thirds of the GPs updated their knowledge and/or skills during the last three years, a majority (ranging from $54 \%$ to $71 \%$ ) stated they are in need of training on this subject. 
Future education should be evaluated carefully, both in terms of satisfaction and effectiveness (knowledge and skills of the participating GPs).

Considering that seeing a larger number of new patients who experienced a traumatic event was the only characteristic that was related to a lower level of experienced barriers, the most effective education may be practising skills by role-playing or using standardised patients. It should be mentioned that there may be an additional inverse relation: GPs who know a lot about the topic might see more patients because they are more alert to the problem and have a more open attitude which invites patients to disclose events.

Our results emphasize the importance of increasing the capacity for referral as well as enhancing the knowledge and skills of GPs. The most urgent areas for further training are detection of ongoing physical or sexual abuse of children, assessing signs of acute danger and learning to confront the care-givers with the abuse in order to open the way to counselling. In training about ongoing abuse of adults priorities are: detection, recognition of acute danger and victim blaming. 


\section{References}

1. Mol SSL, Dinant GJ, Metsemakers JFM, Knottnerus JA. Incidentieverschillen van (gewelddadige) ingrijpende gebeurtenissen in landelijke registratiesystemen, enquetes in de bevolking en onderzoek onder huisartsen; een literatuuroverzicht [Differences in incidence of (violent) traumatic events in the national registration systems, population surveys and studies from family proctice; a review of literature]. Ned Tijdschr Geneeskd 1999;143(25): 1308-1314.

2. Ghent W, Da Sylva NP, Farren ME. Family violence: guidelines for recognition and management. Can Med Assoc J 1985; 132:541-553.

3. Mazza D, Dennerstein L, Ryan V. Physical, sexual and emotional violence against women: a general practice-based prevalence study. Med J Aust 1996;164(1):14-17.

4. Gulbrandsen P, Hjortdal P, Fugelli. General proctitioners' knowledge of their patients' psychosocial problems: multipractice questionnaire survey. BM 1997;314:1014-1018.

5. Reid S, Glasser M. Primary care physician's recognition of and attitudes toward domestic violence. Acad Med 1997;72(1):51-53.

6. Easteal P, Easteal S. Attitudes and practices of doctors toward spouse assault victims: an Australian study. Violence and Victims 1992;7(3):217-228.

7. Gremilion D, Kanof EP. Overcoming barriers to physician involvement in identifying and referring victims to domestic violence. Ann Emerg Med 1996;27:769-773.

8. Brown J, Lent B, Sas G. Identifying and treating wife abuse. J Fam Pract 1993;36:185-191.

9. Cohen $S$, De Vos E, Newberger E. Barriers to physician identification and treatment of family violence: lessons from five communities. Acad Med 1997;72(1):S19-S25.

10. Council on Ethical and Judicial Affairs AMA. Physicians and domestic violence. JAMA 1992;267:3190-3193.

11. Richardson J, Feder G. Domestic violence: a hidden problem for general practice. Br J Gen Pract 1996;00:239-242.

12. Hendricks-Matthews M. A survey on violence education: a report of the STFM violence education tosk force. Fom Med 1991;23:194-197.

13. Sounders D, Kindy P. Predictors of physicians' responses to woman abuse: the role of gender, background, and brief training. J Gen Intern Med 1993;8:606-609.

14. Douma I, Zijda K, Jaspers JPC. Huisartsen en slochtoffers van sexueel geweld. Een onderzoek in Friesland naor de visie, taakopvatting, signalering en hulpverlening van huisartsen. TSG 1987;65(6): 168-170.

15. Sibbald B, Addington-Hall J, Brenneman D, Freeling P. Telephone versus postal surveys of general proctitioners: methodological considerations. Br J Gen Pract 1994;44:297-300.

16. Lydeard S. Commentary: avoid surveys masquerading as research. BM 1993;313:733-734.

17. Koner E, Haighton CA, McCavoy BR. 'So much post, so busy with practice - so, no time!': A telephone survey of general practitioners' reasons for not participating in postal questionnaire surveys. Br J Gen Pract 1998; 48:1067-1069. 


\section{For those}

whose rights were trod upon,

tread lightly

Lest their cries

be muftled

By our fear

to hear 


\section{Exploring the iceberg:}




\section{Abstract \\ Background}

As traumatic events can have detrimental effects on patients' health, it is important for GPs to be aware of these events.

\section{Aim}

To quantify the general practitioners' awareness of their patients' exposure to traumatic events (accidents, disaster, war, robbery, burglary and abuse either in childhood or adulthood) and to identify patient, event and general practitioner characteristics that determine this awareness.

\section{Methods}

A cross-sectional population study with postal questionnaires, performed amongst 948 patients and their 31 general practitioners. Main outcome measures: percentage of traumatic events reported by patients (to researchers) known to the general practitioners; odds ratios for patient, event and general practitioner characteristics as predictors of awareness.

\section{Results}

Highest awareness was found for physical abuse as an adult (16.9\%), lowest awareness for burglaries $(0.9 \%)$; the general practitioner was aware of $7.9 \%$ of patients' traumatic events on average. Of the events told to the general practitioner (this one or a previous one), the doctor was aware of one quarter. Predictors of awareness on multivariable analysis were: lower level of education (OR $0.60,95 \% \mathrm{CI} 0.38-0.93$ ), having told the doctor about the event (OR 3.3, 95\% CI 1.5-7.2) and having a physical handicap caused by the event (OR 7.0, 95\% CI 2.8-18). None of the general practitioner characteristics predicted awareness.

\section{Conclusions}

General practitioners are aware of a small percentage of the traumatic events their patients experience, even when told about the event. Several patient characteristics contribute to awareness. 


\section{Introduction}

In the general population, the chance of experiencing traumatic events such as accidents, abuse and disaster is quite high, with a lifetime cumulative incidence around $50 \%{ }^{1}$. There is a role for the general practitioner in supporting and educating patients who have experienced such events and in recognising the psychological and physical repercussions these events may have ${ }^{1-10}$. An important prerequisite for fulfilling this task, however, is an awareness on the doctor's part for this aspect of their patients' history.

The four studies published on the GPs' awareness of their patients' traumatic experiences are about physical and sexual abuse; two of them are original papers $^{11-14}$. The latter show an awareness of $2-19 \%^{11,12}$. Research on awareness of other types of trauma is lacking.

To be able to advise GPs on how to enhance their awareness, one needs information on the type of patients and events about which the GP is not well-informed. Besides, doctor characteristics may be of importance. On the basis of previous quantitative and qualitative research, we selected the following predictors of awareness for our study: patient's demographics, frequency of GP consultation, nature and impact of events experienced and whether a handicap ensued; doctor's demographics, training and interest in the topic, and personal experience with traumatic events ${ }^{11,15-18}$.

The purpose of our study is to quantify the GPs' awareness of their patients' exposure to traumatic events (accidents, disaster, war, robbery, burglary and abuse either in childhood or adulthood) and to identify patient, event and GP characteristics that determine this awareness.

\section{Methods \\ Participants}

The study was performed in a random sample of the 67,500 patients registered with 12 practices and their 31 GPs (mean age 44, range 34-61; 27 male doctors $)^{10}$. The practices participate in the Registration Network of Family Practices at Maastricht University. The population in the network is similar to the Dutch population as regards age and sex, education, medical insurance and type of household ${ }^{19}$. In 1997, 2997 randomly selected patients, aged 20 years and over, were mailed a questionnaire on the following traumatic events: accidents, burglary, robbery, physical and sexual abuse (in childhood or as an adult), disaster and war. Besides, questions about demographics and health characteristics were included.

The questionnaire, returned by 1498 patients ( $43 \%$ male, mean age 50 ), was sufficiently filled out by 1471 persons. Of these $40 \%$ had experienced one or more traumatic events. 
GPs were asked to fill out questionnaires about the type and date of their patients' traumatic events, for a selection of the respondents. To be included the respondent was to have given the researchers permission to ask the GP for information. Compared to those who did not, respondents who did give permission $(90 \%)$ were more often male (93\% versus $89 \%)$, slightly older on average ( 49 versus 46 years), more often married $(92 \%$ non-singles gave permission, $87 \%$ of the singles), more frequent visitors of their GP ( $21 / 2$ versus 2 times in the past year). They had more often experienced one or more events ( $92 \%$ versus $87 \%$ ), (all differences significant at $\mathrm{P}<0.05$ ). As to level of education, lifetime number of events and the experienced types of events there were no significant differences.

From the pool of respondents giving permission, the GPs received questionnaires for all the patients who had reported an event $(n=530)$, and - to blind for victimisation state - a random sample of those who had reported none $(n=418)$. The doctors were encouraged to look at the patients' records, past or present, in all cases. The response of the GPs to the questionnaire was very high, at $97 \%$ (921 of 948 patient questionnaires returned, mean age of patients: 49 , range $20-89 ; 43 \%$ men).

All GPs filled out a personal questionnaire covering age, sex, practice characteristics, education and knowledge about traumatic events, interest in the topic, conception about their task and personal traumatic experiences.

\section{Analysis}

\section{Definition of matching events}

If an event noted in the patient's and the doctor's questionnaire had happened in the same, the previous or the following year and it concerned the same type of event (e.g. accident in the home) or, in cases of chronic abuse, the same perpetrator, it was considered a "matching" event; otherwise it was considered non-matching. To be on the safe side, if the necessary data was missing, the event was also considered non-matching. This occurred only once.

\section{Predictors of GP awareness: Patient variables}

Matching versus non-matching was the dichotomous outcome variable used to study patient variables as predictors of the doctor's awareness. As there was a possible dependency between awareness of two separate events - or more - experienced by the same patient, and to ensure a cross-section of events as regards severity, only the most recent event per patient was included in the analyses on patient characteristics as predictors of GP awareness.

The patient variables were sex, age, marital status, highest education, frequency of GP consultations in the past year, lifetime number of events experienced, character of the most recent event (assaultive or non- 
assaultive), telling the GP about it, the impact of it on the patient's life and ensuing physical handicaps.

Odds ratios (95\% confidence intervals) for the doctor's awareness were calculated for each of the patient variables. All variables were next entered into a multiple logistic regression analysis (backward elimination). Also, as a certain dependency could be expected between patients of the same doctor, a conditional logistical regression analysis (with the doctor as condition) was performed for the variables of the reduced model.

\section{Predictors of awareness: GP variables}

An exploratory analysis was done to study the relationship between GP characteristics and awareness of traumatic experiences. The outcome variable was the percentage of matches per GP. The GP variables were sex, age, number of years in current practice, education about traumatic events during medical/vocational training and in the past three years, the GP's impression of his/her competence in this field, interest in the topic, knowledge about acute stress disorder, considering initiating the counselling of traumatised patients one's task and personal experience with trauma. Non-parametric tests were used for statistical analysis (continuous variables: Spearman Rho; dichotomous/polytomous variables: Kruskall-Wallis and Mann-Whitney).

\section{Results}

Of the 921 questionnaires filled out by the GPs, 517 concerned patients who had reported events. Sixty-nine (7.9\%) of the 877 events these patients had reported to us were known to the GP (table 1). The GP was more aware of accidents and abuse than of the other types of events.

\section{Table 1 GPs' awareness of events reported by the patients} (31 GPs, 517 patients)

Type of event

A B

B/A

Number of events Number of events reported Percentage of events reported by patients by patients known known to GPs

Serious accidents

211

Burglaries 232

Robberies to the GP

Physical abuse (adult)

Sexual abuse (adult)

Sexual abuse (child)

26

2$$
1
$$
(motches)

12.3

0.9 
Table 2 Patient and event characteristics as determinants of the GP's awareness of a traumatic event in the patient's history (univariate anolysis and multiple logistic analysis)

\begin{tabular}{|c|c|c|c|c|}
\hline \multirow[t]{3}{*}{ Determinants } & \multicolumn{2}{|c|}{ Univariate $(N=517)$} & \multicolumn{2}{|c|}{ Multivariable (full model, $\mathrm{N}=433$ ) } \\
\hline & Odds Ratio & $95 \% \mathrm{Cl}$ & Odds Ratio & $95 \% \mathrm{Cl}$ \\
\hline & (Crude) & & (Adjusted) & \\
\hline $\operatorname{Sex} \boldsymbol{\nabla}$ & 1.3 & $0.70-2.4$ & 1.6 & $0.71 \cdot 3.6$ \\
\hline Age (continuous variable) & 1.0 & $0.98-1.0$ & 1.0 & $0.97-1.0$ \\
\hline \multicolumn{5}{|l|}{ Marital status } \\
\hline single & 1.0 (reference) & & & \\
\hline married & 0.85 & $0.39-1.9$ & 0.65 & $0.23 \cdot 1.8$ \\
\hline divorced/widowed & 1.0 & $0.38-2.9$ & 0.71 & $0.17-2.8$ \\
\hline Education" & 0.65 & $0.45-0.96^{\star}$ & 0.61 & $0.38-0.99^{*}$ \\
\hline Number of visits to the GP in the past year & 1.0 & $0.98-1.1$ & 1.1 & $0.98-1.2$ \\
\hline Lifetime number of events experienced & 0.99 & $0.80-1.2$ & 0.89 & $0.67 \cdot 1.2$ \\
\hline Told the GP about the event ${ }^{\prime}$ & 4.9 & $2.5-9.5^{\star \star}$ & 2.8 & $1.2 \cdot 6.6 *$ \\
\hline \multicolumn{5}{|l|}{ Impact of the event on the patient's life } \\
\hline very negative & 1.0 (reference) & & & \\
\hline negative & 0.21 & $0.08-0.53^{\star \star}$ & 0.43 & $0.13-1.4$ \\
\hline negative/positive & 0.44 & $0.22-0.89^{\star}$ & 1.14 & $0.43-3.0$ \\
\hline (very) positive & 0.29 & $0.06-1.3$ & 0.79 & $0.14-4.5$ \\
\hline Handicap as a result of the event' & 9.1 & $4.0-20^{\star \star}$ & 8.3 & $2.9-23^{\star \star}$ \\
\hline Character of the event & 1.7 & $0.94-3.1$ & 1.4 & $0.60-3.0$ \\
\hline
\end{tabular}

$\boldsymbol{\nabla} 0=$ male, $1=$ female; $" 1=$ lower, $2=$ secondary, $3=$ higher; $10=$ no, $1=$ yes $; 0=$ assaultive, $1=$ non-assaultive (accidents, disaster)

$\star 0.01 \leq P<0.05, * * P<0.01$ 
In the further analyses on GP awareness, only each patient's most recent event was included; of the 517 most recent events, 47 were matching ones. The predictors for greater doctor's awareness found on univariate analysis were lower education, a physical handicap ensuing from the event, a very negative impact of the event on the respondent's life, and having told the doctor about the event (table 2). Of the 68 events reported by the patients to have been told to the GP - the present GP or a previous one only 18 were known to the present GP (not shown in table).

After multiple logistic regression analysis (table 2) a reduced model of three significant variables remained (not shown in table): lower level of education (OR 0.60, 95\% CI 0.38-0.93), having told the doctor about the event (OR 3.3, 95\% CI 1.5-7.2) and having a physical handicap caused by the event (OR 7.0, 95\% CI 2.8-18). There was no interaction between education and telling the doctor, nor between having a handicap and telling the doctor. However, those who felt the event had a very negative impact were more likely to tell their GP about the event $(\mathrm{p}<0.001$, t-test). In the conditional logistic regression analysis, no significant variables remained.

None of the 15 GP characteristics studied reached a 0.05 significance.

\section{Discussion}

This is the first study on the GPs' awareness of a variety of traumatic experiences of their patients. Some $8 \%$ of the events mentioned by patients were known to their GP, with the highest awareness for serious accidents $(12 \%)$ and physical and sexual abuse (11-17\%). A Norwegian study, on violence or threats patients had experienced from a close person, showed results similar to our study with a $19 \%$ awareness ${ }^{11}$. Saunders, in an American study on women reporting physical abuse, found a much smaller tip of the iceberg $(2 \%)^{12}$. However, Saunders only counted abuse recorded by the doctor, while the doctors in our study were allowed to go by memory too. In another study, a review in which the iceberg phenomenon was estimated for adult physical abuse by comparing data from Dutch GP morbidity records with questionnaire surveys in the open population, GP awareness was estimated to be much lower than in the present study $(3 \%)$, which illustrates one of the pitfalls of extrapolating data from studies in different settings, with different definitions ${ }^{14}$.

We have looked into a number of predictors for awareness. Doctors were more aware of events with a very negative impact on the patient's life, which is reassuring as one can expect the need for care to be greater in those cases. Having a physical handicap caused by the event probably enhances awareness, being a lively reminder of the event every time the doctor sees the patient. Increased awareness of the doctor in those with lower education was not explained by these patients more easily telling their 
doctor, since analysis showed no significant interaction between education and telling the doctor. It has been suggested that physicians are reluctant to suspect domestic violence in patients from their own background, leading to lower recognition of such events in their highly educated patients ${ }^{20,21}$. Our findings support this hypothesis, although due to the small numbers we cannot say whether this factor plays a larger role in abuse than in other types of traumata. We can nevertheless conclude that in day-to-day practice we must be alert about traumatic experiences irrespective of level of education.

The doctors' response, at $97 \%$, was very high. The patients' response, although it is of secondary importance considering the design of the study, calls for some discussion. A non-response of $50 \%$ to a questionnaire held in the open population is not unusual, but it could have led to selection bias. The respondents differed slightly in demographic characteristics from the non-respondents, being somewhat more often female, two years older on average and better educated. Sex and age, however, turned out not to be predictive of awareness; our findings on the influence of the level of education imply that awareness is slightly better than observed in our study.

As expected, telling the doctor increases the chance of the doctor being able to retrieve this information at a later stage. Yet, as only one fourth of the events that were disclosed (according to the patient) were known to the current doctor, much information is forgotten or lost. The context within which the event was told, the doctor's attentiveness, as well as the way in which the need for help is expressed may influence remembrance. Poor record-keeping probably also contributes to low awareness. Besides, while the use of the patient's problem-list has been simplified since the introduction of electronic medical records, some problems have to be dealt with. There are no specific codes in the International Classification for Primary Care (ICPC) for several traumatic events, nor for post-traumatic disorder. The various patient information systems are not compatible, which hampers transfer of charts when patients change doctors. In addition, when the doctor suspects domestic violence, he or she may be reluctant to note this because of legislation about patient access to the medical record.

The fact that on conditional analysis the three patient variables (education, telling the doctor, and handicap) lost their significance does not mean that they are unimportant. It does imply, however, that differences between doctors overshadow the differences between patients. Our small sample size, with 31 doctors only, did not allow definitive analysis of GP characteristics that influence awareness. Further studies should especially look at the doctor's role. Characteristics to be studied must be sought in the areas of communication style and recordkeeping. It might also be interesting to investigate the curious finding that there were quite a number of events reported to us by the doctor that had not been reported by the patients in 
their questionnaire, a finding from our study which we did not further explore as it was not our primary aim.

Previous research has shown the detrimental effects traumatic events can have on people's health ${ }^{1-9}$. Our study shows that the GP's awareness for these events is low. Although we think it is neither necessary ${ }^{22}$ nor realistic that the GP is aware of all traumatic events, we can conclude that if patients come to us with hitherto unexplained problems, we must certainly not presume that we are well enough informed about their traumatic history to be excused of asking them about these - sometimes painful - matters. Also, the GP must be more sensitive to a traumatic history irrespective of the patient's level of education. Further research should especially focus on GP characteristics and on methods to improve the GP's awareness. 


\section{References}

1. Kessler RC, Sonnega A, Bromet E, Hughes M, Nelson CB. Posttraumatic stress disorder in the National Comorbidity Survey. Arch Gen Psychiotry 1995;52(12):1048-60.

2. Shalev A, Bleich A, Ursano RJ. Posttroumatic stress disorder: somatic comorbidity and effort tolerance. Psychosomatics 1990;31(2):197-203.

3. Plichta $S$. The effects of woman abuse on health care utilization and health status: a literature review. Womens Health Issues 1992;2(3): 154-63.

4. Falger PR, Velde W op den, Hovens JE, Schouten EG, Groen JH de, Duijn H van. Current posttraumatic stress disorder and cardiovoscular disease risk factors in Dutch Resistance veterans from World War II. Psychother Psychosom 1992;57(4):164-71.

5. Turner RJ, Lloyd DA. Lifetime traumas and mental health: the significance of cumulative adversity. J Health Soc Behav 1995;36(4):360-76.

6. Acierno R, Resnick HS, Kilpatrick DG. Health impoct of interpersonal violence. 1: Prevalence rates, case identification, and risk factors for sexual assault, physical assoult, and domestic violence in men and women. Behov Med 1997;23(2):53-64.

7. Breslau N, Davis GC, Peterson EL, Schultz L. Psychiatric sequelae of posttraumatic stress disorder in women. Arch Gen Psychiatry 1997;54(1):81-7.

8. Resnick HS, Acierno R, Kilpatrick DG. Health impact of interpersonal violence: II. Medical and mental health outcomes. Behavioral Medicine 1997:65-78.

9. Ursano RJ, Fullerton CS, Epstein RS, Crowley B, Kao TC, Vance K, et al. Acute and chronic posttraumatic stress disorder in motor vehicle accident victims. Am J Psychiotry 1999; 156(4):589-95.

10. Mol SSL, Dinant GJ, Vilters-van Montfort PAP, Metsemakers RFM, Akker van den M, Arntz A et al. Traumatic events in a general practice population: the patient's perspective. Fam Pract 2002; 19(4): 390-96.

11. Gulbrandsen P, Hjortdahl P, Fugelli P. General practitioners' knowledge of their patients' psychosocial problems: multipractice questionnaire survey. BM 1997;314(7086):1014-8.

12. Saunders DG, Hamberger LK, Hovey M. Indicators of woman abuse based on a chart review at a family practice center. Arch Fam Med 1993;2(5):537-43.

13. Burris CA, Jaffe P. Wife battering: A well-kept secret. Canadian Journal of Criminology $1984 ; 26(2): 171-77$.

14. Mol SSL, Dinant GJ, Metsemakers JFM, Knottnerus JA. Incidentieverschillen van (gewelddadige) ingrijpende gebeurtenissen in landelijke registratiesystemen, enquêtes in de bevolking en onderzoek onder huisortsen; een literatuuroverzicht [Differences in incidence of (violent) traumatic events in national registration systems, population enquiries and studies from general practice; a review of the literature]. Ned Tijdschr Geneeskd 1999;25(143):1308. 1314

15. Ferris LE. Canadian family physicians' and general practitioners' perceptions of their effectiveness in identifying and treating wife abuse. Med Care 1994;32(12):1163-72.

16. Brown JB, Lent B, Sas G. Identifying and treating wife obuse. J Fam Proct 1993;36(2): 185 191.

17. Ghent WR, Da Sylva NP, Farren ME. Family violence: guidelines for recognition and management. Con Med Assoc J 1985; 132(5):541-53. 
18. Gremillion DH, Kanof EP. Overcoming barriers to physicion involvement in identifying and referring victims of domestic violence. Annals of Emergency Medicine 1996;27:769-773.

19. Metsemakers JFM, Hōppener P, Knottnerus JA, Kocken RJ. Computerized health information in the Netherlands: a registration network of family practices. Br J Gen Pact 1992;42:102-106.

20. Richardson J, Feder G. Domestic violence: a hidden problem for general proctice. Br J Gen Pract 1996;46(405):239-42.

21. Easteal PW, Easteal S. Attitudes and practices of doctors toward spouse assault victims: an Australian study. Violence Vict 1992;7(3):217-28.

22. Cope J. How general practice patients with emotional problems presenting with somatic or psychological problems explain their improvement. Br J Gen Pract 2001;51:724-29. 


\section{Thuiskomst}

Hij kwam thuis. Zei niets.

Er was hem echter duidelijk iets naars overkomen.

Hij kroop met zijn kleren aan in bed. Verborg zijn hoofd onder de deken.

Trok zijn knieën op.

$\mathrm{Hij}$ is rond de veertig, maar op dit moment niet.

Hij bestaat, maar niet meer dan in zijn moeders buik, vele huiden ver, in een beschuttend duister.

Morgen moet hij een lezing houden over de homeostase

in de metagalactische astronautiek.

Maar voorlopig ligt hij opgerold te slapen. 


\section{Abstract}

\section{Objective}

To gather evidence from the open population on whether life events (e.g. divorce and unemployment) generate as many symptoms of post-traumatic stress as traumatic events (e.g. accidents and abuse).

\section{Method}

Data on demographic characteristics and trauma history were collected using a written questionnaire sent to a random sample of 2997 persons, 20 years and over, from the open population. Respondents filled out a PTSD-symptom checklist (PSS-SR, developed by Foa) keeping in mind their worst event. Mean PTSD scores were compared, controlling for differences between the two groups. Differences in item scores and in the distribution of the total PTSD scores were analysed.

\section{Results}

Of the 1498 respondents 832 were eligible for analysis. For the events that happened in the past 30 years the PTSD scores were higher on average for the life events than for the traumatic events; for earlier events the scores were the same for both types of events. These findings could not be explained by differences in demographics, trauma history or individual item scores, nor by differences in the distribution of the total PTSD scores.

\section{Conclusions}

Life events can generate at least as many PTSD symptoms as traumatic events. Our findings call for further studies on the specificity of traumatic events to generate PTSD. 


\section{Introduction}

Post-traumatic stress disorder ( PTSD) is a construct that has been questioned from various points of view. One of the discussions revolves around the definition of the stressor that could lead to the disorder. According to criterion Al in the DSM-IV the patient is to have been exposed to an "extreme traumatic stressor involving direct personal experience of an event that involves actual or threatened death or serious injury, or other threat to one's physical integrity; or witnessing an event that involves death, injury or threat to the physical integrity of another person; or learning about unexpected or violent death, serious harm, or threat of death or injury experienced by a family member or other close associate".

If one were to take a range of events and place them on a continuum of intensity, one could order them according to the immediacy of the threat to life. It is clear that on this continuum events such as combat, rape and disaster - the events that originally gave rise to the diagnosis of post-traumatic stress disorder - are at the end of the continuum that certainly fulfils criterion AI. Which events should be placed at the other end of the continuum? Should this be events in which the threat to life is less immediate, such as having been diagnosed with cancer or being HIV-positive? And is death of a spouse after a long-term illness included? There is room for debate whether these types of events fulfill the Al criterion. One way of solving the dilemma is by looking at the evidence: indeed, events such as terminal diseases and losing a significant other after a long term illness have been shown to give rise to PTSD $^{1-4}$.

As stressors that signify death on the long-term have been shown to lead to PTSD, the question is raised whether more common stressors that pose a threat to life in a more symbolic manner, by upsetting the normal order of things and the way we picture ourselves in our world, such as serious problems with work, finances and relationships, and chronic diseases, also lead to the disorder. If severe difficulties that do not fulfill the PTSD stressor $\mathrm{Al}$ criterion indeed give rise to PTSD, this could imply that the stressor criterion should be broadened to include such life events. A positive consequence could be the generation of new ideas on treatment: therapies proven to be useful in PTSD could be tried out in this new group of "victims". On the other hand, there is some resistance against creating such a new group of victims from several points of view. There could be social implications in terms of medicalisation and financial compensation ${ }^{5.7}$. It could also have consequences in terms of responsibility: "Many have argued that giving "victim" status to persons experiencing these lesser events is an abuse of this status. Such critics hold that defining these lesser events as "stressors" promotes a culture that externalizes the causes of personal distress, in contrast to a culture of individual responsibility" 8 . 
From the theoretical point of view, broadening of the concept could give rise to further doubt about the validity of PTSD, the only DSM-IV diagnosis that requires an event as a causative factor. If all types of stressors can give rise to PTSD-symptoms, the disorder only distinguishes itself from other anxiety disorders in its symptomatology.

Empirical evidence on the potential of severe life difficulties to cause PTSD is scarce. Two studies on a total of eight persons showed the presence of all the symptoms of PTSD after employment related problems ${ }^{9,10}$. In a quantitative study among 427 English adolescents the Impact of Event Scale was used to measure their PTSD score after a wide range of events (e.g. life threat to respondent, witnessing an attack and parental separation) ${ }^{11}$. Using the recommended cut-off score of 35 , one third of those experiencing parental separation had PTSD.

The results of these three studies fuel the hypothesis that more types of stressors than those fulfilling the Al stressor criterium can give rise to PTSD symptoms. To further investigate this issue the present study was performed. For reasons of generalisibility subjects were randomly selected from the general population; a wide range of events was studied. Events ranged from typical traumatic events as defined in the PTSD stressor Al criterion such as accidents and war, to more common life events such as relational problems, problems with study or work, and chronic diseases.

In this article we will answer the following questions:

- Do those whose worst event is a traumatic event currently have more PTSD symptoms than those whose worst event is a life event?

- Are some of the items on the PTSD checklist more typical for traumatic events, and others for life events?

\section{Methods}

Design

A cross-sectional study using a self-report questionnaire was performed in a random sample from a family practice population. The family practice population in the Netherlands represents the general population since practically every Dutch inhabitant is registered in a family practice.

\section{Study Population}

The study was performed in a random sample of the 67,500 patients registered with 12 practices and their 31 GPs. The practices participate in the Registration Network of Family Practices at the University of Maastricht, province of Limburg. The population in the network is similar to the Dutch population as regards age and sex, education, medical insurance and type of household $^{12}$. 
The questionnaire, sent to 2997 patients randomly selected from this Registration Network, aged 20 years and over, was filled out between February and April $1997^{13}$. Fifty percent of the questionnaires was returned ( $43 \%$ men, mean age 50 years). Eighty-five percent of the respondents lived with family/partner, $14 \%$ alone and $1 \%$ otherwise. Thirty three percent had private health insurance and $67 \%$ had national health insurance, $44 \%$ had only primary education, $43 \%$ had completed secondary education, $13 \%$ had completed higher education. Except for insurance type, the demographic variables differed significantly $(\mathrm{p}<0.05)$ between respondents and nonrespondents. The differences considered relevant were the following: of the respondents $43 \%$ were male, of the non-respondents $52 \%$; respondents had had more education ( $56 \%$ had secondary or higher education versus $44 \%$ amongst non-respondents). The respondents were 2 years older on average; with an over-representation of 60-70 year olds and under-representation of 20-30 year olds.

Of 1497 respondents, 832 were eligible for the aim of our study, the comparison of PTSD scores after traumatic versus life events. Reasons for exclusion were: not having experienced any event, not having specified one's worst event or having chosen more than one worst event. Those whose worst event had happened in 1997 were also excluded as some of these subjects could be suffering from an acute stress disorder (symptoms of acute stress within one month of an event).

\section{Measurements}

A questionnaire was developed covering demographic data and several health status correlates (use of medical care, drugs, alcohol, sedatives), followed by a checklist on personal experience with accidents, burglaries, robberies, sexual and physical abuse (in childhood or adulthood), disaster or war, or regarding a loved person: chronic serious illness or sudden death. The next three questions were: have you experienced any other events; which was the worst event and in which year did you experience this? Respondents were asked to fill out part 3 of the Post-traumatic stress Symptom Scale - Self Report version (PSS-SR, developed by Foa) keeping this worst event in mind $^{14}$.

Part 3 of the PSS-SR consists of the 17 criteria on the three subscales for PTSD as listed in the DSM 3-R or DSM-IV. There are 5 items on re-experiencing, 7 on avoidance/numbing and 5 on arousal. The respondents were asked how often they had experienced each symptom in the past month (never $=0$, a few times a month $=1$, a few times a week $=2$, a few times a day or continuously $=3$ ). The maximum score is 51 . As the distribution of PTSD scores on the PSS-SR was skewed to the right, we performed a transformation: ${ }^{10}$ logarithm of (total PTSD score +1 ). This score is called "log PTSD score" in this article. The transformed total log PTSD score was 
our main outcome variable; when relevant it was converted back to the original score (geometric mean).

Criteria for missing values on the PSS-SR were the following: one missing was allowed on each of the five items subscales, and two missings on the seven items subscale (Foa, written communication). The score filled in for the missing value was the average of the respondent's values on that subscale.

The PSS-SR was originally validated in two American samples - sexually abused women and a group of victims of various traumata ${ }^{14}$. The reliability of the Dutch version of the checklist, studied in persons referred to ambulatory care for symptoms of post-traumatic stress $(n=63)$, showed a Cronbach's alpha of $\mathbf{0 . 8 8}$ for the total score (A. Arntz, personal communication). In a sample of 113 Dutch women who had experienced a miscarriage, the Cronbach's alpha was $0.8^{15}$. Cronbach's alpha in the present sample was 0.92 for the total score; for the three subscales of re-experiencing, avoidance and arousal the Cronbach's alphas were $0.83,0.83$ and 0.78 respectively.

\section{Analysis}

Based on the examples given in the DSM-IV the following events were classified as traumatic events: accidents, robbery, sudden death loved one, murder or suicide of loved one, physical or sexual abuse as an adult or child, disaster, war, learning about trauma experienced by loved one and witnessing violence. Burglary without confrontation with the burglar, relational problems, problems with study/work, chronic illness or non-sudden death of a loved one and serious illness self were classified as life events. When it was not clear whether a decease was sudden or not it was classified as nonsudden.

Demographic characteristics and trauma history of the traumatic events and the life events groups were compared, using t-tests and chi-square tests to test for statistical significance. Log PTSD scores were calculated per type of event. Next, the mean log PTSD score (total and three subscales) for the traumatic events group and life events group were calculated. This was followed by an analysis of co-variance in which the the mean log PTSD scores were again calculated, but were now adjusted for differences between the two groups regarding demographics and trauma history. All variables shown in table 1 were included in the latter analysis.

To see whether respondents from the traumatic events group would score significantly higher on certain items of the PSS-SR scale, whilst those from the life events group would score higher on other items, a non-paremetric test (Mann-Whitney) was chosen as the distributions of the item scores were skewed to the right. Because of the large number of items (17), Bonferroni correction was done. 
Table 1 Demographic characteristics and trauma history of the traumatic events and life events groups ( $N=\mathbf{8 3 2}$ )

Group

$\begin{array}{cc}\text { Worst event was } & \text { Worst event was } \\ \text { traumatic event } & \text { life event } \\ N=299 & N=533\end{array}$

Demographics

Age :

$\%<45$

48

$45-64$

$>64$

Country of birth ${ }^{\circ}$

\% non-Dutch

Marital Status ${ }^{\circ}$

\% Single

Married

Divorced/ Widowed

Living Situation ${ }^{\circ}$

$\%$ Living alone

With partner (and children)

One parent family

$76 \quad 77$

Living with parents/family/home

33

Highest education ${ }^{\circ}$

\% Lower

Middle

Higher

Occupation ${ }^{\circ}$

\% Elementary

Lower

Secondary

Higher

Academic

Trauma history

Confronted with other peoples traumatic events and life events on a day-to-day basis ${ }^{\circ}$

$\%$ yes

Abused as a child (physically or sexually) ${ }^{\circ}$

$\%$ yes

Total number of traumatic events (PTSD-type) excluding index event" Mean

Number of years since "worst" event "**

Mean

${ }^{\circ}$ Chi-square test

- T-test (two-sided)

** significant at the 0.01 level 


\section{Results}

There were 299 subjects whose worst event could be classified in the traumatic events group and 533 in the life events group. Table 1 shows the minor differences in demographic characteristics between the two groups. The only variable showing a statistically significant difference is "number of years since the event": those whose worst event was a traumatic event experienced it 18 years ago on average; this was 12 years for those whose worst event was a life event.

Table 2 shows that, except for physical and sexual abuse - which lead to the highest PTSD scores - the scores for the traumatic events and the life events are in the same range. The average total PTSD score (table 3) is higher for those whose worst event was a life event than for those whose worst event was a PTSD type event. The three subscales follow the same pattern. None of the differences between the two groups is significant.

Possibly, the fact that the traumatic events, on average, happened earlier than the life events could explain this finding. To check for this a posthoc analysis was done, comparing total log PTSD scores per group after stratification (before 1939, 1940-1945, five year strata for 1946-1995, 1996). For five out of the six strata before 1966, the average log PTSD scores are highest for the traumatic events. In contrast, from 1966 onwards the life events group had higher scores in all strata. The differences, however, were non-significant for each stratum (t-tests, p <0.05). Next, taking 1966 as a cut-off point, two new strata were formed. For events before 1966 the mean $\log$ PTSD scores were 0.78 and 0.56 for the traumatic and life event groups respectively $(t=-1.9, \mathrm{df}=90, \mathrm{p}=0.056)$. The relation reversed after 1966, the scores being 0.61 and 0.71 respectively $(t=2.8, d f$ $=703, p=0.006)$. Therefore, for events that happened in the past 30 years, current PTSD scores are higher in those whose worst event was a life event than in those whose worst event was a traumatic event.

After adjusting for differences between the two groups in demographics and trauma history, the average PTSD score is significantly lower in the traumatic events group than in the life events group (estimated marginal means of $\log$ PTSD score: 0.62 and 0.71 respectively, $F=5.11, \mathrm{df}=685, \mathrm{p}$ $=0.024$ ). This analysis was repeated for each of the two large strata (before and since 1966). This generates the following corrected scores: before 1966: traumatic event 0.70 and life event $0.68(\mathrm{~F}=0.031, \mathrm{df}=65, \mathrm{p}=0.86)$; since 1966: 0.59 and $0.71(\mathrm{~F}=7.8, \mathrm{df}=607, \mathrm{p}=0.005)$.

Post hoc, we postulated that there might be a difference in the distribution of the PTSD scores between the two groups, in the sense that there may be a number of persons with very high PTSD scores from traumatic events. The maximum log PTSD scores were 1.67 (original score $=46$ (geometric mean)) for the traumatic events and 1.64 (original score $=43$ (geometric mean)) for the life events group. The second approach was to count 


\section{Table 2 Mean total PTSD-score' per type of worst event $\left(\mathbf{N}=803^{2}\right)$}

\begin{tabular}{|c|c|c|c|c|c|}
\hline & N & $\begin{array}{c}\text { Traumatic } \\
\text { events }\end{array}$ & $\begin{array}{c}\text { Original } \\
\text { score } \\
\text { (geometric } \\
\text { mean) }\end{array}$ & $\begin{array}{l}\text { Life } \\
\text { events }\end{array}$ & $\begin{array}{l}\text { Original } \\
\text { score } \\
\text { (geometric } \\
\text { mean) }\end{array}$ \\
\hline Accidents & 42 & 0.53 & 2.4 & & \\
\hline \multicolumn{6}{|l|}{ Sudden death loved one (not murder, or } \\
\hline unknown whether murder) & 142 & 0.58 & 2.8 & & \\
\hline Witnessing violence & 4 & 0.60 & 3.0 & & \\
\hline Disoster & 16 & 0.61 & 3.1 & & \\
\hline Murder or suicide of loved one & 26 & 0.68 & 3.8 & & \\
\hline War & 23 & 0.71 & 4.1 & & \\
\hline Robbery & 5 & 0.88 & 6.6 & & \\
\hline Physical abuse adults & 9 & 0.94 & 7.7 & & \\
\hline Sexual abuse adults & 4 & 1.09 & 11.3 & & \\
\hline Physical abuse or sexual abuse child & 13 & 1.09 & 11.3 & & \\
\hline \multicolumn{4}{|c|}{ Burglary without confrontation of burglar 11} & 0.54 & 2.5 \\
\hline \multicolumn{6}{|l|}{ Death of loved one (non-sudden or } \\
\hline Miscellaneous, not traumatic & 14 & & & 0.61 & 3.1 \\
\hline (Chronic) illness loved one & 95 & & & 0.71 & 4.1 \\
\hline Serious illness self & 91 & & & 0.82 & 5.6 \\
\hline Problems with study/work & 19 & & & 0.83 & 5.8 \\
\hline Relational problems & 81 & & & 0.88 & 6.6 \\
\hline
\end{tabular}

110 ogarithm of (PTSD-score + 1)

2 PTSD-symptom checklist missing in 29 cases

\section{Table 3 Mean crude logPTSD scores* for the traumatic events and life events} groups

Events

Subscale A Subscale B Subscale C Total Total PTSD-score: Re-experiencing Avoidance Arousal PTSD Original score score (Geometric mean)

Worst event was traumatic event 0.29 0.33

0.42

0.64

$(\mathrm{N}=284)$

Worst event was

life event

0.71

4. 1

$(\mathrm{N}=519)$

All differences between the two groups (for the total score and for each of the subscales) are non-significant at 0.05 level (t-test)

${ }^{10}$ logarithm of (PTSD-score +1 ) 
the number of persons in each of the two groups that scored higher than the 90th percentile score of the total group (log PTSD score $=1.32$, original score $=20$ (geometric mean $))$. In the traumatic events group $10 \%$ scored higher than 1.32; in the life events group $11 \%$ did (chi-square $=0.065$, df $=1, \mathrm{p}=0.79$ ). This indicates that amongst the respondents whose worst event is a life event, the top range of PTSD scores is reached as often as amongst the otherwise traumatised.

Another explanation for the PTSD score being higher in the life events group than in the traumatic events group was sought in our assignment of events to the categories. The sudden death category (categorised as a traumatic event) contained events of a wide range of severity, from witnessing a partner's violent death to hearing about the fatal heart attack of a far-away relative. This could have decreased the PTSD scores in the traumatic events group. Therefore, the effect of assigning the sudden deaths to the life events group was studied: the total log PTSD score of the traumatic events group now rose above that of the life events $(0.71$ versus 0.68 respectively, $t=$ $0.53, \mathrm{df}=801, \mathrm{p}=0.60)$, as did the scores on the subscales. However, the difference was only significant for the arousal subscale (0.49 and 0.43 respectively, $\mathrm{t}=-2.1, \mathrm{df}=810, \mathrm{p}=0.036)$. Another group of events, deaths about which it was not clear whether they had been sudden, had in first instance been allotted to the non-sudden death category (life events). Therefore this group could include a number of sudden deaths too, unjustly increasing the scores in the life events group. To check for this, the analysis was repeated putting all deaths (non-sudden and sudden deaths) in the traumatic events group. This had a considerable effect: the total life events score rose to 0.77 on average, while the total traumatic events score fell to 0.62 $(\mathrm{t}=4.7$, df $=801, \mathrm{p}<0.01)$. In summary, to whichever group the 'deaths' are assigned, the total PTSD scores of the life events group are not lower than those of the traumatic events group.

The mean ranks of all of the 17 PSS-SR-items except three (table 4, items 8, 16 and 17) are higher in the life events group. After Bonferroni correction none of the differences are significant. Therefore, none of the PTSD symptoms seem more typical for either traumatic or life events.

\section{Discussion}

To our knowledge, ours is the first study in the general population, on the propensity of a range of severe difficulties in life that do not fulfil the DSM-IV PTSD stressor criterion A1, to give rise to PTSD symptoms. Our findings show that persons from the open population whose worst event is a life event such as chronic illness, marital discord or unemployment, on average have more PTSD symptoms from this event than persons whose worst event is a traumatic type of event such as an accident or disaster. As this is a 


\section{Table 4 Mean ranks of PTSD-scores per item, traumatic versus life events}

\section{groups $(\mathrm{N}=803)$}

Item Content:

number events

1 Upsetting thoughts or images about the traumatic event

2 Bad dreams or nightmares about the traumatic event

3 Reliving the traumatic event, acting or feeling as if it was happening

$$
\text { ogain }
$$

$4 \quad$ Feeling emotionally upset when reminded of the traumatic event

Traumatic Life events

393

409

419

\section{Experiencing physical reactions when reminded of the traumatic event}

406

398 traumatic event event Having much less interest or participating much less often in important activities

10 Feeling distant or cut off from other people

Feeling emotionally numb

Feeling as if future plans or hopes will not come true

* significant difference at $\mathrm{p}<0.05$ level (Mann-Whitney test)

rather unexpected finding, we have tried to refute it in several ways. After stratifying for the only difference found in demographic and trauma characteristics between the two groups - time since the event - we found that the finding holds true for events that occurred at some time in the past 30 years. The latter finding perhaps implies that in the very long run the impact of a life event wears out, in terms of PTSD, while that of a traumatic event is more persistent.

One could argue that the average difference in total PTSD score between the two groups, at 0.7 on the PSS-SR, is not clinically relevant. Yet, although this difference is indeed small, the found scores remain curious as one would expect the life events group to have less, and not more symptoms. Also, as was shown by comparing the distributions of the PTSD scores, the scores at the top end of the range, after both types of events, are comparable. This means that there is considerable suffering from both types of events in terms of PTSD. 
Another explanation for our finding was sought in the allocation of those whose worst event was a sudden or a non-sudden death of a loved one to either the life events group or the traumatic events group. The results, however, did not counter our first finding.

If no difference could be found between the two groups regarding the total PTSD score there could still be a difference on the item level; perhaps some of the 17 symptoms of post-traumatic stress are typical after life events and others after traumatic events. Our analyses showed that this was not the case.

The reliability of the PSS-SR-checklist was found to be good in selected populations and it was also found to be reasonably predictive of PTSD diagnosed by interview ${ }^{14,15}$. However, use in the open population has not been documented. The reliability in our sample, expressed as Cronbach's alpha, was good. But, as the PSS-SR checklist is a written questionnaire, we were unable to check whether the respondents understood all items correctly. For example, the question on "reliving the event, acting or feeling as if it was happening again" may be interpreted as actively remembering the event, rather than as an intrusive memory, by those who have never experienced a traumatic event. In further research on this topic, using a more detailed PTSD symptom checklist or using interviews should be considered.

We chose to exclude all persons who had chosen two or more events because the variable "number of years since the worst event" could obviously not be calculated in this group. Besides, we would not have been able to include those whose worst events were from both categories in the item analysis as one cannot tell to which type of event (life or traumatic) they are referring when filling out an item.

Although a higher response than $50 \%$ would have been preferable, our response rate is not unusual taking into account the taboo around some of the topics questioned ${ }^{16}$. Also, the questionnaire was quite lengthy and complicated: besides a section on PTSD, there were questions about general health and a quite detailed section about care sought and received for a number of traumatic events experienced by the respondent ${ }^{13}$.

The question is whether the non-response was selective. The questionnaire contained a list of eight traumatic events, and only two life events (burglary and illness other), followed by an open question about other events experienced. If a person has experienced one event only, a mild life event, the memory of that mild event may not be evoked by the open question and the respondent may therefore not feel the questionnaire pertains to him or her. The memory of a severe life event may be evoked more easily, triggered by reading the list of mostly traumatic events. Non-response amongst those who experienced a mild life event (other than burglary or illness other) may have ensued, resulting in relatively severe life events being reported. Yet, we also know that some people prefer to avoid painful mem- 
ories and therefore some subjects with severe life events will refrain form responding, countering the former effect. This would also hold true for the traumatic events: those without a traumatic event may think the questionnaire was not meant for them; those with may not want to be reminded of it and therefore not respond. Altogether we have insufficient reason to think that there was a selection bias. Enhancing the total response in further research, however, is important. Home visits were recently shown to give rise to a good response in a Dutch mental health study ${ }^{17}$. They may also be a good opportunity for performing interviews, as suggested above.

To quote Bremner: "There is a natural tendency to resist stress-related diagnoses, given their potentially explosive impact on societal approaches to responsibility and accountability. The challenge to our field is to find the appropriate balance" 7 . Should we now advise clinicians to ask about symptoms of posttraumatic stress after life events? Or should we reconsider the validity of the diagnosis PTSD $^{18}$ ? It is too early for either of these, but our study does stress the importance of looking for more empirical evidence on the consequences of events other than typically traumatic ones, in terms of PTSD. 


\section{References}

1. Kelly B, Raphoel B, Judd F, Perdices M, Kernutt G, Burnett P, Dunne M, Burrows G: Posttraumatic stress disorder in response to HIV infection. Gen Hosp Psychiatry $1998 ; 20(6): 345-52$

2. Cordova MU, Studts JL, Hann DM, Jacobsen PB, Andrykowski MA: Symptom structure of PTSD following breast cancer. J Trauma Stress 2000;13(2):301-319

3. Cleiren MPHD, Diekstra RFW, Kerkhof AJM, Wal J van der. "Mode of death and kinship in bereavement. Focusing on 'who' rather than 'how.' ". Crisis 1994;15(2):52

4. Schut HA, Keijser J de, Bout J van den, Dijkhuis JH. Post-traumatic stress symptoms in the first years of conjugal bereavement. Anxiety Research 1991;4:225-34

5. Middleton $\mathrm{H}$, Shaw I. Distinguishing mental illness in primary care. We need to separate proper syndromes from generolised distress. BM 2000;320(7247):1420-1

6. Summerfield $D$. The invention of post-traumatic stress disorder and the social usefulness of a psychiotric category. BM 2001;322:95-98

7. Bremner JD. Acute and chronic responses to psychological trauma: where do we go from here? Am J Psychiatry 1999;156(3):349-51

8. McFarlane AC, Kolk BA van der. Trauma and its challenge to society. In: Traumatic stress. The effects of overwhelming experience on mind, body and society. Kolk BA van der, McFarlane AC, Weiseath L, editors. New York, Kluwer Academic/Plenum Publishers, 1996 pp 24-46

9. Scott MU, Stradling SG. Post-traumatic stress disorder without the trauma. Br J Clin Psychol $1994 ; 33: 71-4$

10. Ravin J, Boal CK. Post-traumatic stress disorder in the work setting: Psychic injury, medical diagnosis, treatment and litigation. American Journal of Forensic Psychiatry 1989;10:5-23

11. Joseph S, Mynard H, Mayall M. Life-event and post-traumatic stress in a sample of English odolescents. Journal of Community \& Applied Social Psychology 2000;10:475-482

12. Metsemakers JFM, Höppener $P$, Knottnerus JA, Kocken RJJ. Computerized health information in the Netherlands: a registration network of family practices. Br J Gen Pact 1992;42:102-106

13. Mol SSL, Dinant GJ, Vilters-van Montfort PAP, Metsemakers RFM, Akker M van den, Arntz A et al. Traumatic events in a general practice population: the patient's perspective. Fam Pract 2002; 19(4): 390-96

14. Foa BE, Riggs SD, Dancu CV, Rothboum BO. Reliability and validity of a brief instrument for assessing post-traumatic stress disorder. J Trauma Stress 1993;6(4):459-473

15. Engelhard IM, Hout MA van den, Arntz A. Posttraumatic stress disorder after pregnancy loss. Gen Hosp Psychiatry 2001;23(2):62-6

16. Koss MP, Woodruff WJ, Koss PG. Criminal victimization among primary care medical patients: prevalence, incidence, and physicion usage. Behav Sci Law 1991;9:85-96

17. Bijl RV, Zessen G van, Ravelli A, Rijk C de, Langendoen Y. Psychiatrische morbiditeit onder volwassenen in Nederland: het NEMESIS-onderzoek. I. Doelstellingen, opzet en methoden [Psychiatric morbidity among adults in The Netherlands: the NEMESIS-Study. I. Objectives, design and methods. Netherlands Mental Health Survey and Incidence Study]. Ned Tijdschr Geneeskd 1997; 141(50):2248-52 
18. Kudler $\mathrm{H}$. The limiting effect of paradigms on the concept of traumatic stress. In: International handbook of human response to trauma. Shalev AY, Yehuda R, McFarlane AC (editors). New York, Kluwer Acodemic/Plenum Publishers, 2000, pp 3-11 


\section{Last Post}

$[\ldots]$

Als alle rivieren van inkt waren

en alle bomen pennen,

dan nog zou men het leed van Auschwitz

niet op kunnen schrijven.

Het was Jacob Silberberg die dat citeerde

in de documentaire Ein einfacher Mensch:

hij had behoord tot het Sonderkommando

dat de vergaste lijken cremeerde.

De documentaire bracht een uur lang zijn ogen in beeld. De film hield op, maar die ogen niet. Hij kon niet meer voorbij een station komen

of hij zag doden uitstappen.

Hij kon niet meer praten of hij moest zwijgen.

Hij kon niets meer zien of hij zag. 


\section{Determinants of a high PTSD

\section{events:}

\section{a population based study}




\section{Abstract \\ Background}

It is important that the general practitioner recognises patients with posttraumatic stress disorder (PTSD) in order to initiate an adequate intervention. Recognition will be enhanced by knowing the characteristics of patients with PTSD symptoms.

\section{Aim}

To identify personal and health related indicators of PTSD symptoms in subjects from the general population who have suffered a stressful event.

\section{Methods}

Cross-sectional population-based study in a random sample of 2997 patients, 20 years and over, from a large general practice population in Limburg, the Netherlands.

Outcome variable: total PTSD score for subject's worst event, measured with Post-traumatic stress Symptom Scale - Self Report version (PSS-SR). Bivariate and multivariable techniques were used to find determinants of high PTSD symptom scores.

\section{Results}

The following characteristics were found to be independently associated with a high PTSD symptom score: living without a partner, having an occupation that requires a low level of education, category of worst event experienced, having experienced several traumatic events, frequent visits to the GP, the use of sedatives and visiting a mental health care worker. Being elderly was shown to protect for PTSD symptoms.

\section{Conclusion}

Several patient demographics and health characteristics to which the GP has easy access are related to high PTSD symptoms after stressful events. Knowledge of these characteristics can alert the GP to the presence of PTSD. 


\section{Introduction}

Some patients consult their general practitioner (GP) for support and advice after having experienced a traumatic event ${ }^{1}$. Those who see the GP shortly after the event may have been reassured about the generally benign course of symptoms such as hyper-arousal, intrusive memories, numbness, as well as the inclination to avoid places and people that remind one of the event. Nevertheless, some of these patients will develop a depression or an anxiety disorder. In this article we focus on the symptoms of a specific anxiety disorder, post-traumatic stress disorder (PTSD), which is reported to occur in some $10 \%$ of the open population ${ }^{2}$. Knowledge about characteristics associated with PTSD symptoms can facilitate recognition by the GP.

Research on determinants of PTSD has mainly been performed in the United States, Canada and Australia. Most of it is about populations who have suffered a communal event, such as a fire or hurricane. Some studies, however, are from the open population and cover a range of individually experienced traumatic events, making them especially relevant to general practice $^{2-12}$.

The evidence about factors related to high PTSD scores is summarised here. Only one is consistently found to be associated with a higher score for PTSD: a history of child abuse $e^{4,7,11}$. Female sex is often related to higher PTSD scores $2,3,7-9,11,13-18$, but some studies show no difference between the sexes $^{19-22}$. Variables shown not to predict PTSD are current age ${ }^{9.16 .23}$ and marital status ${ }^{9.19,21-23}$, whilst there is conflicting evidence about ethnicity ${ }^{20-23}$ and education ${ }^{3.21-26}$. Lower intelligence was shown, in one study, to be predictive $^{27}$. Contradictory evidence has been found for the lifetime number of traumatic events ${ }^{6,16,19,21,28}$, for alcohol abuse ${ }^{16,29}$ and substance abuse $e^{7,10.29}$.

Considering differences in culture and healthcare systems, one must be cautious about generalizing findings from the United States, Canada and Australia to other populations. We have therefore performed a study on determinants of PTSD in a sample of patients from the Netherlands. Aiming to advise the GP when to be alert about symptoms of PTSD, we have looked at variables that are easily accessible to the GP: personal and health related determinants.

\section{Method}

\section{Participants and measures}

The study was performed in a random sample of the 67,500 patients registered with $31 \mathrm{GPs}^{1}$. The GPs participate in the Registration Network of Family Practices at Maastricht University. The population in the network is similar to the Dutch population as regards age, sex, education, medical insurance and type of household ${ }^{30}$. In 1997, 2997 randomly selected patients, aged 20 years and over, were mailed a questionnaire about person- 
al and health characteristics (use of medical care, drugs, alcohol, sedatives). Patients were asked whether they had ever experienced one of the following personally: accidents, burglaries, robberies, sexual and physical abuse (in childhood or as an adult), disaster or war, or regarding a loved one: chronic illness or sudden death. The next questions were: have you experienced any other events, which was the worst event, and in which year did you experience this? Respondents then filled out part 3 of the Post-traumatic Stress Symptom Scale - Self Report version (PSS-SR), keeping this worst event in mind ${ }^{31}$.

Part 3 of the PSS-SR scale consists of the 17 criteria on the PTSD subscales listed in DSM-IV: 5 items on re-experiencing, 7 on avoidance/numbing and 5 on arousal. The respondents were asked how often they had experienced each symptom in the past month (never/not at all $=0$, a few times a month/slightly $=1$, a few times a week/quite a bit $=2$, a few úmes a day or continuousiy/very much so $=3$; maximum score 51 ).

The PSS-SR scale was originally validated in two American samples: sexually abused women and a group of victims of various traumata ${ }^{31}$. Cronbach's alphas for the Dutch version of the PTSD score were 0.88 (63 subjects referred to ambulatory care for symptoms of PTSD) and 0.80 (113 women who had miscarried) (A. Arntz, personal communication) ${ }^{32}$. In the present sample Cronbach's alphas were 0.92 for the total score and 0.83 , 0.83 and 0.78 for the subscales of re-experiencing, avoidance and arousal respectively.

\section{Analysis}

Regarding missing values on the PSS-SR scale the following criteria were used: one missing was allowed on the five item subscales, two on the seven item subscale (Foa, written communication). The score filled in for the missing value was the respondent's average on that subscale. The distribution of the total PTSD scores being skewed to the right, a transformation was done: ${ }^{10}$ logarithm of (total PTSD score +1 ). For illustrative purposes, the "log PTSD score", was converted back to the original score (geometric mean) in the tables.

All personal and health indicators were included in a bivariate analysis and a multiple linear regression analysis. The "worst events" chosen by respondents were categorised either as traumatic events (events that qualify for developing PTSD according to the DSM- $\mathrm{IV}^{33}$ ) or as life events (see box 1). There were also respondents who chose two or more worst events, instead of identifying one as requested. The resulting three event categories were included as an independent variable called "worst event category". The (continuous) outcome variable was the total log PTSD score. The multivariable analysis was done by hand, by backward elimination (exclusion criterion $\mathrm{P}>0.05$ ). 


\section{Box 1 Categorisation of events: traumatic events and life events}

Traumatic events

Personol experience with:

accidents, robbery, physical or sexual abuse as an adult or child, disaster, war, witnessing violence

Regarding a loved one:

sudden death, murder, suicide, learning about a trauma they experienced

Life events

Personal experience with:

problems with relations, work or study, serious illness, burglary without assault

Regarding a loved one:

chronic illness, non-sudden death

To illustrate the working of the final model, PTSD scores were calculated for patients with certain assumed characteristics.

\section{Results}

\section{Response}

Of the 2997 questionnaires, 1498 were returned (50\% response, $43 \%$ male, mean age 50 years). Eighty-five percent lived with family/partner, 14\% alone and $1 \%$ otherwise. Thirty three percent had private health insurance while the rest had national health insurance; $44 \%$ had a low level of education, $43 \%$ had completed secondary education and 13\% had completed higher education. Except for insurance type, the demographic variables differed significantly $(\mathrm{p}<0.05)$ between respondents and non-respondents. Of the respondents $43 \%$ were male, of the non-respondents $52 \%$; respondents were less often single ( $14 \%$ versus 19\%), had more education ( $56 \%$ had secondary or higher education versus $44 \%$ amongst non-respondents) and were 2 years older on average.

Twenty-seven questionnaires were excluded because they had been insufficiently filled out. Of the remaining 1471, 1189 respondents had experienced one or more events (see figure 1). Of the latter group, 179 had not filled out their worst event. The 42 patients whose worst event happened in 1997 were excluded as theirs could be symptoms of an acute stress disorder ${ }^{33}$. Characteristics of the remaining 968 subjects are shown in tables 1 and 2. The variable drug use was omitted in further analyses as it occurred in only 12 patients. 


\section{Figure 1 Group allocation of respondents}

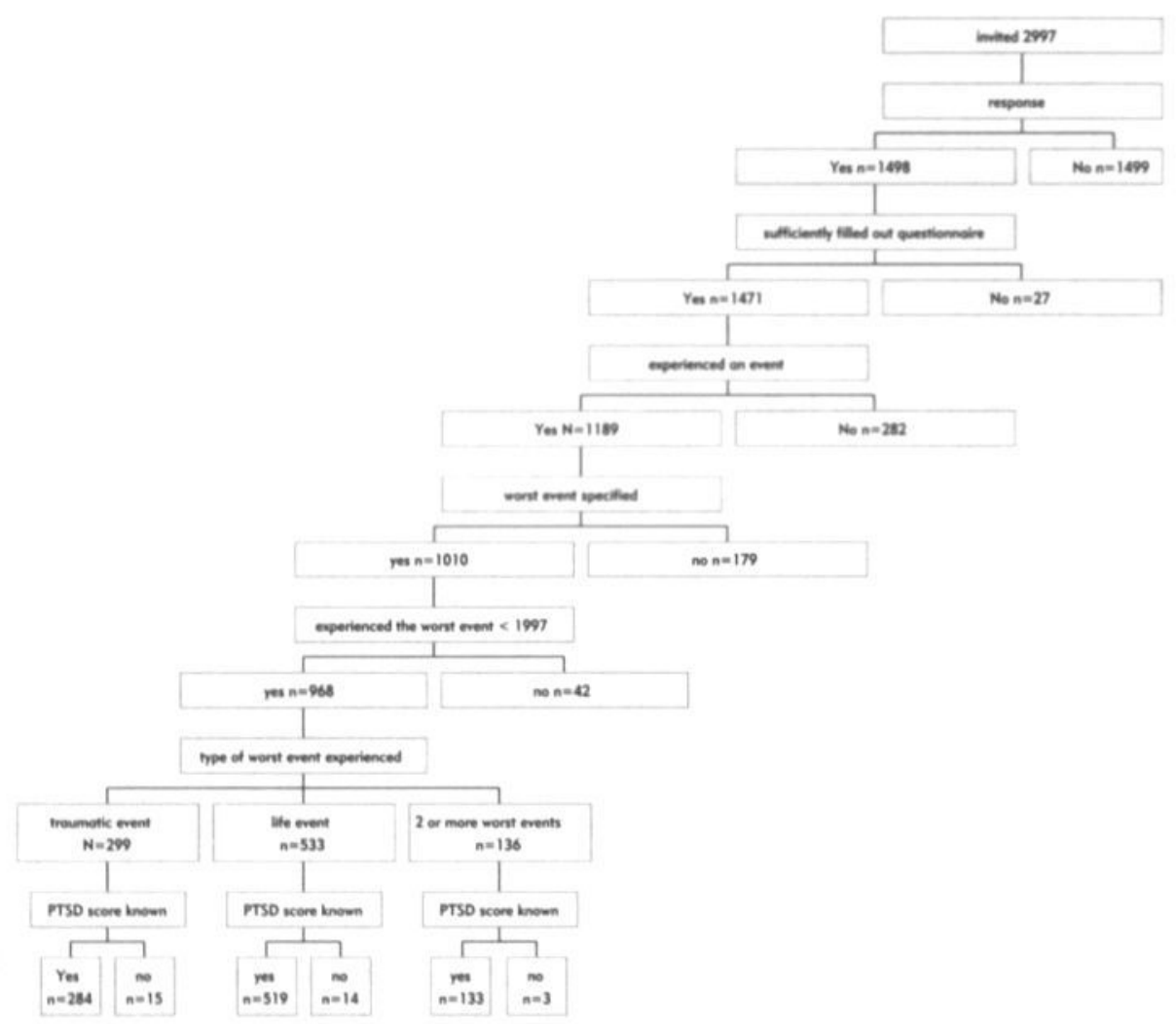

Several personal characteristics of the 179 respondents who had failed to fill out a worst event differed significantly from the 968 who had $(\mathrm{p}<$ $0.05)$ : they had less education ( $52 \%$ secondary or higher education versus $63 \%)$, were more often non-Dutch $(10 \%$ versus $5 \%)$ and had experienced fewer traumatic events (1.0 versus 1.3$)$.

\section{Bivariate analysis}

The average total log PTSD score was 0.71 (SD 0.469), range $0.0-1.67$ (geometric means: average 5.1, range $0-47$ ). As tables 3 and 4 show, most of the bivariate relationships between the variables studied and the PTSD score are statistically significant $(P<0.05)$.

\section{Multivariable analysis}

The reduced model of the multivariable analysis (table 5) shows that living without a partner and having an occupation that requires a low level of education is related to a high score. As "occupation" was highly correlated to "formal education" ( $r=0.75)$, the regression analysis was repeated leaving 


\section{Table 1 Characteristics of respondents: personal characteristics ( $N=968$ )}

Percentoges

\% Men

$\%<45$ years 45

$45-64$ years

$>64$ years

\% Born in the Netherlands

Marital status

\% Single

Married

Divorced/widowed

Type of household

$\%$ Alone

One parent family 3

With partner (and children)

With parents/family/in a home/otherwise

Formal education

\% Lower

Middle

Higher

Level of education required for (last) occupation

\% Elementary

Lower

Secondary 34

Higher 20

Acodemic

\% Confronted with other peoples' traumatic events and other life events on a day-to-day basis 11

\% Abused as a child (physically or sexually)

Worst event category

$\%$ Traumatic event

Life event

Chose more than one worst event 
Percentages

\begin{tabular}{lr}
\hline Visits to the GP in the post 12 months & 26 \\
$\% 0$ & 47 \\
$0-3$ & 28 \\
$>3$ & 39 \\
$\% \geq 1$ visits to specialist in past 12 months & 18 \\
$\% \geq 1$ visits to physiotherapist in past 12 months & 3 \\
$\% \geq 1$ visits to social worker in past 12 months & 5 \\
$\% \geq 1$ visits to mental health care in past 12 months & 11 \\
$\% \geq 1$ admissions to hospital in past 12 months & 21 \\
\hline using sedatives (incidentally/regularly) & 5 \\
\hline Mean alcohol intake in glasses/week & Means \\
\hline
\end{tabular}

out "occupation"; now "formal education" remained in the reduced model. Being elderly protects against PTSD symptoms. It was suggested that this could be the consequence of the events of the elderly being less recent on average, which in turn would result in their impact having worn off. Therefore, the variable "years since worst event" and its interaction with age were added to the reduced model. The ensuing regression coefficients, though significant $(\mathrm{P}<0.05)$, were very small ("years since event" $=-0.006$, "years since event*age 45-64" $=0.003$ and "years since event*age $>64 "=$ 0.008) showing that the influence of the recency of the event on the PTSD score is not clinically relevant.

Choosing a life event or choosing more than one event, as worst event, is related to higher PTSD scores than choosing a traumatic event. The more traumatic events a patient has experienced in his/her lifetime, the higher the PTSD score. More frequent visits to the GP, the use of sedatives and visiting a mental health care worker are also related to high scores. As the last variable can be considered both a predictor for and an outcome of a high PTSD score, the analysis was repeated without this variable. The variables in the reduced model did not change; the adjusted R-square changed minimally, from 0.164 to 0.154 . 


\section{Table 3 Bivariate analysis: Personal characteristics as indicators for PTSD} $\left(N=936^{1}\right)$

Mean $\log$ PTSD-score (geometric mean PTSD-score)

Sex $* *$

Men

$0.63(3.3)$

Women

$0.76(4.8)$

Age Categories'

$<45$

$0.68(3.8)$

45-64

$0.75(4.6)$

$>64$

$0.70(4.0)$

Country of birth"

Netherlands

$0.70(4.0)$

Other

Marital status ${ }^{\star \star \star}$

Single

$0.70(4.0)$

Married

$0.67(3.7)$

Divorced/widowed

$0.86(6.2)$

Type of household ${ }^{\dagger *}$ *

With partner (and children)

$1.02(9.5)$

Alone

$0.85(6.1)$

One parent family

$0.66(3.6)$

With parents/family/in a home

$0.72(4.2)$

Formal education ${ }^{\dagger}$ **

Lower

$0.80(5.3)$

Middle

$0.69(3.9)$

Higher

$0.61(3.1)$

Level of education required for (last) occupation ${ }^{\dagger} \star \star$

Elementary

$0.84(5.9)$

Lower

$0.78(5.0)$

Secondary

$0.68(3.8)$

Higher

$0.58(2.8)$

Academic

$0.57(2.7)$

Confronted with other peoples' traumatic events and other life events on a day-to-day basis"

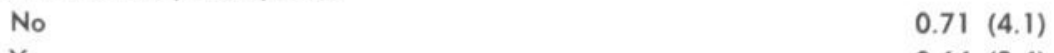

Yes

Abused as a child (physically or sexually) **

No

$0.69(3.9)$

Yes

$0.98(8.5)$

Worst event category ${ }^{\dagger}$ **

Traumatic event

$0.64(3.4)$

Life event

$0.71(4.1)$

Chose more than one worst event

$0.83(5.8)$

Correlation coefficient

Total number of traumatic events ${ }^{\circ} \star \star$

0.15

Years since worst event *

$-0.07$

* Significant at the 0.05 level; ** Significant at the 0.01 level; " mean (log) PTSD-score, t-test; 'mean (log) PTSD-score, ANOVA; 'Pearson correlation coefficient 


\section{Table 4 Bivariate analysis: Health indicators as indicators for PTSD $\left(N=936^{1}\right)$}

Mean log PTSD-score

(geometric mean)

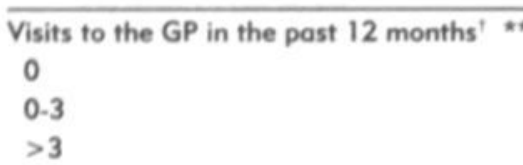

$0.60(3.0)$

$0.67(3.7)$

$0.85(6.1)$

Visits to speciolist in past 12 months" **

0

$\geq 1$

$0.76(4.8)$

Visits to physiotherapist in past 12 months" **

0

$0.68(3.8)$

21

$0.80(5.3)$

Visits to social worker in past 12 months" **

0

$0.69(3.9)$

$\geq 1$

$0.98(8.5)$

Visits to mental health care in past 12 months" **

0

$0.68(3.8)$

$\geq 1$

$1.06(10.5)$

Admissions to hospital in past 12 months

0

0.69 (3.9)

$\geq 1$

$0.76(4.8)$

Sedatives, current use $e^{* *}$

Never

$0.64(3.4)$

Incidentally/regularly

$0.96(8.1)$

Correlation coefficient

Alcohol intake *

$-0.08$

** Significant at the 0.01 level

"mean (log) PTSD-score, t-test

meon (log) PTSD-score, ANOVA

${ }^{\circ}$ Pearson correlation coefficient

132 respondents excluded in this analysis (incomplete PSS-SR checklist)

The first patient used to illustrate the interpretation of the reduced model is a 66-year old retired scientist, living with his partner. His worst and only - traumatic event is an accident. He visited his GP twice last year. His total PTSD score would be 1 . The second is a 30-year old manual labourer, living with a partner, who has had a car accident and an occupational injury and who has been dismissed from work. He visited his GP five times last year. The dismissal was his worst event. His total PTSD score would be 7 . Had he been a single parent on sedatives, his score would have been predicted by the model to be 21 . 
Table 5 Multivariable linear regression analysis; personal and health indicators, reduced model $(\mathrm{N}=786)$

Independent variabele

Intercept

Value

Regression coetficient

0.62

Age

$<45$ (reference)

45-64

$>64$
$-0.01$

$-0.12$
$-0.78-0.57$

$-0.32--0.21$

Type of household

With partner (reference)

Alone

One parent family

Living with parents/family/in a

home

$\{0=$ no, $1=$ yes

$1-5=$ low - high

Level of education required

for (last) occupation

Worst event category

Traumatic event (reference)

Life event

Chose 2 or more events

Total number traumatic events

Visits to the GP

$$
\begin{gathered}
0=0 \\
1=1-3 \\
2=>3
\end{gathered}
$$

$0=$ no, $1=$ yes

$$
0=0,1=\geq 1
$$

$0=$ no, $1=$ yes

$$
0=\text { no, } 1=\text { yes }
$$

0.11

0.17

$0.04-0.18$

$0.07-0.27$

$0.04 \quad 0.02-0.07$

0.09

$0.04-0.13$

0.23

$0.09-0.37$

Sedatives

0.22

$0.14-0.30$

\section{Discussion}

This is the first European study on determinants of PTSD symptoms after a wide range of events, performed in the open population. Consistently with most previous studies our findings confirm female $\operatorname{sex}^{2,3,7,8,11,13,14,16-18,26}$ as a determinant of PTSD. However, multivariable analysis shows this relation is overshadowed by other variables with a stronger association. The same holds true for a history of child abuse ${ }^{4,11}$. Contrary to earlier research, our study shows the type of household to be a determinant: living without a partner is related to higher scores than with; single parents are at an extra risk ${ }^{9,19,21-23}$. 
This finding is in line with evidence that social support enhances one's ability to cope with adversity ${ }^{26}$.

Our finding that being elderly is a protective factor has not been found previously in civilian populations ${ }^{26}$. The result that those with less formal schooling or lower educational job requirements have higher PTSD scores, confirms earlier findings ${ }^{25,26}$. Besides, it may be connected to evidence about lower intelligence as a risk factor for PTSD ${ }^{27}$.

Experiencing more traumatic events leads to higher PTSD scores. This gives support to the theory of cumulative adversity or vulnerability ${ }^{6.11}$. Persons whose worst event was a more ordinary stressful life event (e.g. divorce or non-sudden death), had higher PTSD symptom scores than those whose worst event was a typical PTSD traumatic type of event (e.g. an accident or disaster). Although this is a rather curious finding from the theoretical point of view, there is increasing evidence that events that do not quite qualify as traumatic events, nevertheless give rise to PTSD $^{3+-37}$. This topic is discussed in chapter 6 .

Most studies use the worst event as the index event; we followed suit. Breslau argues that using a random event instead, has the advantage of giving insight in the effects of a representative sample of events ${ }^{11}$. As we did not aim at finding which percentage of events leads to PTSD symptoms, but at finding determinants of present PTSD symptoms, using the worst event seems legitimate.

Whereas most studies ask about onset and duration of PTSD symptoms subsequent to the event, we questioned respondents about current PTSD symptoms. An advantage of our approach is the limited recall bias. Also, it gives GPs an idea of PTSD symptomatology in their present practice population.

The response to our questionnaire, at $50 \%$, is not unusual, taking into account the taboo around some topics in our questionnaire, as well as it's length and difficulty. Two of the demographics in which non-respondents differed significantly may have led to bias. These are type of household and education, the only determinants that both remained in the reduced model and showed a sizeable difference between respondents and non-respondents. Non-respondents were more often single and had less education. As these two variables were related to a high PTSD score, the mean score will probably be higher in reality than in our sample. Response bias from another group, those not filling out their worst event, points in the same direction, as here too schooling was less. However, these two response biases are unlikely to have influenced the final model, as type of household and education were included in the multivariable analysis.

The average patient from our sample has a PTSD score of five. This means that he or she, for example, has nightmares a few times a month, tries hard not to think of the event a few times a week and feels slightly 
emotionally numb and distant or cut-off from other people. The PTSD scores calculated for three fictitious patients illustrate that, when using the determinants in daily practice, the GP should especially look for patients in which several determinants cumulate.

As our study is cross-sectional, causality must be considered with care. The determinants "age" and "worst event category" cannot be the effect of a high PTSD score and could therefore be considered risk factors. Paying frequent visits to the GP, however, is likely to be the consequence of distress, as are visits to mental health workers. Taking sedatives may have contributed to the PTSD symptoms, through avoidance of feelings which in turn hampers coping ${ }^{38}$ or seeking treatment ${ }^{39}$, but it can also be the consequence of PTSD symptoms such as sleeping problems. For type of household the causality can point both ways too: someone may become single after partner abuse, or a single person may have trouble coping for lack of social support. A more complicated mechanism could be that those without a partner, with little education and taking sedatives could - due to their lifestyle - be at a higher risk of experiencing more traumatic events, which in turn will increase their PTSD score ${ }^{5}$.

Our findings would be all the more interesting if the determinants found could also be used in a prognostic model enabling the GP to selectively follow-up patients that are at a high risk of developing PTSD after stressful events. To facilitate further research on the prognostic value of determinants, data collection could be done by "life charting", a method that can also be used retrospectively ${ }^{40}$.

Altogether, the patient characteristics associated with PTSD found in this study can be useful to alert the general practitioner to the diagnosis, especially when several characteristics are clustered in one patient. As the determinants found explain only a small part of the variance, other variables should also be studied e.g. psychiatric history and peri-traumatic factors such as dissociation, preferably using a methodology in which the time relationship between determinants and outcome can be examined ${ }^{26}$.

\section{References}

1. Mol SSL, Dinant GJ, Vilters-van Montfort PAP, Metsemakers RFM, Akker M van den, Arntz A et al. Traumatic events in a general practice population: the patient's perspective. Fam Pract 2002; 19(4): 390-96.

2. Kessler RC, Sonnega A, Bromet E, Hughes M, Nelson CB. Posttraumatic stress disorder in the National Comorbidity Survey. Arch Gen Psychiatry 1995;52(12):1048-60.

3. Breslau N, Davis GC, Andreski P, Peterson E. Traumatic events and posttraumatic stress disorder in an urban population of young adults. Archives of General Psychiotry $1991 ; 48(3): 216-222$. 
4. Davidson J, Hughes D, Blazer D, George L. Post-traumatic stress disorder in the community: an epidemiological study. Psychol Med 1991;21(3):713-21.

5. Breslau N, Davis GC, Andreski P. Risk factors for PTSD-related traumatic events: a prospective analysis. Am J Psychiotry 1995; 152(4):529-35.

6. Turner RJ, Lloyd DA. Lifetime traumas and mental health: the significance of cumulative odversity. J Health Soc Behav 1995;36(4):360-76.

7. Breslau N, Davis GC, Andreski P, Peterson EL, Schultz LR. Sex differences in posttraumatic stress disorder. Arch Gen Psychiotry 1997;54(11):1044-8.

8. Stein MB, Walker JR, Hazen AL, Forde DR. Full and partial posttraumatic stress disorder: findings from a community survey. Am J Psychiatry 1997; 154(8):1114-9.

9. Breslau N, Kessler RC, Chilcoat HD, Schultz LR, Davis GC, Andreski P. Trauma and posttraumatic stress disorder in the community: the 1996 Detroit Area Survey of Trauma. Arch Gen Psychiotry 1998;55(7):626-32.

10. Bromet E, Sonnega A, Kessler RC. Risk factors for DSM-III-R posttroumatic stress disorder: findings from the National Comorbidity Survey. Am J Epidemiol 1998; 147(4):353-61.

11. Breslau N, Peterson EL, Kessler RC, Schultz LR. Short screening scale for DSM-IV posttraumatic stress disorder. Am J Psychiatry 1999;156(6):908-11.

12. Taubman-Ben-Ari O, Rabinowitz J, Feldman D, Vaturi R. Post-traumatic stress disorder in primary-care settings: prevalence and physicians' detection. Psychol-Med 2001;31 (3): 55560.

13. Patterson DR, Carrigan L, Questad KA, Robinson R. Post-traumatic stress disorder in hospitalized patients with burn injuries. J Burn Care Rehabil 1990;11(3):181-4.

14. Rubonis AV, Bickman L. Psychological impairment in the wake of disaster: the disasterpsychopathology relationship. Psychol Bull 1991;109(3):384-99.

15. Breslau N, Davis GC. Posttraumatic stress disorder in an urban population of young adults: risk factors for chronicity. Am J Psychiatry 1992;149(5):671-5.

16. Hubbard J, Realmuto GM, Northwood AK, Masten AS. Comorbidity of psychiatric diagnoses with posttraumatic stress disorder in survivors of childhood trauma. J Am Acad Child Adolesc Psychiatry 1995;34(9):1167-73.

17. Berton MW, Stabb SD. Exposure to violence and post-traumatic stress disorder in urban adolescents. Adolescence 1996;31(122):489-98.

18. Ehlers A, Mayou RA, Bryant B. Psychological predictors of chronic posttraumatic stress disorder after motor vehicle accidents. J Abnorm Psychol 1998;107(3):508-19.

19. Joseph S, Yule W, Williams R, Hodgkinson P. Correlates of posttraumatic stress at 30 months: the Herald of Free Enterprise disaster. Behov Res Ther 1994;32(5):521-524.

20. Buckley TC, Blanchard EB, Hickling EJ. A prospective examination of delayed onset PTSD secondary to motor vehicle accidents. J Abnorm Psychol 1996;105(4):617-25.

21. Koren D, Arnon I, Klein E. Acute stress response and posttraumatic stress disorder in traffic accident victims: a one-year prospective, follow-up study. Am J Psychiotry 1999;156(3):36773.

22. Ursano RJ, Fullerton CS, Epstein RS, Crowley B, Koo TC, Vance K, et al. Acute and chronic posttraumatic stress disorder in motor vehicle accident victims. Am J Psychiatry 
23. Astin MC, Lowrence KJ, Foy DW. Posttraumatic stress disorder among battered women: risk and resiliency factors. Violence Vict 1993;8(1):17-28.

24. Green MA, Berlin MA. Five psychosocial variables related to the existence of post-traumatic stress disorder symptoms. J Clin Psychol 1987;43(6):643-9.

25. Green BL, Grace MC, Lindy JD, Gleser GC, Leonard A. Risk factors for PTSD and other diagnoses in a general sample of Vietnom veterans. Am J Psychiotry 1990;147(6):729-33.

26. Brewin C, Andrews B, Valentine J. Meta-analysis of risk factors for posttraumatic stress disorder in troumo-exposed adults. J Consult Clin Psychol 2000;68(5):748-66.

27. McNally RJ, Shin LM. Association of intelligence with severity of posttraumatic stress disorder symptoms in Vietnam combat veterans. American Journal of Psychiatry 1995; 152(6):936-938.

28. Koopman C, Classen C, Spiegel D. Predictors of posttraumatic stress symptoms among survivors of the Oakland/Berkeley, Californio, firestorm. Am J Psychiatry 1994;151(6):888-94

29. Boscarino JA. Diseases among men 20 years after exposure to severe stress: implications for clinical research and medical care. Psychosom Med 1997;59(6):605-14.

30. Metsemakers JFM, Höppener P, Knottnerus JA, Kocken RJJ. Computerized health information in the Netherlands: a registration network of family practices. Br J Gen Pact 1992;42:102-106.

31. Foa BE, Riggs SD, Dancu CV, Rothbaum BO. Reliability and validity of a brief instrument for assessing post-traumatic stress disorder. J Trauma Stress 1993;6(4):459-473.

32. Engelhard IM, van den Hout MA, Arntz A. Posttraumatic stress disorder after pregnancy loss. Gen Hosp Psychiatry 2001;23(2):62-6.

33. American Psychiatric Association APA. Diagnostic and statistical manual of mental disorders. Washington DC: APA, 1994.

34. Schut HA, Keijser J de, Bout J van den, Dijkhuis JH. Post-traumatic stress symptoms in the first years of conjugal bereavement. Anxiety Research 1991;4:225-34.

35. Scott MJ, Stradling SG. Post-traumatic stress disorder without the trauma. Br J Clin Psychol $1994 ; 33: 71-4$.

36. Cleiren MPHD, Diekstra RFW, Kerkhof AJM, Wal J van der. Mode of death and kinship in bereavement: Focusing on 'who' rather than 'how'. Crisis 1994;15(2):52.

37. Kelly B, Raphael B, Judd F, Perdices M, Kernutt G, Burnett P, et al. Posttraumatic stress disorder in response to HIV infection. Gen Hosp Psychiatry 1998;20(6):345-52.

38. Minnen A van, Arnzt A, Keijsers GPJ. Prolonged exposure in patients with chronic PTSD: predictors of treatment outcome and dropout. Behaviour research and therapy in press.

39. Turner SW, McFarlane AC, Kolk BA van der. The therapeutic environment and new explorations in the treatment of post-traumatic stress disorder. In: Kolk BA van der, McFarlane AC, Weiseath $L$, editors. Traumatic Stress. The effects of overwhelming experience on mind, body and society. New York/London: Guilford press, 1996.

40. Osuch EA, Brotman MA, Podell D, Geraci M, Touzeau PL, Leverich GS, et al. Prospective and retrospective life-charting in posttraumatic stress disorder (the PTSD-LCM): A pilot study. J Trauma Stress 2001;14(1):229-239 


\section{Liefdesgedicht}

Jij hebt de dingen niet nodig

om te kunnen zien

De dingen hebben jou nodig om gezien te kunnen worden

K. Schippers 


\section{General discussion and conclusions}

Chapter 8

Summary

Somenvatting

Dankwoord

Curriculum

Appendix 1

Appendix 2 


\section{Introduction}

In this last chapter, we will first report the main results of this thesis. Next, we will discuss the methodological strengths and weaknesses of our study. This is followed by recommendations for further research. Finally, we will give recommendations for day-to-day practice and suggestions for their implementation, both for general practice training and for policy-makers.

The primary focus of this study was to describe the care in general practice for patients who have experienced traumatic and other stressful events, from the perspectives of both the patient and the general practitioner.

The research questions posed were:

1. What is the incidence of traumatic events in the general population in the Netherlands? (Chapter 2)

2. Which role do patients who have experienced traumatic events assign their GPs? (Chapter 3)

3. How is the care they receive appreciated by these patients? (Chapter 3)

4. Which barriers do GPs encounter in the care of patients who experience a traumatic event? (Chapter 4)

5. Are there GP characteristics that determine the number of barriers a GP experiences? (Chapter 4)

6. To what extent are general practitioners aware of their patients' exposure to traumatic events? (Chapters 5)

7. Are there patient, event or GP characteristics that determine this awareness? (Chapter 5)

8. Do life events gives rise to as many PTSD symptoms as traumatic events? (Chapter 6)

9. Which personal and health characteristics are determinants of PTSD symptoms in persons who have suffered a stressful event? (Chapter 7)

\section{Main findings}

The literature study on the incidence of traumata in the general population showed that abuse (both sexual and physical) is the most studied topic (chapter 2). The incidences found for these events differ greatly from study to study, depending on data sources and definitions. In general the registration studies - whether they were police records or general practice records showed much lower incidences than the surveys held in the open population. For sexual and physical abuse the cumulative incidences we found among the subjects from the general practice population we studied (chapter $3)$, were on the whole lower than those found in previous studies: ours ranged between 2 and $4 \%$, while most of the studies report cumulative incidences around $20 \%^{1-4}$. There were insufficient data about accidents, robberies, disaster and war experiences to enable comparison. 
Ours is the first study on trauma care for a range of events from the point of view of general practice care in the Netherlands, and probably in Europe. We conclude that the majority of patients find they cope well enough without professional help - with or without the help of their family and friends (chapter 3). Those who do seek professional help assign the GP an important role. They expect sympathy, care for physical complaints and a few good talks, as well as - especially after child abuse - referrals, all of which are within the competence of the general practitioner. Although, in general, the care these patients receive is appreciated, there is room for improvement. Patients would like their GPs to show more sympathy and support, listening attentively to their story and taking the initiative in future consultations to ask how the patient is coping. The ideas that the doctor lacks time and that trauma care is not medical enough keep some patients from consulting. Feelings of shame and guilt, and fears about confidentiality deter patients from bringing up abuse.

From the interviews with a random sample of Dutch GPs, data were collected on barriers they perceive in caring for patients who have suffered traumatic events (chapter 4). Caring for those who have trouble coping with accidents gives rise to problems of a more organisational and administrative nature, while caring for those in the other three categories studied (ongoing physical and sexual abuse of children and adults, and incest in the past) leads to more emotional or attitudinal problems. Between 60 and $70 \%$ of the GPs report that the facilities for referral for the four types of events are insufficient or inadequate.

Ongoing child abuse (sexual or physical) gives rise to the greatest number of barriers. Often named problems here are lack of skills to confront the parents with the suspected abuse and fear for the consequences of this confrontation. Contrary to our expectations, that older, male doctors would encounter more barriers ${ }^{5}$, the number of barriers was not related to the doctors' personal characteristics. However, experience seems to help, as those who see more patients within a category experience fewer barriers. It may however also mean that those who know much about this topic are better at recognizing victims.

Lack of awareness of GPs for their patients' traumatic history was studied as a possible barrier to giving adequate trauma care. A first impression of this so-called iceberg phenomenon could be gotten from our literature review in which the incidences of abuse reported by persons from the open population were compared to incidences reported by GPs. It showed that there is an important iceberg phenomenon: incidences of adult physical abuse reported by GPs amount only about $3 \%$ of those reported by victims; for adult sexual abuse the percentages lie between 1 and 15 . 
The study on GP awareness in our own population (chapter 5) showed that the percentage we had calculated from the literature on abuse was probably too low. The awareness of physical abuse of adults turned out to be $17 \%$, instead of the estimated $3 \%$. For adult sexual abuse, the awareness also at $17 \%$ - was slightly over the upper range of our calculations from the literature. The awareness of the GPs from our study, over all events, was $8 \%$. After excluding the burglaries, the average awareness was $10 \%$. Three patient characteristics were predictive for a high awareness on the doctor's part: having had little education, having told the doctor about the event and having a handicap caused by the event. Even though telling the doctor - this doctor or a previous one - was shown to enhance present awareness, only a quarter of the events told were known to the present GP. This implies that much information is lost. None of the doctor characteristics turned out to be predictive for awareness.

Current symptoms of PTSD were found both in respondents whose worst event ever was a typical traumatic event in terms of the DSM-IV (e.g. an accident or disaster) and in those whose worst event lacked this immediate threat to one's physical integrity (e.g. divorce, unemployment or chronic illness) (chapter 6). For events that had happened in the past 30 years, the life events gave rise to even more PTSD symptoms than the traumatic events. As this finding is contradictory to the general notion that post-traumatic stress is specifically caused by traumatic events, and not by all kinds of stressful events, several analyses were done to see if the finding should be repudiated. The reliability of the PSS-SR, the scale used to measure PTSD symptoms, was high in terms of Cronbach's alpha. There were no symptoms in the checklist that were typical for traumatic or for life events. Differences in demographics and trauma history did not explain our finding. A sensitivity analysis was performed as there was some doubt whether to assign the deaths (sudden and non-sudden) to the traumatic or life events group; the allocation did not influence the results. In summary, on the basis of our data, we could not reject the finding that there is suffering, in terms of PTSD symptoms, from all types of stressful events. This confirms earlier evidence that PTSD is not unique to events with an immediate threat to one's physical integrity, but may also ensue from events with a threat in the long term. Besides, it adds a new group of events: events that pose a threat to life in a more symbolic way.

Some of the personal and health characteristics that we found to be positively associated with chronic PTSD symptoms after stressful events (chapter 7) are in keeping with earlier findings: having had little formal education, having experienced several traumatic events ${ }^{6}$ and the use of sedatives $^{7}$. We found being elderly to be a protective factor. In the few studies 
in which the current age of the respondent was studied, it was not found to be associated with PTSD. That living without a partner, especially when one is a single parent, is related to higher scores seems logical on the basis of earlier findings about social support enhancing coping with events. Paying frequent visits to the GP - another determinant of a high PTSD score - may be caused by the increased number of health problems in victims. After correcting for all the personal and health characteristics, the conclusion that a life event - as worst event - gives rise to more PTSD symptoms than a traumatic event stands. Seeing victims with several of the above named characteristics, should alert the GP to PTSD.

\section{Methodological considerations}

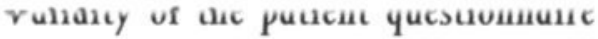

\section{Response and missing values}

Our response to the patient questionnaire - at $50 \%$ - at first sight seems rather low. However, if one looks at response percentages in other Dutch studies on traumatic events in the open population we did well. Responses found previously are 35\% (partner abuse), 44\% (abuse in the family), 37 and $66 \%$ (a range of public and private violent events) and $51 \%$ (child sexual abuse) ${ }^{1-3,10,11}$.

The important question is whether the non-response was selective and thus influenced our results. We had data on age and sex distribution, type of household, level of education and type of health insurance for all subjects. This enabled us to deduce two effects of possible response bias. First, the GP awareness of their patients' traumatic events is probably slightly higher in reality than in our sample because of under-representation of those with less education, a group in whom GP awareness was found to be higher. Secondly, the average PTSD score found in the population is probably higher because the high-scoring less well educated and single persons were underrepresented in our sample.

As we needed detailed data on each type of event experienced by the respondent, and we did not know beforehand which types of events each respondent had experienced, constructing a questionnaire with multiple referrals to questions further on was inevitable. The consequence was that a number of respondents lost their way, resulting in missing values. A way to simplify the questionnaire would have been a two-step postal questionnaire: the first asking which events had been experienced; the second containing further questions about the respondent's own experiences only. The drawback would be a decrease in response because of the two rounds. A possible alternative for decreasing the missing values, would have been to take inter- 
views. Yet, this could lead to bias through inter-rater differences between interviewers, and suggestibility of respondents. Besides, the size of the sample population would have to be smaller, interviewing being expensive and time-consuming. The pros and cons of the various solutions should be considered in further studies, also in relation to the specific study objectives.

\section{Cumulative incidences}

Although the study of the incidence of traumatic events was not our primary focus, we have compared the cumulative incidences reported by our population to those from earlier Dutch studies. This was only possible for abuse. Firstly, the lower incidences we found may in part be explained by differences in definition ${ }^{1-3}$. In the second place, in two of the studies about abuse the methodology differed considerably from ours ${ }^{2,3}$. Their respondents were approached with greater persistence: an introductory letter, recruitment by telephone, frequent reminders, home visits etc. Besides, the use of interviews ${ }^{1-3}$ may have given the feeling that finally someone was prepared to listen. This method may have especially motivated victims to participate. Also, interviewers gradually guided the respondents to the more delicate events, giving them the opportunity to identify with them ${ }^{2,3,8,9}$. The described approach was intensive and comprehensive, but may on the other hand have introduced false-positives. Therefore, one cannot definitively say which study has come up with the most realistic incidences. Yet, considering the fact that our cumulative incidences for abuse are lower than those of all previous studies, we conclude that ours are conservative.

\section{Answer categories regarding care}

We based the formulation of the questions in the section about care-seeking on ideas from brainstorm sessions with colleagues. When asked for reasons for not seeking professional help (see chapter 3, tables 6 and 7) respondents chose the option "other reason" rather often, which indicates that our answer categories covered this topic insufficiently. A preparatory focusgroup study amongst patients could perhaps have suggested several more relevant themes.

\section{The interviews about barriers experienced by GPs}

The interviews held with GPs on caring for traumatized patients show which are the most important barriers they experienced - a hitherto unexplored field in the Netherlands. The low response - despite the financial incentive may be a consequence of the increased workload of GPs in recent years, as well as the plethora of questionnaires they are subjected to. On screening Medline publications (1997-2001) responses on GP surveys (keywords: trauma, abuse, victim) were shown to be higher in other countries, ranging 
from $50 \%$ to $80 \%$. As it is likely that the interest for our topic is lower amongst non-respondents, the barriers have possibly been underestimated.

One of the aims of our study was to enhance the GP's care for patients who have experienced traumatic events. The experts who discussed our results in an expert meeting (Appendix 1) recognised the topics we have come up with as relevant. Offering post-graduate education based on the learning needs formulated by members of the target population is a good way to motivate them to participate ${ }^{12}$. Of course, in addition to these subjective learning needs, gathering objective data by observing actual performance could be useful ${ }^{13}$. However, considering the low incidence of patients consulting for traumatic events, videotaping real consultations for assessment would not be feasible. Sending standardised patients into the surgery would be an option, but a very expensive one. Moreover, a realistic instruction for these standardized patients as to patient history would be difficult. All in all, we think that our findings suffice to plan a set of learning goals for postgraduate education, recommendations for which will be given in a later section.

\section{The iceberg phenomenon}

The extent of the iceberg phenomenon - the GPs' lack of awareness for their patients' traumatic events - turned out to be more modest in "real life" than suggested by our literature review. Possibly extrapolating data from sources with different definitions and populations gave rise to an underestimation of the awareness. On the other hand, one could also argue that the awareness we found in our own study was an overestimation. As said before, the incidence of abuse reported by our patients, was lower than expected on the basis of previous studies, which means that some patients probably did not report their experiences to us. It is likely that patients who reported their events to us, will be more inclined to speak about them to their GP, than patients who did not report them to us. This implies that among those not reporting to us, the GPs' awareness is even lower than the percentage we found, which would decrease the average awareness for events in the whole population. However, whether the extent of the GPs' awareness for their patients' traumatic events is $2 \%$ or $10 \%$, the conclusion that it is low does not change.

Concerning GP characteristics as predictors of awareness: we probably found no predictive characteristics due to the modest power to detect GP characteristics.

\section{Life events give rise to as high PTSD scores as traumatic events}

The study about life events giving rise to as high PTSD scores as traumatic events (chapter 6) is unique in the sense that, to our knowledge, it is the first time this has been researched in an open population and covering a 
wide range of events. Although we have shown on the basis of our data that it is not likely to be an erroneous finding, it certainly needs further falsification. To our opinion, this should especially be sought in the interpretation of the items on the PTSD checklist used. To give an example: the item about being reminded of the event while not wanting to, may be interpreted as "thinking about it" rather than as an intrusive thought by those who have never experienced intrusive memories. Another issue of validity is that when listening to the histories of victims of the most severe traumatic events, it seems that their symptoms have a certain quality that one does not hear when speaking to patients about the effects of "more ordinary" events. Perhaps this cannot be caught in questionnaires with a closed answer format.

\section{Determinants of PTSD}

The determinants of PTSD found in our study can give direction in whom to be alert about PTSD symptoms. At the same time, one must keep in mind that the explained variance at $15 \%$, though not unusual in such studies, is rather low.

A methodological issue, when studying PTSD, is the choice of the index event. Similar to most studies, our respondents were asked to refer to one event (their worst) when filling out their PTSD checklist. Asking respondents to think of one event makes the work of the researchers easier as the date and nature of the index event are clear. Also, the person filling out the checklist need only think about one event. Besides, it is easier to compare scores when all respondents have thought about one event only. Some of our respondents, however, chose two or more worst events. The average PTSD symptom score in this group was higher than that of the respondents who chose one worst event. Someone who experienced a car accident and a rape could, for example, have nightmares about the car accident and have difficulty remembering the rape, which would give higher PTSD scores than if they had chosen one event only. It cannot be excluded that some of those who chose only one event had another equally traumatic second experience, but chose to comply to the researcher's wishes by choosing one event only. Some of their symptoms may therefore not have been recorded. Whether one asks respondents to choose one worst event only or allows more "worst" events to be chosen, will depend on the aim of one's study.

To enable comparison with other countries, and to substantiate advice to policy-makers, it would have been interesting to know what percentage of the population suffers from PTSD. However, we decided not to calculate this for several reasons. First of all, we did not ask people about fear, helplessness and horror (the A2 criterion for PTSD in DSM-IV). To date, no wellvalidated checklists for measuring the $\mathrm{A} 2$ criterion exist ${ }^{14}$. In the second place, it is difficult to set a cut-off point when using a self-report checklist because it is not clear from the DSM-IV with which frequency and intensity 
patients should have symptoms to fulfill the criteria for PTSD. Thirdly, the ways of dealing with missing values vary. The fourth reason is that we know from clinical practice that there are people with many symptoms on two of the three DSM-IV scales, who would not meet the criteria for PTSD for lack of symptoms on the third scale, while they do suffer and need treatment. In an attempt to solve this problem various criteria have been suggested to diagnose "partial PTSD" among such patients. As these criteria differ from author to author, comparing prevalences of partial PTSD is difficult ${ }^{15,16}$. In summary, we would not advocate using written checklists to assess the percentage of the population suffering from PTSD.

\section{Recommendations for further research}

To enable the GP to selectively follow up patients who are at a high risk of developing PTSD after a recently experienced event, longitudinal research is indicated. Victims of a variety of events, visiting their GPs, could be studied. Winkler, Bryant, Schnyder and Marmar suggest promising predictors for such a study ${ }^{17-20}$. Important issues on collecting longitudinal data are discussed in the International Handbook of Human Response to Trauma ${ }^{14,21,22}$. As PTSD is not the only sequel to traumatic events, including others such as depression and somatisation, could be considered. This would facilitate selective follow-up of victims at risk of insufficient coping in general, rather than in terms of PTSD only.

Our study on the propensity of life events to give rise to PTSD-symptoms calls for replication. To make sure the items are understood correctly and to study the intensity and quality of the PTSD-symptoms reported, the use of PTSD-interviews including open-ended questions is called for.

Dealing with victims of ongoing abuse was found to be more difficult than dealing with the aftermath of acute events such as accidents, and of incest in the past. Although there is a clear need for increasing knowledge, skills and the capacity for referral, the question posed in the expert meeting is whether the attitude of some GPs towards abuse keeps them from recognising victims and dealing adequately with them (see chapter 4 and appendix 1 of this thesis) ${ }^{23}$. To understand such attitudinal barriers more fully, a qualitative study is indicated. We suggest a focus group interview - with GPs of all ages, to cover for changes in attitude through time.

GPs experience the greatest number of problems when dealing with ongoing child abuse. A way to teach GPs to confront the parents with the suspected abuse and coach them towards specialised care, may be by asking doctors from the Social Services Register for Child Abuse to come to the practice to do joint consultations. The feasibility of such an approach needs to be explored. 
It is clear from many previous studies that traumatic events have detrimental effects on patients' health, which in turn increases the costs of the health care system and the costs for society on account of sick leave. Should the GP therefore take the initiative to discuss traumatic events? In cases of current abuse in the family we think this is mandatory. Concerning events from the past, however, the benefit is less clear. From daily practice GPs will have positive experiences with the disclosure of events, for example when they have clarified the origins of sleep disturbances, chronic pain or anxiety, or where it has led to a more sympathetic approach to patients who react emotionally when being submitted to a vaginal or rectal examination. However, one-sixth of the patients from our study wished no professional care because they thought it would not help them; several experts questioned the benefit of inviting patients to disclose events. The scientific evidence on this topic is circumstantial and contradictory. Schilte, for example, has shown that - in somatising patients - detailed disclosure of past events to a GP is not helpful in terms of subjective health, medical consumption and sick leave; Ormel on the other hand has shown that recognizing and labeling (moderate) psychological and psychiatric disorders by the GP does give better outcomes in terms of psychopathology and social functioning ${ }^{24.25}$. In summary, the benefit of the GP bringing up the topic of past traumatic events more systematically (for example in all cases of unexplained symptoms) over usual care should be investigated.

A major barrier found in this study, the insufficient capacity for referral to mental health care workers, could be decreased by augmenting subsidies to responsible agencies. Although we would certainly recommend this, it may be worthwhile to look also into the efficiency with which the available capacity is presently being used. Questions such as whether victims are being sent from pillar to post before getting appropriate care, whether the intake procedures are efficient and whether the therapies they receive are evidence-based should be answered. Another way to decrease the problem of capacity would be to train an interested group of doctors in simple techniques of trauma therapy. Exposure techniques are at present the state of the art regarding PTSD treatment, but not all variants are feasible in the setting of general practice ${ }^{26,27}$. Writing therapy may be an option; it's feasibility and effectiveness in general practice, could be explored ${ }^{28-30}$.

\section{Recommendations for daily practice}

The recommendations given in this section follow the phases of a patient consultation in general practice. They are based on the results of our study, the discussion in the expert meeting (see Appendix 1), the literature on this topic, as well as on my personal evaluation of the available material. 


\section{Recognising symptoms of insufficient coping with traumatic experiences;} bringing up the topic

- When doing an intake consultation with a new patient, the GP should tell the patient that he/she is prepared to discuss traumatic events.

- Poster or folder material should be available in the waiting-room, stating that traumatic experiences can be discussed with the GP, and stating the rules of confidentiality

GPs should

- know that, on average, they are aware of some $10 \%$ of their patients' traumatic events only

- know that they may be less aware of traumatic experiences in those with higher education

- know which signs and symptoms point towards of ongoing abuse

- have the skills to ask about a sensitive type of traumatic event such as abuse

- in cases of suspected child abuse, have the skills to confront parents with their suspicions

\section{Intervention after disclosure of an event}

GPs should

- use their basic communication skills: listen well, explore further, show empathy and make the patient feel they are being taken seriously

- $\quad$ suggest follow-up in all patients, as selective follow up is insufficiently evidence based

- in case of a recent event: teach patients about normal reactions and stress the importance of making optimal use of one's social network

- be extra alert about referral in those who have been abused, as their wish for referral is greater

- be extra alert about PTSD in patients with several of the following characteristics: young persons living without a partner, with little education, who have experienced several traumatic events, are on sedatives and often visit the GP.

\section{In general}

GPs should

- $\quad$ show an open attitude when patients bring up psychosocial topics or topics under taboo (e.g. sexual problems), and should take time to discuss these

- know what the current ideas are on how the cycle of violence works in violent families, and reflect on their personal attitude regarding issues such as blaming the victim 
- be aware that repeatedly dealing with traumatized patients can give rise to vicarious victimization, a reason to participate in a supervision or intervision group ${ }^{23,31}$

- discuss issues around recordkeeping of traumatic events with their colleagues (recording of suspicions and confirmed events, transfer of records to colleagues etc.).

\section{Implementation}

It was suggested in the expert meeting that GPs are presently insufficiently aware of the need to enhance their care for traumatized patients. We therefore suggest the development of a multifaceted programme of postgraduate education in which increasing the awareness is the first aim, followed by several educational interventions.

To begin with a set of articles on the topic could be published in a popular medical journal. The first article could be the report of an interview held with a group of GPs about their attitudes towards trauma care. By including GPs of both sexes, with varying ages and types of practices, the reader would be able to identify with one of the speakers, and get interested in the topic. The next articles would aim at increasing knowledge; they could cover issues such as the cycle of violence in partner abuse and giving psycho-education after an acute trauma. In these articles reference should be made to courses available on this topic.

Our finding that greater experience with victims decreases the problems experienced with caring for them, implies that an educational programme should contain sufficient skillstraining through role play and practising with standardised patients. This idea is supported by the educational literature on learning new skills. Also, we would recommend those who develop the course material to consult patients who have been victims of traumatic events, in order to incorporate their expertise in the programme.

\section{Recommendations for policy-makers}

Extra resources should be made available to facilitate post-graduate training on the topic of trauma care, both in vocational training and in continuous medical education.

One of the ways to meet the problem of insufficient referral capacity would be by developing a system in which all the possibilities for referral for the various traumata are registered per region, for example by using a website. Waiting times and the effectiveness of various therapies could also be registered in the system. As such a facility must be updated regularly, structural funding should be provided. 
Increasing the capacity for referral is a responsibility of the government and health insurance companies, and could be stimulated for example by increasing the budget made available for mental health care institutes. 


\section{References}

1. Dijk T van, Flight S, Oppenhuis E, Düssmann B. Huiselijk geweld; aard, omvang en hulpverlening: Den Hoog: Ministerie van Justitie, 1997.

2. Römkens RG. Gewoon geweld? Omvang, aard, gevolgen en ochtergronden van geweld tegen vrouwen in heteroseksuele reloties [Ordinary Violence?]: Amsterdam, Lisse: Swets \& Zeitlinger, 1992.

3. Draijer N. Seksueel misbruik van meisjes door verwanten. Een landelijk onderzoek naar de omvang, de aord, de achtergronden, de emotionele betekenis en de psychische en psychosomatische gevolgen. [Sexual abuse of girls by relatives. A national study on occurence, nature, background, emotional, psychological and psychosomatic sequelea]. Den Hoog: Ministerie van Sociale Zaken en Werkgelegenheid, 1988.

4. Langeland W, Vlugt M van der, Draijer N. Boek: Omvang, aard en achtergronden van seksueel misbruik van meisjes door niet-verwanten. Utrecht: Stichting tot Wetenschappelijk onderzoekomtrent Seksualiteit en Geweld, 1990.

5. Gulbrandsen P, Hjortdahl P, Fugelli P. General practitioners' knowledge of their patients' psychosocial problems: multipractice questionnaire survey. BM 1997;314(7086):1014-8.

6. Brewin C, Andrews B, Valentine J. Meta-analysis of risk factors for posttraumatic stress disorder in trauma-exposed adults. J Consult Clin Psychol 2000;68(5):748-66.

7. Jacobsen LK, Southwick SM, Kosten TR. Substance use disorders in patients with posttraumatic stress disorder: a review of the literature. Am J Psychiatry 2001;158(8):1184-90.

8. Acierno R, Resnick HS, Kilpatrick DG. Health impact of interpersonal violence. 1: Prevalence rates, case identification, and risk factors for sexual assault, physical assault, and domestic violence in men and women. Behav Med 1997;23(2):53-64.

9. Weaver TL. Method variance and sensitivity of screening for traumatic stressors. I Trauma Stress 1998; Vol 11(1):181-185.

10. Ploeg HM van der, Buuren ET, Wöstmann M, Hulshof RE, Huisman SJ, Kleijn WC. Psychologisch onderzoek naar (het ontbreken van) de hulpvraag van slachtoffers van geweld. Deel I: Het meten van de omvang van enkele vormen van geweld en het in kontakt komen met slachtoffers. Lisse: Swets en Zeitlinger, 1985.

11. Mayhew P, Dijk JJM van. Criminal Victimization in eleven industrialised coutries. Key findings from the 1996 international crime victims survey. Den Hoog: Ministerie van Justitie/WODC, 1997.

12. Hodges B, Inch C, Silver I. Improving the psychiatric knowledge, skills, and attitudes of primary core physicions, 1950-2000: A review. Am J Psychiatry 2001;158(10):1579-86.

13. Rethans JJ, Norcini J, Baron-Moldonado M, Blackmore D, Jolly B, LaDuca T, et al. The relationship between competence and performance: implications for assessing proctice performance. Medical Education (In press).

14. Corcoran CB, Green BL, Goodman LA, Krinsley KE. Conceptual and methodological issues in trauma history assessment. In: Shalev AY, Yehuda R, McFarlane AC, editors. International handbook of human response to trauma. New York: Kluwer Academic/Plenum Publishers, 2000:223-32.

15. Stein MB, Walker JR, Hazen AL, Forde DR. Full and partial posttroumatic stress disorder: findings from a community survey. Am J Psychiatry 1997;154(8):1114-9. 
16. Carlier IV, Lamberts RD, Fouwels AJ, Gersons BP. PTSD in relation to dissociation in traumatized police officers. Am J Psychiotry 1996;153(10):1325-8.

17. Winkel FW, Wohlfarth T, Bloauw E. Police based early detection of persistent type A trouma symptomatology in crime victims: the validity of rapid, objective risk assessment. International Journal of Low and Psychiatry (In press).

18. Bryant RA, Harvey AG. Avoidant coping style and post-traumatic stress following motor vehicle accidents. Behov Res Ther 1995;33(6):631-5.

19. Schnyder U, Moergeli H, Klaghofer R, Buddeberg C. Incidence and prediction of posttraumatic stress disorder symptoms in severely injured occident victims. Am J Psychiotry 2001;158(4):594-99.

20. Marmar CR, Weiss DS, Schlenger WE, Fairbank JA, Jordan BK, Kulka RA, et al. Peritraumatic dissociation and posttraumatic stress in male Vietnam theater veterans. Am J Psychiatry 1994;151(6):902-7.

21. Friedman S, Shalev AY. Prospective studies of the recently traumatized. In: Shalev AY, Yehuda $\mathrm{R}, \mathrm{McF}$ arlane $\mathrm{AC}$, editors. International handbook of human response to trauma. New York: Kluwer Academic/Plenum Publishers, 2000:249-61.

22. Niles BL, Newman E, Fisher LM. Obstacles to assesment of PTSD in longitudinal research. In: Shalev AY, Yehuda R, McFarlane AC, editors. International handbook of human response to trauma. New York: Kluwer Academic/Plenum Publishers, 2000:213-22.

23. Sugg NK, Inui T. Primary care physicians' response to domestic violence. Opening Pandora's box. JAMA 1992;267(23):3157-60.

24. Schilte AF, Portegijs PJ, Blankenstein AH, Horst HE van der, Latour MB, Eijk JT van, et al. Randomised controlled trial of disclosure of emotionally important events in somatisation in primary care. BM 2001;323(7304):86.

25. Ormel J, Brink W van den, Koeter MW, Giel R, Meer K van der, Willige G van de, et al. Recognition, management and outcome of psychological disorders in primary care: a naturalistic follow-up study. Psychol Med 1990;20(4):909-23.

26. Kindt $M$, Hovens H. Posttraumatische stress stoornis. In: Balkom ALM van, Oppen P van, Dyck R van, editors. Behandelingsstrategieën bij angststoornissen. Houten/Diemen: Bohn Stafleu van Loghum, 2001.

27. Sherman JJ. Effects of psychotherapeutic treatments for PTSD: a meta-analysis of controlled clinical trials. J Trauma Stress 1998; $11(3): 413-35$.

28. Gidron Y, Peri T, Connolly JF, Shalev AY. Written disclosure in posttraumatic stress disorder: Is it beneficial for the patient? Journal of Nervous and Mental Disease 1996;184(8):505-507.

29. Pennebaker JW. The effects of traumatic disclosure on physical and mental health: The values of writing and talking about upsetting events. International Journal of Emergency Mental Health 1999; 1(1):9-18.

30. Winkel FW, Snijder N, Blaauw E. Rationality and the treatment of post-victimization emotional disorders: A case study of the counterfactual writing paradigm in structured trauma writing. In: Koppen PJ van, Roos NHM, editors. Rationality, information and progress in law and psychology. Maastricht: Maastricht University Press/Metajuridica Publications, 2001:171-85.

31. Herman J. Trauma and recovery. New York: Basic Books, 1992. 


\section{Liedje}

Het duurt altijd langer dan je denkt, ook als je denkt

het zal wel langer duren dan ik denk dan duurt het toch nog langer dan je denkt.

Het is altijd veel duurder dan je denkt, ook als je denkt

het zal wel duurder worden dan ik denk

dan wordt het toch nog duurder dan je denkt.

Het kost meer moeite dan je denkt, ook als je denkt

het zal wel veel meer moeite kosten dan ik denk dan kost het toch meer moeite dan je denkt.

Het duurt veel korter dan je denkt ook als je denkt

het zal wel korter duren dan ik denk

dan duurt het toch

nog korter dan je denkt.

Judith Herzberg 
Chopter 1

Chapter 2

Chapter 3

Chopter 4

Chapter 5

Chapter 6

Chepter 7

Chopter 8

Summary

Summary

Somenvotting

Dankwoord

Curriculum

Appendix 1

Appendix ? 
In this thesis we describe a study we performed on general practice care for patients who have experienced traumatic events, and on symptoms of posttraumatic stress after both traumatic and other stressful events. After a general introduction to the topic in the first chapter, six chapters follow in which the separate parts of the study are presented.

The first part of our study, described in chapter 2, is a literature study on the incidence of traumata in the Netherlands. We reviewed the literature between 1984-1998 on the incidence of accidents, fires, murder, robbery, and physical and sexual abuse, and found 10 enquiries in the open population, 4 national registration systems and 4 studies performed in general practices. The incidences found differ greatly from study to study, depending on data sources and definitions. In general the registration studies whether they be police records or general practice records - showed much lower incidences than the surveys held in the open population. This makes it difficult to calculate an overall incidence for victimization in the population. A second aim of our literature review was to give an estimate of the extent to which GPs are aware of their patients' experiences. Abuse was the only topic for which the data sufficed: there was a factor difference between 20 and 60 for physical abuse and between 7 and 100 for sexual abuse, indicating that GPs register only a small percentage of their patients' experiences with abuse.

Chapter 3 aims at giving insight in the care patients assign their general practitioner after experiencing one of the following events: serious accidents, burglary, robbery, physical and sexual abuse, disasters and war. A postal questionnaire was sent to a random sample of 2997 patients of 20 years and over. The patients were recruited from the practice population of 32 GPs who participate in a registration network of academic practices connected to Maastricht University. Fifty percent of the patients responded. The majority of those who experienced traumatic events found they coped well enough without professional help. For those who did want help the GP played an important role. Care can be improved in several ways: GPs should be more supportive and attentive when being consulted about this topic and patients would like the doctor to be more active in bringing up the topic, as well as in initiating follow-up. Also, it should be made clear to patients that the GP can play a role in caring for those who have trouble coping with a traumatic event, and that what the patient tells the GP is confidential.

In chapter $\mathbf{4}$ the perspective of the doctor is described: which problems do GPs experience when caring for patients who have experienced traumatic events in the past (an accident or incest), or patients who live in a traumatic situation (physical or sexual abuse in the home, of children or adults). A 
random selection of 500 Dutch doctors, both sexes equally represented, were asked to participate in a telephone interview. Forty-two percent took part. They experienced the most problems in dealing with cases of (suspected) child abuse that was still ongoing. Topics in which the greatest number of GPs felt their knowledge and skills were insufficient were: recognizing signals of ongoing abuse in the home, the phase of confronting the parents of a child that one suspects to be abused, and the intial stages of counselling. These topics should receive special attention in the training of doctors. Another major problem encountered by some two-thirds of doctors was the lack of capacity when referring, a topic policy-makers should look into further.

To further assess the iceberg phenomenon studied in chapter 2, we studied the awareness of the GPs described in chapter 3, of their patients' experience with accidents, disaster, war, robbery, burglary and abuse either in childhood or adulthood (chapter 5). From the population described in chapter 3 , we chose all patients who had experienced an event, as well as a random sample of patients who indicated they had not experienced any traumatic events. The patients' GPs were asked what they knew about the experiences of these patients, without being told, of course, what they had disclosed to us about their experiences. Highest awareness was found for physical abuse as an adult $(16.9 \%)$, lowest awareness for burglaries $(0.9 \%)$. On average, the general practitioner was aware of $7.9 \%$ of patients' traumatic events. Of the events told to the general practitioner (this one or a previous one), the doctor was aware of one quarter. Patient characteristics that predicted GP awareness (multivariable analysis) were: lower level of education (OR 0.60, 95\% CI 0.38-0.93), having told the doctor about the event (OR 3.3, 95\% CI 1.5-7.2) and having a physical handicap caused by the event (OR 7.0, 95\% CI 2.8-18). Data about the GPs were also collected, in order to identify characteristics that predict awareness; none were shown to be predictive. In conclusion, the hypothesis on the basis of the literature study was confirmed, namely that GPs are aware of a small percentage of their patients' traumatic events; several patient characteristics contribute to this awareness.

In chapter 6, we describe a study in which we compared symptoms of post-traumatic stress disorder (PTSD) in two groups of patients: those who have experienced traumatic events typical for generating PTSD, such as accidents and abuse, and those who have experienced other stressful events such as unemployment, divorce, chronic illness (life events). The subjects from the study population described in chapter 3 had filled out a PTSD symptom checklist (Post-traumatic Stress Symptom Scale - Self-report Version, PSS-SR, developed by Foa) for their worst event. Of the 1498 respondents, 852 were eligible for this part of the study. The data showed that the PTSD 
scores were higher on average for the life events than for the traumatic events that happened in the past 30 years; for earlier events the scores were the same for both types of events. These findings could not be explained by differences in demographics, trauma indicators or individual item scores, nor by differences in the distribution of the total PTSD scores. We conclude that life events can generate at least as many PTSD symptoms as traumatic events. Our findings call for further studies on the specificity of traumatic events to generate PTSD.

It is important that the GP recognizes patients with post-traumatic stress disorder (PTSD) in order to initiate adequate intervention. Recognition will be enhanced by knowing the characteristics of patients with PTSD symptoms. The study on this topic, performed in the population described in chapter 3, is described in chapter 7. Data of 968 of the 1498 respondents qualified for this part of the study. This was a larger group than the one described in chapter 6 as we now included patients who had chosen two or more worst events besides those who had chosen one worst event only. Using linear regression analysis, with the total PTSD symptom score as continuous outcome variable, the following personal and health characteristics were found to be independently associated with a high PTSD score: living without a partner, having an occupation that requires a low level of education, type of worst event experienced, having experienced several traumatic events, paying frequent visits to the GP, the use of sedatives and visiting a mental health care worker. Being elderly was shown to protect for PTSD symptoms. Knowledge of these characteristics can alert the GP to the presence of PTSD. In future these indicators should preferably be studied longitudinally to gain insight in which of these have a causal relation with PTSD, and thus to facilitate selective follow-up of those at risk of the disorder.

In the last chapter (chapter 8) the findings are summarized and the research methodology discussed. Also, recommendations for future research and for daily practice are given. The latter have been discussed in an expert meeting, the minutes of which can be found in appendix 1. The recommendations have also been incorporated in a booklet with tips for GPs on communicating with patients who have experienced traumatic events; it can be found as an attachment to the back cover of this thesis. 
Chepter

Chapter 2

Chopter 3

Chopter 4

Chapter 5

Chopter o

Chopter 7

Chopter 8

Summary

\section{Samenvatting}

Dankwoord

Curriculun

Appendix

Appendix 2 
In dit proefschrift wordt een onderzoek beschreven over de hulp van de huisarts aan patiënten die traumatische gebeurtenissen hebben meegemaakt, alsmede over symptomen van posttraumatische stress, zowel na traumatische gebeurtenissen als na andere ingrijpende gebeurtenissen. $\mathrm{Na}$ een algemene inleiding op het onderwerp in het eerste hoofdstuk, volgen zes hoofdstukken waarin de verschillende onderdelen van de studie besproken worden.

Het eerste onderdeel van deze studie, beschreven in hoofdstuk 2 is een literatuurstudie over de incidentie van traumata in Nederland. De traumata die we bestudeerden zijn ongevallen, brand, moord, beroving, plotse dood, fysieke mishandeling en seksueel misbruik. Tien enquêtes in de open populatie, vier landelijke registratiesystemen en vier studies uitgevoerd in de huisartspraktijk werden tussen 1984 en 1998 gepubliceerd. De gevonden incidenties variëren sterk, afhankelijk van de bron, de methodologie en de gebruikte definities. In het algemeen geven de registratie studies - bijgehouden door de politie of door huisartsen - veel lagere incidenties dan de enquêtes gehouden in de open bevolking. Dit bemoeilijkt het berekenen van een incidentie van slachtofferschap in de populatie.

Een tweede doel van onze literatuurstudie was het schatten van de mate waarin huisartsen op de hoogte zijn van de gebeurtenissen die hun patiënten meemaken. De enige gebeurtenissen waarover voldoende gegevens voorhanden waren, bleken fysieke mishandeling en seksueel misbruik te zijn. Er was een factor 20 tot 60 verschil tussen de incidentie van fysieke mishandeling blijkend uit enquêtes in de open bevolking en de incidenties in huisartsenregistraties. Voor seksueel misbruik was dit verschil 7 tot 100 maal.

In hoofdstuk 3 wordt inzicht gegeven in de visie van patiënten op de huisartsenzorg na één van de volgende gebeurtenissen: ernstig ongeval, inbraak, beroving, fysieke of seksuele mishandeling, ramp en oorlog. Aan 2997 willekeurig geselecteerde patiënten van 20 jaar en ouder werd een schriftelijke enquête toegestuurd. De steekproef werd getrokken uit alle patiënten ingeschreven bij één van de 32 huisartsen die deelnemen aan het Registratie Netwerk Huisartspraktijken van de Universiteit Maastricht (RNH). Vijftig procent van de patiënten stuurden de enquête terug. De meerderheid vond dat ze goed konden omgaan met traumatische gebeurtenissen zonder professionele hulp. Voor degenen die wel hulp wensten, speelde de huisarts een belangrijke rol. De zorg kan op de volgende manieren verbeterd worden: de huisarts zou meer steun moeten geven, meer aandachtig moeten luisteren en de patiënt meer serieus moeten nemen. Een deel van de patiënten zou ook graag willen dat de huisarts zelf het onderwerp ter sprake brengt en een vervolgafspraak voorstelt. Sommige patiënten aarzelen of het onderwerp wel medisch genoeg is om met de huisarts te bespreken en zijn bevreesd dat wat 
zij de huisarts vertellen verder verteld zal worden. Aan deze aspecten dient in de scholing van huisartsen aandacht besteed te worden.

Het perspectief van de huisarts op het verlenen van zorg na traumatische gebeurtenissen wordt beschreven in hoofdstuk 4. Aan 500 Nederlandse huisartsen, willekeurig getrokken uit een bestand van alle Nederlandse huisartsen, werd gevraagd deel te nemen aan een telefonische enquête. Ter sprake kwamen problemen die huisartsen ervaren bij de zorg aan patiënten die moeite hebben met het verwerken van een gebeurtenis uit het verleden (een ongeluk of incest) en patiënten die in de huiselijke kring worden mishandeld of misbruikt, zowel kinderen als volwassenen. De respons was $42 \%$. De geënquêteerden ondervonden de meeste problemen bij het omgaan met gezinnen waarin kinderen mishandeld of misbruikt worden. Ongeveer de helft van de deelnemende huisartsen vond dat ze onvoldoende kennis en vaardigheden had voor het herkennen van signalen van huiselijk geweld, het confronteren van de ouders van een kind dat vermoedelijk mishandeld wordt, en met het aanvangen met een behandeling. Dit zijn allen onderwerpen voor nascholing. Een probleem dat door tweederde van de dokters ervaren werd, was het gebrek aan mogelijkheden om te verwijzen. Dit onderwerp verdient bijzondere aandacht van beleidsmakers in Nederland.

Om meer zicht te krijgen op het ijsbergfenomeen - kort beschreven in hoofdstuk 2 - bestudeerden we in welke mate de huisartsen wiens patiënten deelnamen aan de schriftelijke enquête beschreven in hoofdstuk 3 , op de hoogte zijn van de gebeurtenissen die hun patiënten meemaken. Het betrof ongelukken, rampen, oorlogen, berovingen, inbraken, fysieke mishandeling en seksueel misbruik (hoofdstuk 5). De huisartsen kregen over alle patiënten die aan de onderzoeker één of meer van deze traumata hadden gemeld, en van een random steekproef patiënten die geen traumata hadden gemeld, een vragenlijst over welke gebeurtenissen hun patiënten volgens hen hadden meegemaakt. De huisartsen bleken het beste op de hoogte van lichamelijke mishandeling bij volwassenen (16.9\%) en het minst goed op de hoogte van inbraken $(0,9 \%)$. Gemiddeld bleken de huisartsen van $7,9 \%$ van de gebeurtenissen op de hoogte. Van de gebeurtenissen die ooit aan een huisarts verteld waren was de huidige huisarts van één kwart op de hoogte. Bij patiënten met bepaalde kenmerken bleek de huisarts beter op de hoogte dan bij anderen (multi-variabele analyse): weinig onderwijs genoten hebben (OR 0,60,95\% BI 0,38-0,93), het aan de huisarts verteld hebben van de gebeurtenis ( OR 3,3 , 95\% BI 1,5 - 7,2) en het hebben van een lichamelijke handicap als gevolg van de gebeurtenis (OR 7,0,95\% BI 2,8 - 18). Er werd ook gekeken of bepaalde huisartskenmerken voorspellend waren voor het op de hoogte zijn; dit bleek echter niet het geval. Samenvattend werd de hypothese gebaseerd op het literatuuronderzoek bevestigd: huisartsen zijn 
gewaar van een klein percentage van de traumatische gebeurtenissen van hun patiënten. Enkele patiëntenkenmerken zijn hierbij voorspellend.

De patiënten uit de studiepopulatie die werd beschreven in hoofdstuk 3 hadden over hun meest ernstige gebeurtenis een vragenlijst over posttraumatische stress stoornis (PTSS) ingevuld (Post-traumatic stress Symptom Scale Self Report version, PSS - SR, ontwikkeld door Foa). In hoofdstuk 6 wordt een studie beschreven waarin twee groepen patiënten worden vergeleken ten aanzien van symptomen van posttraumatische stress. De eerste groep zijn mensen wier meest erge gebeurtenis een gebeurtenis was die volgens de DSM IV aanleiding kan zijn tot PTSS, zoals een ongeval of mishandeling, een zogenaamde traumatische gebeurtenis. Mensen die als meest erge gebeurtenis een life event aangaven (bijvoorbeeld ontslag, scheiding of een chronische ziekte), vormden de tweede groep.

Van onze 1498 respondenten kwamen er 852 in aanmerking voor dit deel van de studie. Voor de gebeurtenissen van de afgelopen 30 jaar bleken de PTSS-scores hoger indien het een life event betrof dan indien het een traumatische gebeurtenis was; voor gebeurtenissen die langer dan 30 jaar geleden gebeurd waren, bleken de scores even hoog voor beide soorten gebeurtenissen. Deze bevindingen konden niet verklaard worden door verschillen in demografische kenmerken, trauma indicatoren of individuele item-scores noch door verschillen in de verdeling van de PTSS-scores. Samenvattend concluderen we dat life events minstens even veel PTSS-symptomen kunnen geven als traumatische gebeurtenissen. Verder onderzoek naar de specificiteit van traumatische gebeurtenissen voor het veroorzaken van PTSS is geïndiceerd.

Kennis van de kenmerken van patiënten met PTSS zal de herkenning van deze aandoening ten goede komen. Dit onderdeel van de studie, uitgevoerd in de populatie beschreven in hoofdstuk 3, staat beschreven in hoofdstuk 7. De gegevens van 968 respondenten werden geanalyseerd. Dit is een grotere groep dan de groep beschreven in hoofdstuk 6, aangezien naast de patiënten die als ergste gebeurtenis één gebeurtenis hadden gekozen, ook de patiënten konden meedoen die twee of meer "meest ernstige gebeurtenissen" hadden gekozen. Na de lineaire regressie analyse, met de totale PTSS score als uitkomstmaat, bleken de volgende patiënten- en gezondheidskenmerken onafhankelijk geassocieerd met een hoge PTSS-score: leven zonder partner, een beroep hebben met een laag opleidingsniveau, de aard van de gekozen meest ernstige gebeurtenis, het meegemaakt hebben van meerdere traumatische gebeurtenissen, het frequent bezoeken van de huisarts, het gebruik van kalmeringsmiddelen en bezoek aan maatschappelijk werk of psycholoog. Ouder zijn bleek te beschermen tegen PTSS-symptomen. In de toekomst zouden deze en andere indicatoren bij voorkeur longitudinaal onderzocht 
dienen te worden om te kijken of de relatie met PTSS causaal is; met die informatie zou een selectieve follow-up kunnen plaatsvinden van patiënten met een hoog risico op PTSS na een traumatische gebeurtenis.

In het laatste hoofdstuk (hoofdstuk 8) worden de bevindingen samengevat en de onderzoeksmethodologie besproken. Ook worden er aanbevelingen voor toekomstig onderzoek en voor de dagelijkse praktijk gegeven. De aanbevelingen voor de dagelijkse praktijk zijn besproken in een expert bijeenkomst waarvan de notulen zijn toegevoegd in appendix 1. De aanbevelingen zijn bovendien opgenomen in een cahier voor communicatie en attitude over ingrijpende gebeurtenissen; dit is bijgevoegd als bijlage. 
Chopter I

Chopter 2

Chapter 3

Chopter 4

Chopter 5

Chopter 6

Chopter 7

Chopter 8

Summary

Somenvottin

Dankwoord

Dankwoord

Curriculum

Appendix 1

Appendix 2 
Veel mensen hebben bijgedragen aan de totstandkoming van dit proefschrift; graag wil ik hen daarvoor bedanken. Allereerst waren er de patiënten die de moeite namen de lange vragenlijst in te vullen: hun gegevens vormen de basis voor dit onderzoek. Onontbeerlijk was de medewerking van hun huisartsen, allen deelnemers aan het Registratie Net Huisartspraktijken (RNH): de huisartsen van de gezondheidscentra Heer, Dr. Van Kleef, Hoensbroek, het Withuis en Grote Schuur, en de huisartsen V. Zwietering, M. Op den Kamp, B. de Wit, F. Guldemond en Y, Guldemond-Hecker, P. Hulshof, R. Panhuysen, R. Costongs, V. Kaiser, W. Veldhuizen en F. Soomers. Veel dank ook aan hun praktijkassistenten. Daarnaast waren er de 211 huisartsen uit een landelijke steekproef die deelnamen aan het telefonisch interview over knelpunten; hun antwoorden gaven belangrijke aanwijzingen voor aanbevelingen op het gebied van nascholing en beleid.

Een bijdrage aan het ontwikkelen van de patiëntenvragenlijst en de knelpuntenenquête werd geleverd door Mevrouw C. Dijkmans, psychologe en de huisartsen B. van der Steen, Y. Janssen, R. Leinders, J. en T. Kramer, K. Hautermans J. Raaymakers, P. Manschot, T. van Cleef, A. van Deelen, G. Pacilly, A. Kramer, E. Hoogenraad, J. Stoffers, H. Zwanikken Th. van der Waart, F. Soomers, F. Vissers en V. Kaiser.

Bij de dataverzameling en -verwerking speelden Gregor Fransen, Mieke Witte en de efficiënte en geduldige dames van de beldienst en data-invoerservice een belangrijke rol.

Onmisbaar was de onderzoeksassistentie die ik in de loop van de jaren kreeg: Jim Tatipata, Petra Koken, Reini Bretveld, Paula Rinkens, Karin Aretz en, last but not least, Pauline Vilters. Dank voor je zorgvuldigheid en voor je engelengeduld als we een regressie voor de tiende keer, en dan ook nog handmatig, moesten "draaien". De secretariële ondersteuning werd verzorgd door Chantal van Wunnik-Hoogveld, Joke Oud, Paddy Hinssen en Hilde Sielhorst, en, als laatste grote redder in de nood, Elisa Melman. Naast gouden handen, bracht je altijd een grote dosis vrolijkheid mee.

De projectgroep bestond uit André Knottnerus, Geert-Jan Dinant, Job Metsemakers, Arnoud Arntz en tijdelijk Marjan van den Akker.

André, je gaf me de smaak voor het doen van onderzoek toen ik mijn HAIO-scriptie bij je deed. Jij hebt het oorspronkelijke idee voor dit project bedacht en vormgegeven en je hebt me bij de uitwerking ervan zorgvuldig begeleid. Al was het dal soms nog zo diep, na een vergadering met jou had ik altijd weer zin om door te gaan. Je bent mijn grote voorbeeld als onderzoeker, ethicus en droge grappenmaker. Ik ben heel dankbaar dat ik bij jou promoveer.

Geert-Jan, vooral in de eerste jaren was je er altijd, voor even tussendoor of voor ons reguliere overleg. Je hielp knopen doorhakken en verminderde de complicaties. Job, jij hebt me vooral de laatste jaren begeleid. Je systematisch redeneren wees heel vaak de weg, je adviezen op belendende gebieden heb ik zeer gewaardeerd. 
Marjan, jij trok het onderzoek weer vlot op een cruciaal moment door een belangrijk onderdeel op je te nemen, de knelpunten-enquête. Ook daarna stond je altijd klaar om mijn vragen te beantwoorden. Arnoud, je leverde een belangrijke bijdrage vanuit de psychologie. Je zorgde voor een frisse wind en veel nieuwe ideeèn. Arnold Kester, je gaf waardevolle adviezen rondom de keuzes voor analyses. Linksom of rechtsom, uiteindelijk kwamen we er altijd.

Gedurende de hele periode werd ik begeleid door een externe begeleidingscommissie bestaande uit Berthold Gersons, hoogleraar Psychiatrie aan de UvA (voorzitter), Vroon Pigmans, huisarts en staflid bij het NHG, Giel Hutsschemaekers, hoogleraar Psychologie in Nijmegen, en een bestuurslid van de Stichting Slachtoffer en Samenleving van Achmea, mevrouw Legrand-van den Boogaard, directeur van het Canisius Ziekenhuis, opgevolgd door Joke Lanphen, huisarts. De vergaderingen werden namens Achmea ook bijgewoond door Willem van Duin en Rob Kars. De leden van de commissie volgden mijn werkzaamheden met aandacht en gaven constructieve feedback. De nadruk op implementatie heeft mij gestimuleerd hieraan veel aandacht te besteden, een taak die naadloos aansloot bij mijn werk op het Nederlands Huisartsen Genootschap. Kees in 't Veld en Ron Helsloot, dank voor het bieden van die mogelijkheid.

Het was erg leuk om mijn broedsel van vele jaren te delen met de experts van de klankbordgroepbijeenkomst ("Expert meeting”), en weerklank te vinden voor mijn aanbevelingen.

Achmea en de leden van het Bestuur van de Stichting Slachtoffer en Samenleving (SASS/Achmea): de studie over dit belangrijke onderwerp (al zeg ik het zelf!) is door u geëntameerd en financieel mogelijk gemaakt, waarvoor veel dank. De interesse die $\mathrm{u}$ onderweg toonde voor de inhoud van mijn onderzoek was stimulerend.

De Capaciteitsgroep Huisartsgeneeskunde heeft zich ingespannen om de studie verder te faciliteren. Graag wil ik een aantal mensen speciaal noemen. De secretaressen Hanny, Ine, Marlies, Frits, Linda, Judith en Pascale, jullie waren er altijd voor alle “vragen tussendoor". Ellen, Katinka, Dick, Huub en Ton: dank voor jullie steun in moeilijke tijden. De collegae ganggenoten Sjoerd, Judith, Roelf, Jelle, Piet, Magda, Helene, Sylvia, Wim, Rogier, Ben, Marjan en Trudy, ik heb genoten van het academisch discours en niet minder van jullie gezelligheid. Jurenne en Marion, jullie waren heerlijke kamergenoten. Altijd in voor een babbel, of voor het ventileren van misstanden, ver weg of dichtbij, en voor het zoeken naar diplomatieke oplossingen.

Yvonne van Leeuwen en Marjan Pollemans, jullie waren mijn lichtende voorbeelden van vrouwen in de wetenschap. 
A thanks to all my friends from EGPRW. The critical questions, positive feedback and the camaraderie have made our meetings a bi-annual joy. They gave me a more European perspective on GP care, and a diverse view on research methodologies with influences from sociology and anthropology. 'Till next time!

Marieke en Gerben, Marianne, Tonia, Mint, Vic en Josephine, Katinka, Robert, Frank en de "Dames van het Dikke Boek", jullie gaven mij een lief en gastvrij Maastrichts onthaal. En dan zijn er alle andere vrienden en vriendinnen verspreid over het land, die ook mijn toppen en dalen meegenoten: Karin, Emmie, Bernice, Anne Marie, Rens, Loes, Caroline, Josephine, Raymond en Gerben. Fijn dat jullie er allemaal zijn!

Lieve familie. Caspar, well bro, now your li'l sissy's got her $\mathrm{PhD}$ ! Liesbeth, ondanks de fysieke afstand, altijd geinteresseerd. Judit, my powerful sister in "arms". Petra, veel dank voor je beeldende bijdragen, en Carla, voor je altijd zo positieve aanwezigheid. Lieve papa en mama, al vroeg was ik bezig met het uitvoeren van "experimentjes" en jullie gaven het goede voorbeeld met het doen van grootse "projecten". Die twee elementen samen vormden de vruchtbare bodem voor dit grote karwei. Het is volbracht. Hoera! 
Chopter 1

Chopter 2

Chopter 3

Chapter A

Chopter 5

Chopter 6

Chopter

Chopter 8

Summary

Samenvattin

Donkwoord

\section{Curriculum Vitae}

Curriculum

Appendix

Appendix 2 
Saskia Mol was born on November 19th, 1961 in Bukumbi, Tanzania, where her parents built and ran a hospital. After living in various African countries as well as in the United States, she finished her schooling in 1979 (VWO) at the Herman Jordan Montessori school in Zeist, the Netherlands.

She studied Cultural Anthropology at Leiden University during one year, after which she entered medical school at Maastricht University. She participated in several educational committees within the faculty. She also did a three-month clerkship in Tanzania, taking part in the community medicine rotation based at the University of Dar es Salaam and working at Bukumbi Hospital.

On acquiring her medical degree in 1987 she worked as a resident in surgery in Kerkrade and Zaandam. In 1988 she started the two-year vocational training in general practice, based at Maastricht University, with Peter Jordans in Swalmen. She won the national prize for 1991's best research paper by a trainee: "Aan de Vloedlijn", a diagnostic study on vaginal discharge in general practice patients.

From 1991 to 1994 she combined part-time practice in Stein (doctors Govaert, Leclercq and Dinant) with a university appointment at the Department of General Practice of Maastricht University. She participated in the PhD studies of Marjan Pollemans and Yvonne van Leeuwen on growth in knowledge of trainees and teachers in general practice. She also worked as a tutor and as a teacher of communication skills in the undergraduate curriculum.

Since 1994 she has been a staff member at the Dutch College of General Practitioners, where she makes educational material aimed at the implementation of the college guidelines. Besides, she has done research around setting cut-off points for knowledge tests.

From 1995 until 2001 she was active in the European General Practice Research Workshop (EGPRW), both as a national representative and as a member of the executive board.

She started the study presented in this dissertation, at Maastricht University in 1996. 


\section{Report of the expert meeting}

Project on GP Care after Stressful Events

Report of the Expert Meeting

10 September 2001

14.30 - 17.30 hours in Utrecht,

The Netherlands 


\section{Present:}

D. Arentz, GP in Haarlem

Mrs. I. van Beek, psychologist,Transact, Utrecht

L. van Berkesteijn, GP, Chair of the Working Group on Teaching (collaboration of vocational training schemes in the Netherlands)

Mrs. H. Blok, GP in Rotterdam

Mrs. J. Lanphen, GP in Blaricum, Boardmember of Achmea Foundation Victim and Society (funding body of the project)

J. Manders, Dutch College of GPs

J. Metsemakers, GP, tutor of the author, Associate Professor, Department of General Practice, Maastricht University

Mrs. S. Lo Fo Wong, GP in Rotterdam, Advisory Board for Guidelines of Dutch College of GPs

Mrs.V. Pigmans, GP in Utrecht, staff member Implementation, Dutch College of GPs

Mrs. L. van Rijn, GP, teacher in vocational training, Free University, Amsterdam

P. Schepp, GP, CME-organiser

E. Sietsma, GP, policy-maker, National Association of GPs

P. van Splunteren, Zorg Onderzoek Nederland / MW, staffmember for implementation strategies

Mrs. G. van der Weele, former GP, staffmember Guideline Development, Dutch College of GPs

H. Goettsch, chairperson

Mrs. P. Vilters, minutes

Mrs. S. Mol, researcher

Cancellations from:

N. van Egmond, GP

B. Terluin, GP 
After a word of welcome the participants introduce themselves.

The procedure of the meeting is explained: the recommendations will be presented and discussed one by one, regarding both relevance and formulation.

In the following report each of the conclusions of our study will be followed by the resulting recommendation. We then describe the discussion by the experts. Where relevant, the new formulation of the recommendation is given. The accepted recommendations are in italics.

\section{Conclusions and recommendations from the patients' perspective}

\section{1}

\section{Conclusion}

Three quarters of the patients have no wish for professional help (police, social work, doctor, etcetera). Three quarters of them find they cope well, with or without the help of family and friends.

Recommendation: In general the GP should stimulate patients to keep up a good social network, in order to be able to revert to this in times of need.

The experts think this recommendation is not relevant to all patients. Therefore certain groups should be specified. Also, it is not useful to ask after the social network of new patients, as by the time the traumatic event takes place the social network may have changed. They stressed that the lack of a social network is a risk factor in not coping well with an event.

\section{New formulation for recommendation 1.1:}

The GP is conscious of the fact that the lack of a good social network is a risk factor for coping badly with a traumatic event.

If a patient consults about a traumatic event, the GP asks about the social network and whether the patient uses it.

\section{2}

\section{Conclusion}

Sixty percent of those who want professional help after a traumatic event want it from the GP (especially after sexual abuse, physical abuse and accidents). Ninety five percent of the GPs find that bringing up this topic is a task of a GP. Eighty percent find that starting treatment is also the GP's task. 
Recommendation: The task GPs have in caring for patients seeking help after a traumatic event should be a topic in the Toekomstvisie Huisartsen (the discussion about the future of general practice in the Netherlands).

The experts are surprised about the finding that $95 \%$ of the GPs find it their task to help in cases of traumatic events. This suggests that although $95 \%$ find it their task they don't perform this task. Another query: What do we mean by treatment? The conclusion is that the basic skills of recognizing that a traumatic event took place or that people are not coping well, as well as giving patient education about the normal reactions to traumatic events and the need to refer as well as motivating the patient are tasks of the GP. Treatment is not considered a task of the GP. The idea comes up to instigate a training for GPs who would like to specialize in treating this group of patients. No conclusion is drawn whether or not the recommendation should be discussed in the Toekomstvisie.

\section{New formulation for recommendation 1.2}

Each GP has a task in recognizing insufficient coping with traumatic events, giving patients education about the normal effects of a traumatic event and, in case of insufficient coping, assessing whether someone needs to be referred as well as motivating the patient for referral.

\section{3}

\section{Conclusion}

A quarter of those who do not seek help, find that they do not cope well in the end.

Recommendation: When a GP knows about a traumatic event he or she should actively ask whether a person wants help, even if the patient does not ask for help explicitly.

The first problem with this recommendation is that GPs may lack the time necessary to discuss this topic. Secondly, a discussion ensues on whether GPs should only look for signals of traumatic events or whether they should also ask people how they are coping, with the risk of interfering with the autonomy of the patient. Or is it the other way around, do patients wonder why doctors do not raise the topic? As we know from earlier studies (van der Ploeg) victims often hesitate to ask help. Besides, the patient is free to accept or reject the doctor's help.

The recommendation is accepted in its original formulation. 


\section{Conclusion}

The patient's need for care is greatest after sexual and physical abuse (child/adult). Abuse has the greatest impact on the life of the respondents, followed by robbery.

Recommendation: Be extra alert in those who have been abused: these events have the greatest impact and are more often a reason for the patient to seek care.

A problem with this recommendation is that war is not named as an experience with a great impact. This is probably because there are few asylum seekers in our population. The second problem with the recommendation is that it is too vague.

\section{New formulation for recommendation 1.4}

The GP carefully asks after the need for care, especially in people who have experienced abuse or war.

\section{5}

\section{Conclusion}

What people want from the GP is: initiative from the doctor's part to ask about traumatic events and to pursue the topic, support, sympathy, help for physical complaints and a few good talks, as well as the initiative on the doctor's part for follow-up. In cases of abuse (sexual and physical) people want to be referred more often than after the other events.

Recommendation: The GP uses the following style of communication when people talk about their traumatic event:

- Asking further questions on when, what, where, etc.

- Giving support and sympathy

- Asking whether and when people would like to pursue the topic

- Asking about physical complaints

In cases of abuse the GP is especially alert about the wish for referral.

The experts are surprised that the common communication skills named above are not generally performed by GPs. However, as the results of our study show that some patients' expectations are not met, the recommendation should be made anyway. One of the experts says that the recommendation about the follow-up should be formulated more strictly in the sense that the doctor should say that he or she will revert to the topic in following consultations. 


\section{New formulation for recommendation 1.5}

The GP uses the following style of communication when people talk about their traumatic event:

1. Asking further questions on when, what, where, etc.

2. Giving support and symphony

3. Arranging a follow-up appointment

4. Asking about physical complaints

In cases of abuse the GP is especially alert about the wish for referral.

\section{6}

\section{Conclusion}

A quarter of those who wish help from the GP do not consult. Reasons mentioned by patients:

- The subject is not medical enough

- The patient thinks that the doctor has no time

- Fear for lack of confidentiality

- Shame and guilt, especially in cases of abuse

Recommendation 1.6 a: To help people who hesitate to consult the GP, the GP uses a communication style in which he or she:

- $\quad$ shows to be open to discuss psycho-social aspects

- builds in moments of quiet during the consultation, for example by pausing or by asking the patient whether there is anything else they are consulting for today.

The sentence about building in quiet moments is reason for controversy. On the one hand it is a very specific part of a good communication style, which makes some experts wonder whether it should be named specifically. On the other hand it is an often neglected part of the consultation. Suggestions for a revised recommendation are not given.

My idea in hindsight is:

\section{New formulation for recommendation 1.6 a:}

To facilitate those who do want GP care but hesitate to ask this, the GP uses a communication style in which:

- he or she shows to be open to discuss psycho-social aspects

- the GP uses a style of communication in which he or she facilitates the patient in bringing up traumatic events, e.g. by ensuring moments of quiet in the consultation.

Recommendation $1.6 \mathrm{~b}$ : The GP asks the patient about traumatic events during the intake consultation. 
There are no data on the percentage of practices in which intake consultations are done with new patients. Some experts find direct questioning about traumatic events rude and suggest that the GP should tell the patient that they are welcome to discuss this topic in the consultation room.

\section{New formulation for recommendation $1.6 \mathrm{~b}$}

During the intake consultation the GP tells the patient that traumatic events can be discussed with him/her.

Recommendation $1.6 \mathrm{c}$ : When a GP suspects a traumatic event:

- The GP actively asks after the event.

- The GP tells the patient that what the patient tells the doctor is confidential.

The first item is not discussed, as we erroneously thought that we had already discussed it in recommendation 1.3. Regarding the second item, on confidentiality matters, the question rises, whether this is not generally known to patients. Telling by the results of the questionnaire this is not the case. It is probably not accidental that people who have problems with boundaries, as is common among the abused, are not aware of the rules of confidentiality. Altogether the recommendation finds support. Suggestions for a more concrete formulation are made.

\section{New formulation for recommendation $1.6 \mathrm{c}$}

When a GP suspects a traumatic event the GP tells the patient that what the patient tells the doctor is confidential, also for the patient's family members.

Recommendation $1.6 \mathrm{~d}$ : The possibilities around the empowerment of women who have been abused must be studied.

This recommendation has been insufficiently worked out to allow for discussion. It is therefore cancelled.

\section{7}

\section{Conclusion}

Some patients have chronic symptoms of posttraumatic stress. Their characteristics are:

- Those who are younger

- Those living without a partner

- Those with little education

- Those who have experienced many traumatic events

- Those on sedatives

- Those who often visit the GP

- Those visiting a psychologist or other mental health care worker. 


\section{Recommendation}

The GP is more active in following up patients who have experienced traumatic events if they have several of the above characteristics.

This recommendation is accepted.

\section{8}

\section{Conclusion}

Life events other than traumatic events can give rise to PTSD-type symptoms

The level of evidence is insufficient to formulate a recommendation.

There is some discussion about the overlap between traumatic events and other life events. It is the experience of the practising GPs that life events indeed give rise to PTSD-type symptoms. The question whether the treatment should therefore be the same remains to be answered.

\section{Conclusions and recommendations from the doctor's perspective}

\section{1}

\section{Conclusion}

Of the categories: accidents, incest in the past, ongoing physical or sexual abuse of children or adults, the most barriers were experienced with ongoing abuse of children.

Recommendation: Of the various categories of traumatic events, child sexual and physical abuse should receive extra attention in CME offered to general practitioners.

The experts do not agree that child sexual and physical abuse should receive special attention as other areas such as sexual abuse and physical abuse in the partmer relationship should also be taught to doctors.

New formulation for recommendation 2.1

Offering CME about child abuse is a good way to invite GPs to focus on optimising the care for people who have experienced traumatic events.

\section{2. and 2.3}

\section{Conclusion 2.2}

GPs find they have insufficient knowledge about signs and symptoms of abuse of adults and children.

Recommendation 2.2: The GP should have knowledge of signs and symptoms pointing at abuse of adults and children 


\section{Conclusion 2.3}

GPs find they have insufficient knowledge of the signs that point at a high risk of fatal injury in the near future in victims of abuse (adults and children).

Recommendation 2.3: The GP should be aware of the signs and symptoms that point at a high risk of fatal injury in the near future in victims of abuse (adults and children).

The above named recommendations are discussed together as it is not certain whether there are clear differences between and signs of non-acute and acute danger. The literature should be read up on this topic. The experts are surprised that GPs think they know so little about these signs and symptoms. They wonder whether this is an alibi not to discuss the topic in the consultation room. They think the problem may lie with application of the acknowledge, rather than the knowledge as such. Lists of signs and symptoms differ from book to book.

Another problem is that the various caregivers around the person who is being abused often pass the responsibility to one another. Probably the best persons to say whether the danger is acute or not are the persons who are being abused themselves. In that case the recommendation should be that GPs take action as soon as they hear from the patient that they are in danger. The experts wonder whether enhancing the GPs' knowledge will help if the problem lies with the attitude, and the capacity for referring is insufficient. Altogether there is insufficient consensus about the recommendation to accept or reformulate it.

\section{4}

\section{Conclusion}

GPs find they have insufficient skills in bringing up the topic of ongoing sexual/physical abuse in adults or children, or of incest in the past.

Recommendation: GPs should increase their skills in asking patients whether they have experienced a traumatic event that is considered a taboo.

Some experts think this recommendation states the obvious. On the other hand it does stress the importance of the GP bringing up the topic. Also, the skill is easily learned. The recommendation is accepted with a small change:

\section{New formulation for recommendation 2.4}

The GP enhances his or her skill in bringing up the topic of physical or sexual abuse.

\section{5}

\section{Conclusion}

GPs find that they have insufficient skills to start treatment (all categories, see 2.1). 
Recommendation: GPs must enhance their skills in treating these groups of patients.

As it was not clear in the interview what we meant by treatment, this recommendation is rejected.

\section{6}

\section{Conclusion}

Some GPs are influenced in their caregiving tasks by the idea that the patient is also guilty of the event.

Recommendation: The GP reflects on his or her attitude regarding the question of guilt in cases of domestic violence and reflects on how this attitude compares to the current knowledge on this topic.

Possibly GPs are insufficiently aware of the consequences of abuse in the long run and how the cycle of violence works. Henceforth the original recommendation is accepted and an extra one is added

\section{Extra recommendation 2.6 b}

The GP knows about the cycle of violence in families in which abuse takes place.

\section{7}

\section{Conclusion}

The greater the experience in caring for traumatic patients the fewer the barriers.

Recommendation: Role-playing, standardized patient contacts and contacts with self-help-groups should be part of the available CME in this field.

A discussion about role-playing ensues: some GPs do not like this approach. Each person has their own learning style. The format of CME-material should be varied and should include knowledge and skills. Maybe less threatening formats than role-play should be developed.

Once again the idea is put forth to develop a teaching module through which some GPs can gain extra expertise in dealing with patients after traumatic events. These colleagues could then be available for consultation by other GPs.

\section{New formulation recommendation 2.7}

$A$ variety of CME-material should be available including role-play, standardised patient contacts and contact with self-help-groups. 


\section{8}

\section{Conclusion}

The GP's awareness of traumatic events is low, even when the patient has told the GP about the event.

Recommendation 2.8 a: GPs must be told about this low awareness for events.

Recommendation 2.8 b: The GP reflects on his or her way of recordkeeping regarding traumatic events.

Recommendation $2.8 \mathrm{c}$ : During vocational training and CME, attention should be paid to appropriate record keeping, both for suspected and confirmed events.

A heated discussion ensues on whether or not to register traumatic events. One expert thinks one should not note such private affairs. The general tendency is towards registering events unless the patient asks not to register them, e.g. when he or she transfers to another doctor. Another topic in the discussion revolves around whether or not to note an event that is only suspected but not confirmed. No final conclusion is drawn, but altogether it seems the recommendation is acceptable, although the terms "be told about" and "reflect on" should be specified.

\section{9}

\section{Conclusion}

The GP is least aware of traumatic events in those with higher education.

Recommendation: The GP must be aware of traumatic events regardless of the level of education of the patient.

This recommendation is accepted. A suggestion for implementation is made: a video in which GPs speak about their own experience of abuse (with respect for their privacy).

\section{Suggestions from the experts for extra recommendations}

GPs should reflect on their attitude and their values regarding traumatic events

There should be patient education material in the waiting room and in the consultation room stating that traumatic events can be discussed with the GP and explaining the rules of confidentiality.

A system should be developed in which all the possibilities for referral for the various traumata are recorded and kept up to date, for example with a web-site. Waiting times and the effectivity of various types of help could also be registered in the system. The idea is that if the doctor knows that the patients can be referred on short notice, an important barrier to bringing up the topic will be taken away. 


\section{Implementation}

The following - sometimes contradictory - ideas are put forward.

- It is possibly too early to think about implementation as the awareness for this topic is insufficient amongst GPs and it is not yet quite clear what doctors should know and do about it.

- The task description will never become quite clear; in the meantime GPs will have to deal with these patients in day to day practice.

- The GP seems to be ready for a project around enhancing trauma care.

- This study is innovative and deserves the GP's attention: the information should also be published internationally.

- A good way to motivate GPs to take part in CME on this subject could be the topic of unexplained physical symptoms as starting point.

- The topic of traumatic events could be an important topic in the mental health theme of the Dutch College of General Practitioners for the next two years. 

of the patient questionnaire 


\section{General questions}

1. What is your date of birth?

2. What is your sex?
Day .... month .... year ....

口 Male

․ Female

3. In which country were you born?

In which country was your father born?

In which country was your mother born?

4. What is your marital status?

$\square$ Never been married

口 Married

$\square$ Divorced

ㅁ Widow/widower

5. Tick the type of household you live in

ㅁ Alone

(more than one option allowed)

$\square$ With partner, without children

$\square$ With partner and children

$\square$ One parent family

$\square$ With parents/relatives

口 Home

ㅁ Other,

6. What is the highest level of schooling

Primary school you finished?

ㄴ Lower vocational training

ㅁ Middle school

Middle level vocational training

ㅁ Secondary school

ㄷ College/highest level vocational training

ㅁ University

7. What is your occupation, and if you no longer work, what was your last occupation?

Please be as precise as possible. E.g. constructionworker is not enough and should for example be steelbender

8. Have you at any point in your life ㅁ No experienced a stressful event?

ㅁ Yes If yes, please name it/them 
9. How often have you had contact with a caregiver for your own health problems?

a. GP

b. Hospital (admission)

c. Specialist outpatient clinic

d. Community nurse

e. Physiotherapist or occupational health therapist

f. Social worker

g. Mental health care worker

10. Do you ever drink alcohol?

11. Do you ever use sedatives or sleeping pills?

12. Do you ever use drugs (for example hash, cocaine, xtc)? in the past 12 months time(s)

of which in the last 2 months time(s)

in the past 12 months time(s)

of which in the last 2 months time(s)

in the past 12 months time(s)

of which in the last 2 months time(s)

in the past 12 months of which in the last 2 months..... time(s) time(s)

in the past 12 months time(s) of which in the last 2 months time(s)

in the past 12 months time(s)

of which in the last 2 months time(s)

in the past 12 months time(s)

of which in the last 2 months time(s)

ㄱes, ... glasses per week, on average

No

Regularly

․ Incidentally

口 Regularly

Incidentally

口 Never

The researchers would like to have your permission to ask your GP about complaints and the illnesses with which you have visited your GP. These facts are necessary for this study. Your anonimity is ensured.

13. I hereby give the researchers 


\section{Stressful events}

Here is a list of stressful events people can experience. Going through this page from top to bottom, tick the boxes that apply to you. Do also tick the events that you have already noted earlier on in the questionnaire.

14. I have experienced the following events myself:
A serious accident at home, at work.
No
$\square$ Yes

in traffic or elsewhere, in which I was

Fill out chapter A later on

involved myself
A burglary in my (temporary) home
or at work and/or a robbery in which
someone tried to rob me or actually
robbed me, by using force or
threatening with it.

ㅁ No

$\square$ Yes

Fill out chapter B later on

A serious illness of long duration of

$\square$ No

$\square$ Yes

someone who was very important to

Fill out chapter $C$ later on

me and/or the sudden death of someone

who was very important to me through

illness without a sickbed (e.g. accident

or heart attack) or by murder or suicide.

As an adult: physical abuse or a threat

No

ㅁ Yes

of physical abuse at home or elsewhere.

Fill out chapter D later on

As an adult: sexual abuse

No

Yes

(by sexual abuse we mean that someone

Fill out chapter E later on touched you in a sexual manner or forced you to undress or to arouse him/her sexually, or that someone tried to penetrate your vagina, anus or mouth in a sexual manner or tried to do this)

As a child: physical abuse

(by sexual abuse we mean that someone touched you in a sexual manner or forced you to undress or to arouse him/her sexually, or that someone tried to penetrate your vagina, anus or mouth in a sexual manner or tried to do this) 
A disaster such as a flood, earthquake,

ㅁ No

ㅁ Yes storm, explosion or an impending disaster

Fill out chapter G later on such as the threat of a river overflowing.

War or peace operation (as a civilian or as

No

ㅁ Yes

a soldier), or detention for political reasons.

Fill out chapter $\mathrm{H}$ later on

You now have an impression of which of the chapters $\mathrm{A}$ to $\mathrm{H}$ you will be filling out later on.

Please go to the next page first. 
The next questions are about the problems and complaints stressful events can give rise to.

* You may never have experienced any stressful events in your life.

* You may have experienced one or more of the stressful events named in the list on the previous page.

* You may possibly (also) have experienced other events, which are not listed.

15. Have you, in your life, experienced one or more stressful events?

16. Are there other stressful events that you have not noted in this questionnaire up to now?

17. What was the worst event you experienced in your life? $\square$ Yes, please proceed with the following questions

№ $Q$ you have finished filling out this questionnaire

№

$\square$ Yes, please describe them below
Year 19.

Event

Please fill out questions $18-34$ keeping in mind this worst event ${ }^{1}$

18. How often in the past month did you have upsetting thoughts or images about the traumatic event that came into your head when you didn't want them to?

19. How often in the past month did you have bad dreams or nightmares about the traumatic event?

20. How often in the past month did you relive the traumatic event, acting or feeling as if it was happening again? $\square$ never

a few times a month

$\square$ a few times a week

ㅁ a few times a day

continuously

$\square$ never

a few times a month

ㅁ a few times a week

$\square$ a few times per night

든inuously

$\square$ never

ㅁ a few times a month

ㅁ a few times a week

$\square$ a few times a day

ㅁ continuously

'Questions 18-34 are the questions of Part 3 of the Post-traumatic Stress Symptom Scale PSS- 
21. How often in the past month did you feel emotionally upset when you were reminded of the traumatic event? (for example, feeling scared, angry, sad, guilty etc.)

22. How often in the past month did you experience physical reactions when you were reminded of the traumatic event? (for example, breaking out in sweat, heart beating fast).

23. How often in the past month did you try not to think about, talk about, or have feelings about the traumatic event

24. How often in the past month did you try to avoid activities, people, or places that remind you of the traumatic event?

25. How often in the past month were you not able to remember an important part of the traumatic event?

26. How often in the past month did you have much less interest or participate much less often in important activities?

27. How often in the past month did you feel distant or cut off from people around you?

28. How often in the past month did you feel emotionally numb? (for example. being unable to cry or unable to have loving feelings) never

ㅁ a few times a month

a few times a week

a few times a day

든inuously

$\square$ never

$\square$ a few times a month

ㅁ a few times a week

$\square$ a few times a day

$\square$ continuously

$\square$ never

ㅁ a few times a month

$\square$ a few times a week

$\square$ a few times a day

continuously

$\square$ never

$\square$ now and then

quite often

$\square$ almost all the time

$\square$ not at all

$\square$ a little

$\square$ quite often

$\square$ very often

Appendix 2
$\square$ no, not at all
$\square$ a little
$\square$ quite often
$\square$ very often
no, not at all
ㅁ a little
$\square$ quite often
$\square$ very often 
29. How often in the past month did you

ㅁ never feel as if your future plans or hopes will

a a few times a month not come true? ( for example, you will not have a career, marriage, children, ㅁ a few times a week or a long life)

30. How often in the past month did you $\square$ never have trouble falling or staying asleep?

a a few times a month

ㅁ a few times a week

$\square$ every night

31. How often in the past month did you

ㅁ never feel irritable or have fits of anger?

D sometimes

$\square$ often

$\square$ very often-always

32. How often in the past month did you have trouble concentrating?

$\square$ never

(for example, drifting in and out of

$\square$ sometimes conversations, losing track of a story

$\square$ often on television, forgetting what you read)

33. How often in the past month were you never overly alert? $\square$ sometimes (for example, checking to see who is $\square$ often around you, being uncomfortable with $\square$ very often-always your back to a door etc)

34. How often in the past month were you never jumpy or easily startled?

口 sometimes (for example, when someone walks up $\square$ often behind you)

very often-always

The next three questions are about the physical consequences of stressful events.

35. Do you have a physical handicap that - Yes was caused by one of the stressful № events in your life? 
38. Please go back to page ... to see which chapters you answered with yes, and fill out these chapters. 


\section{Example of a chapter in the patient questionnaire on care-seeking after a specific event}

\section{Chapter A}

\section{A serious accident at home, at work, in traffic or elsewhere, in which I was}

\section{involved myself}

Please indicate in which year the serious accident or accidents that you experienced took place. If you do not remember the exact year, give an estimate.

1. When did you experience this?

$$
\begin{aligned}
& 19 \ldots \\
& 19 \ldots \\
& 19 .
\end{aligned}
$$

In the next part, which is about the care you sought, please describe the most recent event.

You possibly received support from other persons after having experienced this event, for example from family or friends.

2. Did you receive this support?

ㄴ Yes, from.

№

3. Did you want care from a professional?

Yes (general practitioner, social worker,

ㅁ No, please proceed to question 17 police etc.)

4. Did you tell the GP about the event?

ㄱes

ㅁ No

5. Do you think it is important that your

ㄱes

GP knows that you have experienced

ㅁ No

this event?

6. Did you want help from your GP?

ㅁ Yes

ㅁ No, please go to question 14 
7. Which care did you want from your GP? Yes No

- sympathy

- a number of good talks

- care for physical complaints

- a legal statement

- referral, to.

- a prescription

- other help.

8. Did you ask for this help?

ㄱ Yes

$\square$ No, go to question 14

9. How long after the event did you go to the GP to talk about this?

While it was (still) happening

Shortly after the event

Years later

10. Which help did you get from the GP?

11. How did the consultation with the GP go? (please tick a box per question)

$\begin{array}{cccc}\begin{array}{c}\text { Not } \\ \text { at all }\end{array} & \text { A little } & \begin{array}{c}\text { Quite } \\ \text { a bit }\end{array} & \begin{array}{c}\text { Very } \\ \text { much }\end{array} \\ \square & \square & \square & \square \\ \square & \square & \square & \square \\ \square & \square & \square & \square \\ \square & \square & \square & \square \\ \square & \square & \square & \square \\ \square & \square & \square & \square \\ \square & \square & \square & \square \\ \square & \square & \square & \square \\ \square & \square & \square & \square \\ & & & \\ \square & \square & & \end{array}$

- The doctor invited me to show my feelings

- The doctor put the blame on me

- The doctor said I should try and get over it

- The consultations helped me along

- Altogether I was satisfied with the help I got from the doctor

- Other:

12. What did you miss in the contact with your general practitioner, about this event? 
13. If you could advise a young GP about how they should act when seeing people who have experienced such a event, what would you say?

14. Several reasons follow why people do not visit their GP.

Please indicate your reasons:

- My GP can't deal with these things

- My GP knows too little about such matters

- My GP has no time for such matters

- This type of experience is not medical enough

- I'm afraid my GP will tell someone else about this

- My GP knows the person guilty of the event

- My GP will wonder why I've taken so long to come and talk with him/her

- I am afraid my GP will become prejudiced against me

- Other reasons,

You may have sought help from another caregiver after this event, for example a social worker, a pastor, a psychologist or a psychiatrist, a healer, a lawyer, police or a victim organization.

15. Did you seek this help?

$\square$ Yes,

with

ㅁ No, please go to question 18

16. Did you find the help you sought?

Yes

If no, please explain:

$\square$ No

Go to question 18

17. Here are several reasons for not seeking help from any

professional. Please indicate what your reasons were:

- I got over it without help

- I got over it with help of family and friends

- Seeking care will not help me

- I should work it out on my own

- I only worry at night

- I feel guilty

- I feel ashamed to talk about it

- Other reasons. 


\section{Dutch version of PSS-SR, adapted by A. Arntz, Maastricht University}

1. Hoe vaak heeft u de afgelopen maand last gehad van pijnlijke gedachten of beelden over de gebeurtenis, terwijl u er niet aan wilde denken.

2. Hoe vaak heeft $u$ de afgelopen maand onprettige dromen of nachtmerries over de gebeurtenis gehad?

3. Hoe vaak heeft u de afgelopen maand de ervaring gehad dat de gebeurtenis er weer was, alsof $u$ het opnieuw beleefde, of dat $u$ handelde of zich net zo voelde als toen?

4. Hoe vaak heeft $u$ de afgelopen maand meegemaakt dat u emotioneel overstuur raakte wanneer $u$ aan de ingrijpende gebeurtenis werd herinnerd?

5. Hoe vaak heeft $u$ de afgelopen maand lichamelijke reacties gehad (bv. hartkloppingen, zweet uitbreken) wanneer $u$ aan de gebeurtenis werd herrinnerd?

6. In hoeverre heeft $u$ de afgelopen maand geprobeerd om niet aan de gebeurtenis te denken of geprobeerd om niet de gevoelens te voelen die erbij horen?

7. Hoe vaak heeft u de afgelopen maand geprobeerd om activiteiten, plaatsen of mensen te vermijden die $\mathrm{u}$ aan de gebeurtenis herinneren?
ㅁ nooit

$\square$ een paar keer per maand

een paar keer per week

口 een paar keer per dag

$\square$ voortdurend
ㅁ nooit
$\square$ een paar keer per maand
$\square$ een paar keer per week
$\square$ een paar keer per nacht
$\square$ voortdurend

$\square$ nooit

$\square$ een paar keer per maand

$\square$ een paar keer per week

$\square$ een paar keer per dag

voortdurend

$\square$ nooit

$\square$ een paar keer per maand

$\square$ een paar keer per week

$\square$ een paar keer per dag

$\square$ voortdurend

nooit $\square$ een paar keer per maand

$\square$ een paar keer per week

$\square$ een paar keer per dag

$\square$ voortdurend

nooit

$\square$ een paar keer per maand

$\square$ een paar keer per week

$\square$ een paar keer per dag

$\square$ voortdurend 
8. In hoeverre heeft u de afgelopen maand moeite gehad om belangrijke delen van wat er gebeurd is te herinneren?

9. Was u de afgelopen maand minder geìnteresseerd in dingen die u gewoonlijk belangrijk of leuk vond (bv. hobby's, sociale activiteiten)?

10. Voelde u zich de afgelopen maand op een afstand of afgesneden van andere mensen?

11. Voelde $u$ zich de afgelopen maand gevoelloos (bv, niet kunnen huilen, niet reageren, onmogelijk om gevoelens van liefde te voelen)

12. In hoeverre voelde $u$ de afgelopen maand dat uw toekomstplannen of verlangens de grond in geboord zijn t.g.v. de gebeurtenis (bv. nooit kunnen werken of carrière maken, geen gelukkige relatie kunnen hebben, geen gelukkige kinderen hebben, niet lang zullen leven)?

13. Hoe vaak heeft u de afgelopen maand problemen gehad met inslapen of doorslapen?

14. In hoeverre heeft $u$ de afgelopen maand last gehad van snel geirriteerd zijn of van woede-uitbarstingen? $\square$ helemaal geen

$\square$ beetje

$\square$ nogal

$\square$ erg veel moeite

$\square$ nee, helemaal niet

$\square$ beetje

$\square$ nogal

$\square$ ja, heel sterk

ㅁ nee, helemaal niet

$\square$ beetje

$\square$ nogal

$\square$ ja, heel sterk

$\square$ nee, helemaal niet

$\square$ beetje

$\square$ nogal

$\square$ ja, heel sterk

$\square$ nee, helemaal niet

$\square$ beetje

$\square$ nogal

$\square$ ja, heel sterk $\square$ nooit

$\square$ enkele keren per maand

enkele keren per week

elke nacht

$\square$ nooit

$\square$ soms

口 vaak

ㅁ erg vaak-altijd 
15. In hoeverre heeft u de afgelopen maand moeilijkheden met concentreren gehad (bv, de draad kwijtraken tijdens een gesprek, de t.v. niet meer kunnen volgen, niet meer weten wat je zojuist gelezen hebt)?

16. Was u de afgelopen maand erg waakzaam of op uw hoede (bv. controleren of er niemand in de buurt is, ongemakkelijk wanneer je geen overzicht hebt)?

17. Was u de afgelopen maand erg schrikachtig of snel geschrokken? nooit

ㅁ soms

口 vaak

ㄷ erg vaak-altijd
ㅁ nooit

$\square$ soms

口 vaak

ㅁ erg vaak-altijd $\square$ nooit

$\square$ soms

口 vaak

ㅁ erg vaak-altijd 


\section{Verantwoording citaten}

\section{Foto van het jaar}

Uit: Pieter Mol. De tekenen lezen.

Breda: Uitgever Boekhandel Hein van Kemenade, 1990

\section{Behind the wall}

Tracy Chapman, tekst en muziek

Purple Rabbit Music Inc, 1988

Toestemming: EMI Music Publishing (Holland) B.V.

\section{Thuiskomst}

Uit: Wislawa Szymborska. Uitzicht met Zandkorrel, Amsterdam: Uitgeverij JM Meulenhoff BV, 1997

\section{Liefdesgedicht}

K. Schippers. Uit: Lees nog eens een gedicht. Redactie T. van Deel, Amsterdam: Uitgeverij Querido, 1979

\section{Last Post}

Uit: Herman de Koninck. De gedichten

Amsterdam/Antwerpen: Uitgeverij de Arbeiderspers, 1998

\section{Liedje}

Uit: Judith Herzberg. Doen en laten

Amsterdam: Uitgeverij Rainbow pocketboeken, 1998

Allen met toestemming overgenomen 



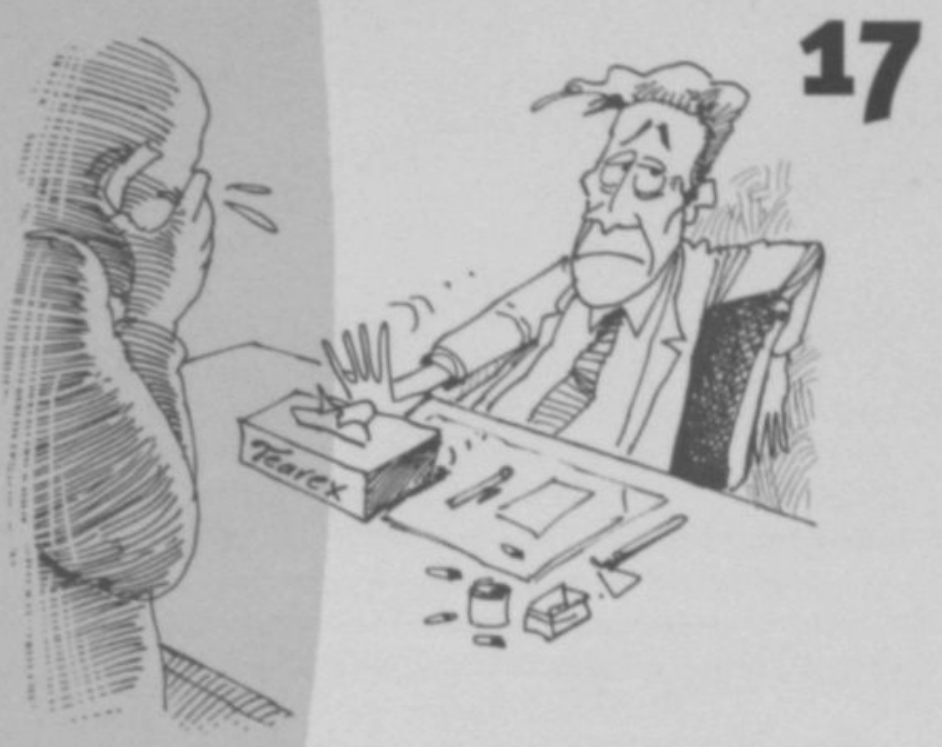

\section{Bent u daar nu nóg} niet overheen...?

Over de begeleiding bij ingrijpende gebeurtenissen

\section{nhy}

nederlands huisartsen genootschap 


\section{Inhoudsopgave}

1. Warming-up 1

2. Wetenswaardigheden 4

2.1. Signaleren 4

2.2. Ruimte voor het verhaal 6

2.3. Hoe vraag ik ernaar... en wat gebeurt er dan? 7

2.4. Begeleiding na een acute gebeurtenis 11

2.5. Verslaglegging en overdracht 13

3. Hints en adviezen 16

4. Oefenstof 19

4.1. Oefenstof voor de individuele huisarts $\quad 19$

4.2. Oefenstof voor in een groep huisartsen 22

5. Leestips 24

N.B.

Middenin dit cahier vindt u een pagina met toetsvragen, het zogeheten 'Toetsblad'. Wij gebruiken dit bij de toekenning van nascholingspunten.

Dit programma is door de LHV tot 1 december 2002 voor anderhalf uur nascholing geaccrediteerd. 
...De heer Saatch, 42 jaar, bezoekt huisarts Geertsema van gezondheidscentrum De Branding. Hij heeft last van verstopping en ook is er pijn en bloedverlies bij defecatie. De huisarts ziet forse aambeien. Ze schrijft laxantia voor en geeft dieetadviezen. Na een maand zijn de klachten niet verminderd en Geertsema verwijst hem voor het plaatsen van een Barron-ligatuur.

Toch blijft de heer Saatch daarna nog klachten houden rond zijn anus. De huisarts ziet bij onderzoek niets bijzonders. Ze kijkt terug in het verslag van de chirurg, maar behalve aambeien zijn er geen afwijkingen gezien. Geertsema legt uit dat de pijn door het litteken komt en over een maand over moet zijn.

Zes weken later belt Saatch weer; hij heeft nog steeds veel pijn. Geertsema schrijft een pijnstillende zalf voor. Na twee weken komt Saatch weer op het spreekuur omdat de zalf niet helpt. Hij maakt een bezorgde indruk.

Als Geertsema vraagt waardoor hij zelf denkt dat de klachten komen, zegt Saatch hiervan geen idee te hebben. Geertsema aarzelt even, maar dan durft ze toch te vragen of hij ooit door iemand rond zijn anus is aangeraakt op een manier die hij niet prettig vond. De heer Saatch schrikt. Wat moeizaam vertelt hij dat hij voor zijn vlucht naar Nederland, nu tien jaar geleden, in zijn eigen land is gemarteld door de staatspolitie. Hij is daarbij ook verkracht. Sinds de ingreep voor de aam. beien dringen herinneringen daaraan zich telkens op. Toen hij destijds in de praktijk kwam, heeft hij wel iets over de martelingen verteld aan dokter Kerstens, een collega uit het gezondheidscentrum. Saatch dacht dat Geertsema dat wel wist en hij praat er niet graag over. Geertsema vindt er echter niets van terug in het dossier.

Deze casus illustreert een aantal problemen waar $\mathrm{u}$ als huisarts tegenaan kunt lopen in het contact met een patiënt die een ingrijpende gebeurtenis heeft meegemaakt. Achter een puur somatische klacht blijkt een heel ander verhaal schuil te gaan. Maar hoe moet u daar nou achterkomen, vooral als het niet in het EMD staat? Bij een man denkt u misschien ook niet zo snel aan misbruikservaringen. En bovendien, hoe formuleert u een adequate vraag hiernaar? Hoe gaat u hiermee nu verder? 
De gevolgen van ingrijpende gebeurtenissen presenteren zich op zeer verschillende manieren in de spreekkamer. Soms komt de patiënt met onbegrepen lichamelijke klachten zoals in de hierboven beschreven casus; soms ook ontdekt u bij een patiënt met een depressie of angststoornis gaandeweg dat bepaalde gebeurtenissen uit het verleden een rol spelen.

Of u op de hoogte raakt van dergelijke gebeurtenissen in de voorgeschiedenis van een patiënt wordt door meerdere factoren bepaald. Patiënten verschillen natuurlijk in het gemak waarmee ze over hun nare ervaringen vertellen. Een goede communicatie kan ertoe bijdragen dat ze zich uitgenodigd voelen om te vertellen over ingrijpende gebeurtenissen, of ze nu in het verleden zijn gebeurd of nog altijd voortduren. Uw ervaringen met andere patiënten met soortgelijke problemen dragen bij aan de herkenning. Als u bijvoorbeeld een praktijk heeft waar meerdere asielzoekers zijn ingeschreven, zult u vaker met de gevolgen van oorlog en vervolging worden geconfronteerd. Werkt $\mathrm{u}$ in een gebied waar recent een ramp gebeurde, dan heeft $\mathrm{u}$ wellicht bijzondere expertise opgedaan in het geven van goede voorlichting op dat gebied en het tijdig signaleren van een falende verwerking.

Patiënten die mishandeld of seksueel misbruikt zijn, komen in alle praktijken voor, maar de mate waarin huisartsen deze problematiek signaleren wisselt sterk. Ze vragen er soms - ten onterechte - niet naar vanwege hun vooroordelen over welk 'type' mensen nare gebeurtenissen meemaakt.

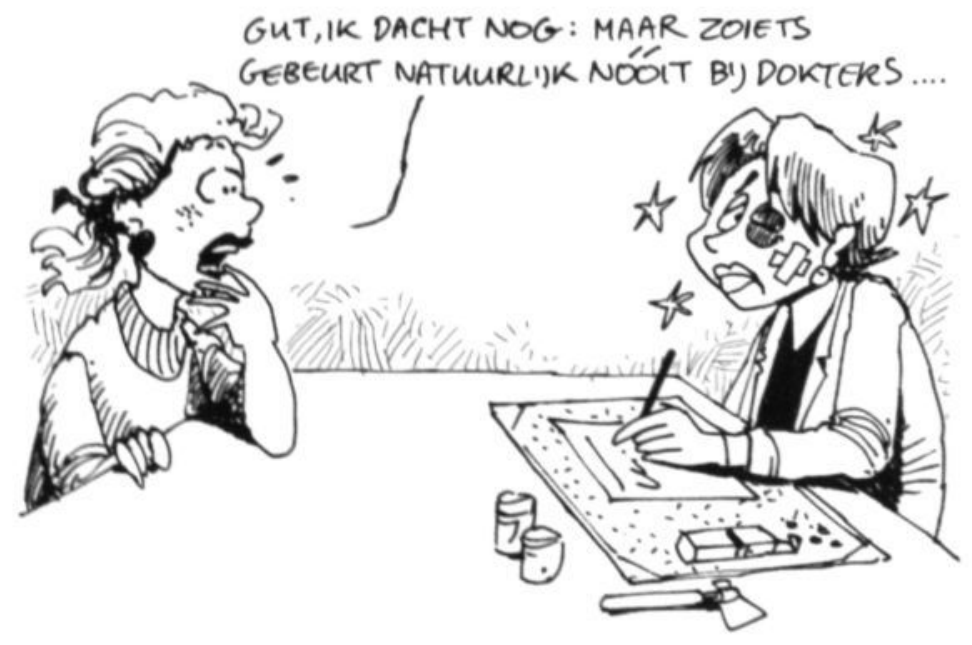

Zijn de verhalen eenmaal boven tafel, dan kunnen ze bij de huisarts een scala aan reacties teweegbrengen. Als u bijvoorbeeld zelf nare ervaringen heeft gehad, vergelijkt u wellicht de manier waarop de patiënt ermee omgaat met uw eigen reacties destijds. Misschien roept dit onaangename gevoelens op, gevoelens die u - zeker in de setting van de spreekkamer - waarschijnlijk liever niet heeft. 
Als het gaat om een gebeurtenis waarbij opzet in het spel is, zoals een beroving of mishandeling, voelt u misschien boosheid jegens de dader. Ook kan het verlenen van zorg na ingrijpende gebeurtenissen u een gevoel van onmacht bezorgen omdat de mogelijkheden om hulp te bieden beperkt zijn. Dit kan zijn omdat u zich onzeker voelt, misschien te weinig van het onderwerp af weet, niet voldoende adequate gesprekstechnieken beheerst, of omdat de verwijsmogelijkheden (te) gering zijn. Maar u kunt ook opzien tegen de tijdsinvestering die een intensieve hulpverlening met zich meebrengt.

In dit cahier worden u handreikingen gedaan voor het omgaan met slachtoffers van ingrijpende gebeurtenissen. Daaronder worden hier langdurige situaties verstaan, zoals oorlog of geweld in het gezin, alsook eenmalige, heftige gebeurtenissen zoals beroving, aanranding of verkrachting, mishandeling, ongevallen en rampen. $\mathrm{Bij}$ al deze ervaringen wordt de fysieke integriteit bedreigd.

Het hoofdstuk 'Wetenswaardigheden' gaat in op het signaleren van ingrijpende gebeurtenissen. Ook de verwerking van acute ingrijpende gebeurtenissen en de daarbij noodzakelijke voorlichting komen aan de orde. Voorts wordt besproken hoe u het uzelf en uw patiënten gemakkelijker kunt maken om gebeurtenissen aan te snijden waarop een taboe rust en hoe u met deze soms moeilijke consulten kunt omgaan. Tevens wordt ingegaan op problemen rond verslaglegging en overdracht aan collega's. Vervolgens worden enkele hints en adviezen voor de praktijk samengevat. In de 'Oefenstof' vindt u een aantal vragen en opdrachten waarmee u, alleen of met een groep collega's, aan de slag kunt gaan. In de 'Leestips' zijn enkele suggesties gedaan voor literatuur waarmee $u$ zich verder in de materie kunt verdiepen. 


\subsection{Signaleren}

Hoe vaak maken mensen ingrijpende gebeurtenissen mee in hun leven? Onderzoeksgegevens leveren het volgende beeld op. Ongeveer 15 procent van de vrouwen in Nederland wordt voor haar zestiende seksueel misbruikt door een verwant of vertrouwenspersoon; bij de helft betreft het penetratie of een poging daartoe. Van de jongens wordt 2 tot 5 procent seksueel misbruikt. Van de kinderen maakt 8 tot 9 procent fysieke mishandeling mee. In 11 procent van de relaties komt ernstige mishandeling voor. Zo'n 10 procent van de bevolking heeft een oorlog meegemaakt als burger of militair. Rond de 15 procent was betrokken bij een ernstig ongeval en een soortgelijk aantal bij een inbraak of beroving. Cijfers over rampen verschillen sterk per regio. Uit onderzoek in Limburg bleek dat ongeveer 40 procent van de ingeschrevenen een of meer van bovengenoemde gebeurtenissen had meegemaakt.

\section{Zijn huisartsen op de hoogte van ingrijpende gebeurtenissen?}

De huisarts, die als gezinsarts de patiënten over vele jaren volgt, zou bij uitstek de persoon moeten zijn die op de hoogte is van de ingrijpende gebeurtenissen die mensen meemaken. Maar is dat ook zo? Wellicht minder dan wordt gedacht. Uit onderzoek is namelijk gebleken dat huisartsen slechts van 8 procent van de door patiënten gerapporteerde gebeurtenissen op de hoogte waren. Van inbraken wisten zij vrijwel niets ( 1 procent), misbruik en mishandeling waren beter bekend ( 10 tot 17 procent). Ongevallen en rampen namen een tussenpositie in. Ook bleek dat de huisarts met name bij patiënten met een hoge opleiding minder goed op de hoogte is.

Nu is het natuurlijk niet zo dat huisartsen alles moeten weten wat hun patiënten meemaken. Soms is een gebeurtenis verwerkt; soms wil een patiënt zelf niet dat de huisarts het weet. Uit het in Limburg uitgevoerde onderzoek bleek echter ook dat van de gebeurtenissen die volgens de betrokkene ooit aan de huisarts waren verteld, nog slechts een kwart bij de huisarts bekend was. Dus driekwart van de gebeurtenissen die de huisarts of diens voorganger ter ore zijn gekomen, raakt 'verloren'. Vermoedelijk spelen een gebrekkige verslaglegging en overdracht naar collega's hierbij een rol. De nadelige effecten van het verloren gaan van vitale informatie werden geillustreerd in de casus in de 'Warming-up'. Het blijft bij alle klachten belangrijk om alle elementen uit de bio-psychosociale anamnese te overwegen, ook, of misschien juist, bij die klachten die niet eenvoudig zijn te interpreteren. 


\section{Wanneer moet de huisarts denken aan ingrijpende gebeurtenissen?}

Wanneer een gebeurtenis uit het verleden onvoldoende is verwerkt, of wanneer men in een voortbestaande gewelddadige situatie verkeert, heeft dit negatieve gevolgen voor de gezondheid. De mogelijke gevolgen zijn zeer divers: onverklaarde lichamelijke klachten en chronische pijn, angststoornissen, depressies, relatie- en seksuele problemen. Daarom kunnen zeer verschillende symptomen in de spreekkamer worden gepresenteerd die alle kunnen duiden op het niet verwerkt hebben van een ingrijpende gebeurtenis.

Bij mishandeling of misbruik in het gezin zijn er enkele bijzondere signalen. Lichamelijk letsel op zich duidt niet op mishandeling, maar de frequentie ervan en ook de geloofwaardigheid van het verhaal over de toedracht kunnen waarschuwingen inhouden. Ook wanneer iemand altijd vergezeld wordt door een ouder of de partner, kan dit een signaal zijn.

Bij misbruik of mishandeling binnen de relatie van volwassenen kunnen de volgende tekenen de huisarts op het spoor zetten: angsten, fobieèn, agressie, een laag zelfbeeld, schuld- en schaamtegevoelens, depressiviteit, nervositeit, relatie- en seksuele

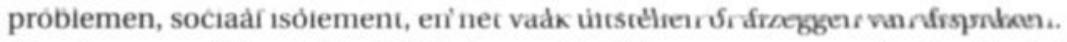
Signalen van mishandeling bij kinderen zijn: tekenen van verwaarlozing, heel stil zijn of juist heel druk, schuwheid, geen vriendjes hebben en leerproblemen (met name een knik in de leercurve).

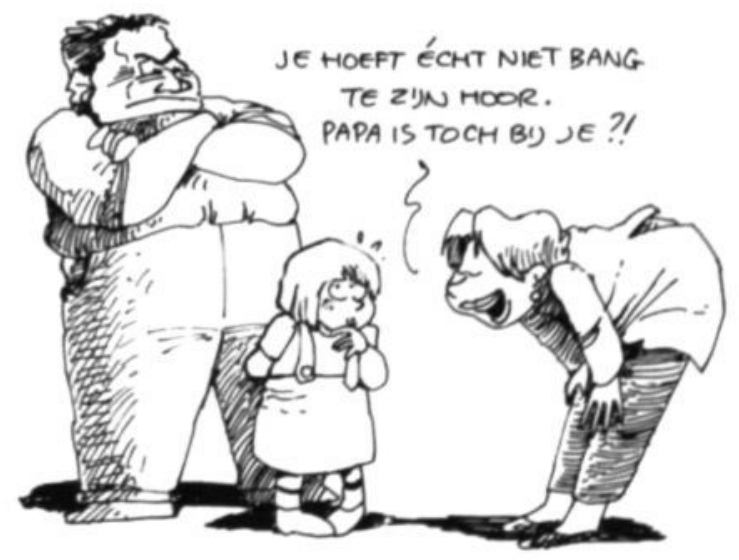

Mogelijke signalen van seksueel misbruik van jonge kinderen zijn (zeker als ze in combinatie voorkomen): slaapproblemen, nachtmerries, eetproblemen, buikpijn, stemmingswisselingen, zich terugtrekken, regressief gedrag, niet bij de leeftijd passend seksueel gedrag, dwangmatig seksueel gedrag, extreem veel masturberen of tonen van de geslachtsdelen, en meer weten en praten over seks dan past bij de leeftijd. Ook angst om te worden aangeraakt of uitgekleed en het niet op de rug durven liggen, zijn aanwijzingen. Beschadigingen in het anale of vaginale gebied zijn alarmerend. 
Bij mishandeling en misbruik, maar ook na ervaringen als een ongeval, oorlog, vluchten of een ramp, kan de huisarts worden gealarmeerd door herbelevingen in de vorm van nachtmerries en zich opdringende gedachten, en symptomen van prikkelbaarheid, slaapproblemen en concentratievermindering. Ook hoort hierbij het vermijden van situaties en mensen die herinneringen aan het gebeurde oproepen. Als deze symptomen kort na het voorval optreden, zijn ze normaal. Houden ze echter langer dan drie maanden aan, dan is dit een teken van onvoldoende verwerking. Er kan dan sprake zijn van een posttraumatische stress-stoornis.

\subsection{Ruimte voor het verhaal}

Heeft de huisarts een rol bij de verwerking van ingrijpende gebeurtenissen? Uit recent onderzoek onder de bevolking bleek dat bij een kwart van de respondenten die ingrijpende gebeurtenissen hadden meegemaakt, behoefte bestond aan professionele hulp. Van hen ziet 60 procent een rol voor de huisarts; ofwel bij 15 procent van de ingrijpende gebeurtenissen wil men graag huisartsenhulp. Toch ging een deel van deze patiënten niet met hun problemen naar de huisarts. Een van de redenen hiervan is dat zij denken dat verwerkingsproblemen onvoldoende medisch van aard zijn om ermee naar de huisarts te gaan. Misschien hebben ze ooit een balletje opgegooid om te kijken hoe de huisarts zou reageren op een psychosociaal probleem. Als ze zich toen niet voldoende gesteund of serieus genomen voelden, of als de huisarts veroordelend reageerde, dan zullen zij hierover niet gauw een tweede keer beginnen.

\footnotetext{
...Mevrouw Bakels, 32 jaar, heeft buikklachten. Huisarts Van der Stelt ziet na anamnese en lichamelijk onderzoek geen aanleiding tot ongerustheid. Hij stelt voor het nog even aan te zien. Bij het vertrek ontspint zich de volgende conversatie.

'Dokter, ik ben de laatste tijd ook weer zo zenuwachtig.' 'Oh?'
}

'Ik zou graag weer die pilletjes hebben die ik een paar jaar geleden van uw voorganger kreeg.'

Van der Stelt zoekt in het EMD het betreffende voorschrift op.

'Ik zie dat u toen temazepam had. Heeft dat goed geholpen?'

'Ja, zeker."

'Ik geef u voor twee weken dezelfde pillen mee.'

'Dank u, dokter.'...

Van der Stelt gaat in deze casus niet in op de zenuwachtigheid van mevrouw Bakels en die krijgt het gevoel dat ze over dit soort dingen maar beter niet kan beginnen. Als Van der Stelt had doorgevraagd, was gebleken dat het recente auto-ongeval van een vriendin van mevrouw Bakels weer allerlei verdrietige herinneringen oproept aan het verongelukken van haar vader drie jaar geleden. 
... Huisarts Van der Stelt vermoedt wel dat de onverklaarbare buikklachten en de vraag om temazepam duiden op spanningen bij mevrouw Bakels. Maar direct bedenkt hij dat het wel eens een uitvoerig consult zou kunnen worden als hij daarop ingaat. Hij heeft het al zo druk en besluit dit niet te doen.

Inderdaad heeft de huisarts lang niet altijd de tijd en rust om uitgebreid op dit soort zaken in te gaan. Maar het hoeft in eerste instantie ook niet altijd uitgebreid. Soms is het ontvangen van begrip al een grote bevrijding voor de patiënt. En dan kan worden bekeken of en, zo ja, wanneer op de problemen zal worden teruggekomen.

Ook gevoelens van schuld en schaamte bij het slachtoffer spelen een rol bij het niet te berde brengen van gebeurtenissen. Slachtoffers van een ramp of oorlog kunnen zich schuldig voelen omdat zij zijn blijven leven terwijl dierbare naasten zijn gestorven. Mensen die mishandeld worden door een partner - of, bij ouderen, door hun kind schamen zich dat ze niet in staat zijn het geweld te stoppen en beginnen er daarom vaak niet over. In dergelijke gevallen zijn mensen bovendien bang dat de dader het zal ontdekken als ze het aan de huisarts vertellen. Dit geldt ook voor seksueel misbruik door een naast familielid.

\subsection{Hoe vraag ik ernaar... en wat gebeurt er dan?}

\section{Formuleringen}

Er bestaat niet één 'ideale' manier om navraag te doen naar ingrijpende gebeurtenissen. Veel hangt af van de relatie tussen de huisarts en de patiènt en de grootte van het taboe dat de gebeurtenis omgeeft. Ook heeft iedere huisarts een eigen stijl: de een is directer dan de ander. Het is goed om gaandeweg het gesprek vage aanduidingen zoveel mogelijk te expliciteren. Met name als het gaat om taboebeladen onderwerpen als misbruik of mishandeling, is het handig om meer en minder concrete formuleringen in petto te hebben.

\footnotetext{
...Mevrouw Vos, 30 jaar, komt met klachten die de huisarts bedacht maken op misbruik of mishandeling. Na lichamelijk onderzoek, dat geen somatische verklaring voor de klachten oplevert, zegt de huisarts:

'We moeten eens goed uitzoeken wat de oorzaak van uw klachten is. Ik heb u onderzocht en kan geen verklaring vinden. Daarom wil ik u nog iets vragen. Soms hebben mensen als ze naar de dokter komen zelf een verklaring voor hun klachten. Heeft u dat misschien ook?'

'Ik zou het niet weten.'

'Soms hebben mensen met uw soort klachten vervelende ervaringen gehad. Kan dat bij u ook het geval zijn?"

"Hoe bedoelt u?"
} 
'Heeft u wel eens vervelende seksuele ervaringen gehad?'

'Seks is niet altijd leuk.'

"Hoe bedoelt u?"

'Nou, gewoon...'

'Heeft u zich weleens gedwongen gevoeld om te vrijen omdat u zich bedreigd voelde?"

De huisarts kan meer of minder specifieke formuleringen gebruiken. Weinig specifieke vragen zijn vaak geschikt als opening. Bijvoorbeeld: 'Heeft u zelf enig idee waardoor uw klachten kunnen komen?' Meer specifieke vragen kunnen concretere informatie opleveren. Bijvoorbeeld: 'Heeft u weleens vervelende seksuele ervaringen gehad?' Het kiezen voor weinig specifieke of juist concrete vragen (en alle soorten vragen daar tussenin) is een kwestie van aanvoelen. Het risico van een indirecte aanpak is dat huisarts en patiënt samen om de hete brij draaien. Dat kost veel tijd en de patiēnt schiet er niets mee op. De oorzaak kan liggen bij de patiënt (die moeilijk over pijnlijke gebeurtenissen praat) maar ook bij de huisarts (die niet durft te vragen naar taboebeladen kwesties). Het risico van een directe aanpak is dat de patiënt schrikt, of zich beledigd voelt dat de huisarts 'zoiets' durft te denken.

Onderstaand volgen enkele voorbeelden van vragen voor het bespreekbaar maken van mishandeling of misbruik bij kinderen.

Weinig specifiek: 'Gebeuren er wel eens dingen die je niet leuk vindt?'

Aansluitend kan een meer concrete vraag volgen: 'Wat gebeurt er dan?' Tussen weinig specifiek en concreet in: 'Ben je weleens bang?', gevolgd door meer gesloten en concrete vragen: 'Is dat als je alleen bent? Ook als er iemand bij je is? Wil je daar iets over vertellen?'

Specifiek/concreet: 'Komt er weleens iemand aan je lichaam, terwijl je dat niet wilt?' Dit kan gevolgd worden door andere meer specifieke vragen: 'Word je dan pijn gedaan? Word je dan weleens geslagen?'

Overigens wordt geadviseerd bij jonge kinderen geen gedetailleerde anamnese af te nemen omdat zij suggestibel zijn. Dit vermindert de betrouwbaarheid van de anamnese als het kind wordt verwezen.

\section{Autonomie}

Het is belangrijk de autonomie van de patiënt te respecteren bij het exploreren van een ingrijpende gebeurtenis en de gevoelens die dat bij de patiènt oproept. De slachtofferrol gaat bij uitstek gepaard met gevoelens van controleverlies en machteloosheid. Er moet dus voor worden gewaakt dat de patiënt die gevoelens niet ook in het contact met de huisarts ervaart. De houding en formuleringen van de huisarts moeten de patiënt het gevoel geven zelf controle over de situatie te kunnen houden. Dit kan bijvoorbeeld door de patiënt te vragen naar de eigen ideeën over de oorzaak van de klachten, maar ook door - als de ingrijpende ervaring eenmaal boven tafel is - te 
benadrukken dat de patiënt keuzemogelijkheden heeft. Dit kan met vragen als: 'Wilt u het er nu over hebben?' of 'Wilt u het er met mij over hebben?'

Het tussentijds samenvatten van wat de patiënt vertelt, zorgt voor rust in het gesprek en laat zien dat de huisarts het verhaal heeft begrepen. De patiënt kan even nagaan of de samenvatting klopt met wat hij/zij bedoelt.

Bij het lichamelijk onderzoek laat de huisarts de patiënt waar mogelijk de controle houden, bijvoorbeeld door te vragen of de patiënt even wil waarschuwen als hij/zij is uitgekleed, of door de vrouw te vragen even het speculum vast te houden als uitstrijkmateriaal moet worden gepakt. Ook kan de huisarts vragen welke houding de patiënt prefereert bij rectaal toucher.

\section{Beledigen}

De vrees dat patiënten beledigd zullen zijn als zij een bepaalde gebeurtenis niet hebben meegemaakt, kan de huisarts ervan weerhouden er navraag naar te doen. Patiènten reageren inderdaad soms beledigd. Aan de andere kant is van slachtoffers van seksueel misbruik bekend dat ze graag hadden gewild dat de huisarts ernaar had gevraagd. Het is een afweging die de huisarts telkens opnieuw zal moeten maken, daarbij in 't oog houdend dat wat door de huisarts soms als angst om te beledigen wordt gezien, misschien met eigen weerstanden te maken kan hebben. Het kan zijn dat de huisarts liever niet geconfronteerd wil worden met (eigen) geweldservaringen en gevoelens van onmacht, boosheid of verdriet.

\section{Grip houden op het consult}

Een andere aarzeling bij de huisarts om ingrijpende gebeurtenissen aan de orde te stellen, is de vrees om een beerput aan problemen open te trekken zonder dat er voldoende gelegenheid is om deze enigszins op orde te brengen. Het is dan nuttig te bekijken welk doel de huisarts heeft bij een dergelijk consult. Dat doel kan maar beter niet te hoog worden gesteld. Als het bijvoorbeeld om partnermishandeling gaat, is het vrijwel onhaalbaar de vrouw zover krijgen dat zij bij haar man weggaat. Dit zal zelden lukken, zo blijkt uit gegevens van vrouwenopvanghuizen. Het is dan ook verstandig de doelstelling van een dergelijk consult te leggen bij luisteren en erkennen. Voor de meeste patiënten is het vooral belangrijk dat ze zich gehoord voelen en dat hun probleem wordt erkend en in kaart gebracht. Dit versterkt hun vaak zeer aangetaste zelfvertrouwen. Ook verzacht een begripvolle, steunende benadering hun schuldgevoel over het niet kunnen stoppen van het geweld of het niet kunnen verlaten van hun partner. Wanneer de patiënt geen energie meer hoeft te stoppen in het tegenspreken van schuld of het verbergen van schaamte, ontstaat de mogelijkheid de feiten reëel onder ogen te zien.

Ook andere traumatiserende ervaringen als berovingen, oorlog of gevangenschap laten sporen na. Sterke gevoelens kunnen naar boven komen wanneer de huisarts daar - soms als eerste en enige - naar vraagt.

Als de nare ervaringen boven tafel zijn gekomen, is het van belang voor zowel huisarts als patiënt dat de huisarts de regie weer stevig in eigen hand neemt. 


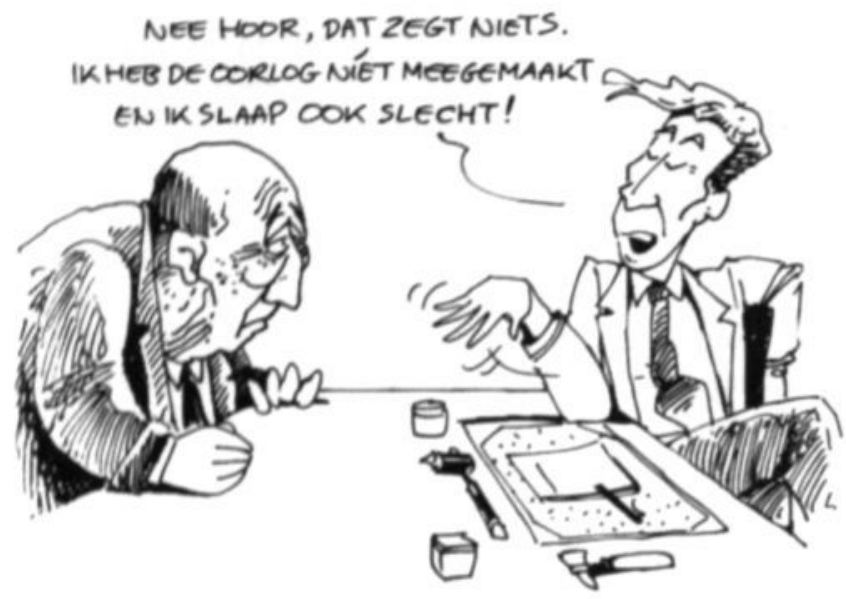

Nadat aan de patiënt duidelijk is gemaakt dat het verhaal goed is begrepen, door samen te vatten en begrip te tonen, gaat de huisarts structureren: wanneer wordt er verder over gesproken en met wie? De tijd tussen dit en een volgend consult kan de patiënt benutten om voor zichzelf na te gaan in hoeverre en met wie hij of zij erover wil doorpraten.

\title{
Het achterhalen van de waarheid
}

\begin{abstract}
...Mevrouw Gelissen komt met haar dochter Anja, 11 jaar, op het spreekuur. Het meisje is nukkig en stil. Ze is al weken moe en haar moeder vraagt of er bloed geprikt kan worden. Bij navraag blijkt Anja slecht te slapen. Ze wordt soms gillend wakker uit nachtmerries, maar ze wil niet vertellen waar die over gaan. Op de vraag van de huisarts of Anja een keer zonder haar moeder komt praten, wordt niet ingegaan.

Mevrouw Gelissen komt de week erna voor zichzelf. Ze vertelt dat Anja, toen ze afgelopen weekend logeerde bij een oom en tante, huilend aan de tante heeft verteld dat zij en haar zusje van 13 zijn misbruikt. Ze wilde niet zeggen door wie. Mevrouw Gelissen geloofde het verhaal niet en toen ze er Anja later naar vroeg, ontkende die het weer. Ook het oudere zusje ontkent alles...
\end{abstract}

Huisartsen aarzelen ook wel eens om te vragen naar ingrijpende gebeurtenissen omdat ze denken dat ze dan moeten beoordelen of die daadwerkelijk gebeurd zijn of niet. Heeft het meisje uit de casus iets verzonnen om aandacht te trekken of is het echt gebeurd? Bij gruwelijke verhalen, bijvoorbeeld van vluchtelingen, kan ongeloof voortkomen uit ontkenning: 'Zulke dingen doen mensen elkaar toch niet aan?!' Ongeloof kan ook te maken hebben met vooroordelen die de huisarts heeft: 'lemand die een gebeurtenis zo theatraal vertelt, heeft het vast verzonnen.' 
Maar waarheidsvinding is gelukkig niet de taak van de huisarts. Of het nu waar is of niet wat patiènten over ingrijpende gebeurtenissen vertellen, het zijn in ieder geval altijd signalen dat er iets aan de hand is. Ook als iemand iets ingrijpends fantaseert, duidt dit erop dat er een probleem is. Samen met de patiënt moet worden gekeken naar de betekenis van het verhaal en naar wat ermee moet worden gedaan.

\begin{abstract}
...De huisarts stelt voor dat mevrouw Gelissen aan Anja vraagt om een keer alleen te komen op het spreekuur, zodat de klacht verder kan worden uitgediept. Mevrouw Gelissen gaat hiermee akkoord en spreekt meteen een tijdstip af met de assistente.
\end{abstract}

\title{
2.4. Begeleiding na een acute gebeurtenis
}

\begin{abstract}
...De heer Mulker, een 54-jarige vertegenwoordiger, belt de assistente en vraagt een recept voor slaappillen. De assistente legt uit dat hij daarvoor een afspraak moet maken op het spreekuur. Als de huisarts vraagt waarom hij slecht kan slapen, vertelt Mulker dat hij zo onrustig is de laatste tijd. En door het slechte slapen kan hij zich niet op zijn werk concentreren. Ook valt hij vaak uit tegen zijn kinderen. Als hij nu maar eens goed slaapt, hoopt hij dat het beter zal gaan. $\mathrm{Na}$ enig doorvragen blijkt dat Mulker tien dagen geleden op een regenachtige avond met zijn auto een fietser heeft aangereden. Het slachtoffer, een twintigjarige vrouw, ligt nog in het ziekenhuis, zij het inmiddels buiten levensgevaar. Hij voelt zich tegelijk boos en schuldig over het ongeval. Hij kan er met weinig mensen over praten.

Hij heeft er een paar keer akelig over gedroomd en overdag dringt zich het ongeluk 'als een film' aan hem op, soms zonder enige aanleiding. Op de vraag wat hij dan doet, vertelt Mulker dat hij onmiddellijk een tijdschrift pakt of de tv aanzet. Maar op tv zijn zoveel akelige beelden, dat hij die dan weer uitzet. Bij navraag blijkt hij ook de plek des onheils te vermijden; hij rijdt liever een paar kilometer om.
\end{abstract}

\section{Normale reacties}

Kort na het meemaken van een ingrijpende gebeurtenis vertonen mensen een scala aan reacties. 's Nachts zijn er nachtmerries en overdag dringen de herinneringen aan de gebeurtenis zich onwillekeurig op. Dit herbeleven wordt afgewisseld met vermijding: ze duwen opkomend verdriet of boosheid weg, er zijn momenten waarop ze er helemaal niet over willen denken of praten, en ze proberen zaken die aan de gebeurtenis doen denken (tv-beelden, de plaats van de gebeurtenis et cetera) te vermijden. Soms voelen ze überhaupt niets. Typisch is ook een verhoogde prikkelbaarheid: snel schrikken, geïrriteerd raken of uit de concentratie gebracht worden. Het zijn allemaal heel normale reacties, die bij een goede verwerking in de loop van de eerste drie maanden zullen afnemen. 


\section{De balans tussen vermijden en herbeleven}

Voor het verwerken van een acute gebeurtenis moet een goede balans worden gevonden tussen vermijden en herbeleven. Als al het organisatorische geregel rondom dokters, verzekeringen, werk en dergelijke voorbij is, is het van belang tijd uit te trekken voor leuke, afleidende bezigheden. Maar daarnaast moet regelmatig tijd worden genomen voor de verwerking van de gebeurtenis, bijvoorbeeld een uur per dag. Dit kan door erover te vertellen, te schrijven, de plek te bezoeken et cetera.

Die balans is belangrijk: zou iemand de hele dag bezig zijn met herbeleving en verwerking, dan kan het leven zijn normale loop niet hernemen. Terwijl anderzijds het voortdurend vermijden van plaatsen, herinneringen en mensen die associaties aan het gebeurde oproepen, de verwerking belemmert.

\section{Sociale steun}

Voldoende sociale steun blijkt onontbeerlijk voor een goede verwerking. Na een gebeurtenis kan iemand zich anders dan anders gaan voelen, maar ook anders dan anderen. Uit vrees dat vrienden en familie er niets van zullen begrijpen, of vinden dat het slachtoffer zich aanstelt of steeds zo ongezellig is, bestaat soms de neiging om zich te isoleren. Dit staat een goede verwerking in de weg.

\section{Slaap- en kalmeringsmiddelen, alcohol en drugs}

Sedativa, alcohol en drugs worden vaak gebruikt om de heftige gevoelens te onderdrukken die herinneringen aan de gebeurtenis oproepen. Uit onderzoek is gebleken dat met het oog op verwerking op de lange termijn, beter van het gebruik van deze middelen kan worden afgezien.

\section{Problemen op lange termijn}

Een deel van de mensen die een ingrijpende gebeurtenis meemaken, zal hieraan op lange termijn problemen overhouden. De meeste van deze problemen, zoals fysieke klachten en depressies, zijn niet specifiek; ze kunnen ook na andere gebeurtenissen en ook zonder bijzondere aanleiding voorkomen. De posttraumatische stress-stoornis kan ontstaan na ingrijpende gebeurtenissen die een bedreiging vormen voor de fysieke integriteit van de persoon of diens naasten. Hiervan is sprake als de verschijnselen van herbeleving, vermijding en prikkelbaarheid, zoals hierboven beschreven, drie maanden na de gebeurtenis nog altijd hinderlijk aanwezig zijn. In principe stelt de psychiater de diagnose op grond van vastgestelde criteria.

Bij welke mensen moet de huisarts nu extra alert zijn op het zich ontwikkelen van een posttraumatische stress-stoornis? Met andere woorden, welke patiënten moeten meer nauwlettend worden gevolgd? Dat zijn patiënten met een of meer van de volgende kenmerken:

1. vrouwelijk geslacht;

2. een lage opleiding;

3. alleenstaand; 


\section{Toetsblad}

17. Bent u daar nu nóg niet overheen...?

Over de begeleiding bij ingrijpende gebeurtenissen

\section{Dit Toetsblad kunt u uitnemen en opsturen naar het Nederlands Huisartsen Genootschap.}

Voor het doornemen van dit cahier en het maken van de vragen uit hoofdstuk 4 is door de Landelijke Huisartsen Vereniging tot 1 december 2002 voor anderhalf uur accreditering verleend onder nummer N01526. Als u een certificaat voor deelname aan deze nascholing wilt ontvangen, wordt $u$ verzocht het Toetsblad ingevuld naar het NHG te sturen.

Zoek nu in hoofdstuk 4 'Oefenstof' op wat u bij de volgende vragen heeft ingevuld en neem dat hier over. 


\section{Zie pagina 19:}

1. Wat dacht u toen de patiënt over de gebeurtenis vertelde?

2. Heeft u zelf ooit een dergelijke gebeurtenis meegemaakt? Zo ja, hoe bent u daar destijds mee omgegaan?

\section{Zie pagina 20:}

4. Vindt $u$ de voorlichting zoals weergegeven in het cahier relevant?

6. Wat heeft u genoteerd over deze gebeurtenis (onder welke ICPC-code), en heeft u deze in de problemenlijst opgenomen? 
Te beantwoorden door degenen die wel een casus uit de eigen praktijk voor de geest konden halen (zie pagina 21):

11. Heeft u dit vermoeden ter sprake gebracht? Zo nee, waarom niet? (Ga door naar vraag 19.) Zo ja, weet u nog welke formulering u daarvoor gebruikte?

14. Werd uw vermoeden bevestigd door de patiënt?

Te beantwoorden door degenen die geen casus uit de eigen praktijk voor de geest konden halen of die vraag 11 ontkennend hebben beantwoord (zie pagina 22):

19. Wat zouden redenen kunnen zijn dat u geen patiënt voor de geest kon halen? Of, indien $u$ vraag 11 ontkennend heeft beantwoord, wat kan daarvan de reden zijn?

En tot slot:

Noteer voor uzelf twee leerpunten die u wilt vasthouden uit dit cahier. 
Ondergetekende verklaart het cahier 'Bent u daar nu nóg niet overheen...? Over de begeleiding bij ingrijpende gebeurtenissen' te hebben doorgenomen en de vragen van het Toetsblad te hebben ingevuld.

Naam:

$\mathrm{m} / \mathrm{v}$

Adres:

Postcode/woonplaats:

Datum:

Handtekening:

Wij verzoeken u dit blad in een ongefrankeerde envelop toe te sturen aan:

Nederlands Huisartsen Genootschap

Afdeling Productontwikkeling en Implementatie

Antwoordnummer 2823

3500 VL. Utrecht 
4. meerdere traumata in het verleden;

5. als kind mishandeld of misbruikt;

6. weinig sociale steun.

Voorts is bekend dat mensen die tijdens het voorval dissocieerden (geen emoties of een verminderd bewustzijn hadden, gederealiseerd of gedepersonaliseerd waren, of zich kort nadien een deel niet konden herinneren) een duidelijk verhoogd risico lopen op een posttraumatische stress-stoornis.

Vooral als er meerdere indicatoren bij één patiënt voorkomen, is dit reden om een vervolgafspraak te maken, bijvoorbeeld na een maand. De huisarts kan dan kijken of de symptomen verminderen en vervolgens handelen naar bevinden.

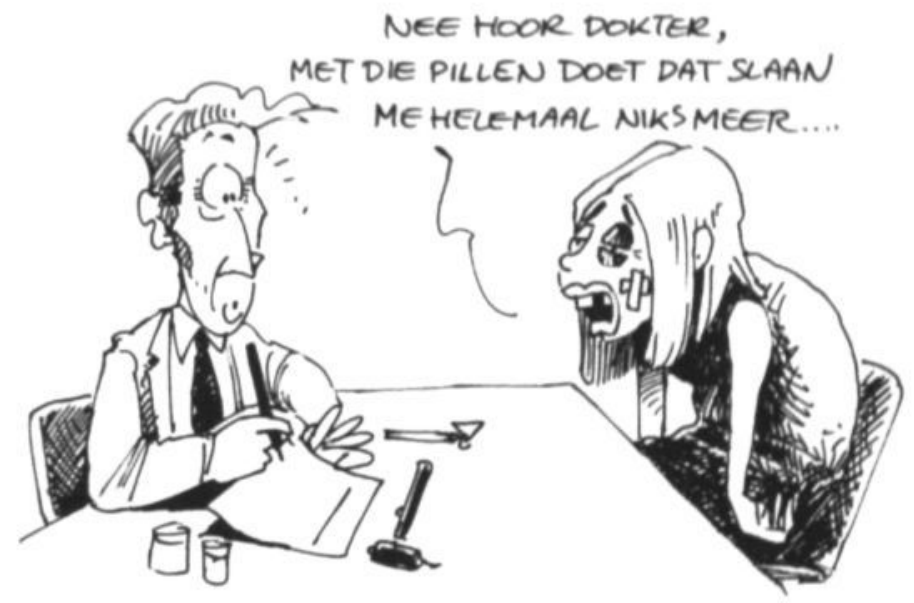

\subsection{Verslaglegging en overdracht}

Zoals eerder gesteld, zijn huisartsen vaak niet op de hoogte van de ingrijpende gebeurtenissen die hun patiënten meemaken doordat de verslaglegging en overdracht niet optimaal zijn. Dit geldt zowel voor eenmalige gebeurtenissen zoals ongevallen en rampen, als voor langdurige situaties zoals oorlog, of geweld tussen partners. Een vervelend gevolg van een tekortschietende verslaglegging werd geillustreerd in de casus over de heer Saatch. Als in de problemenlijst het seksueel misbruik tijdens martelingen was vermeld, had de huisarts bij het verwijzen voor de Barron-ligatuur het onderwerp kunnen aanstippen. Dan was het meneer Saatch duidelijk geweest dat er in het consult ruimte en tijd is om nare ervaringen te bespreken. En er had extra uitleg over de ingreep kunnen worden gegeven om de angst ervoor te verminderen. Gebleken is dat daarmee het herbeleven van een trauma tijdens behandelingen vermindert. 
Wanneer is een ingrijpende gebeurtenis belangrijk genoeg om te noteren? Noteren we een vermoeden dat nog niet is besproken? Stigmatiseren we daarmee te zeer? De wijze van verslaglegging wordt bepaald door overwegingen van de individuele huisarts en door wettelijke regels.

\section{Verslaglegging van ingrijpende gebeurtenissen}

Een eenvoudige vuistregel voor het noteren van een ingrijpende gebeurtenis is dat de patiènt het belangrijk genoeg vond om het erover te hebben. Immers, mensen kunnen soms pas na jaren klachten van een voorval ondervinden, bijvoorbeeld doordat een nieuwe gebeurtenis deze klachten uitlokt. Wanneer de informatie in de problemenlijst is opgeslagen, is de informatie snel beschikbaar, ook voor een nieuwe huisarts.

Op grond van anamnese of lichamelijk onderzoek rijst soms het vermoeden van mishandeling of seksueel misbruik. Als de tijd nog niet rijp lijkt om hiernaar navraag te doen, is het nuttig de objectieve bevindingen in ieder geval in het journaal te noteren (bijvoorbeeld in de S-regel 'vertelt van trap te zijn gevallen' en in de O-regel 'hematomen R. bovenarm'). Zo kan hierop later worden teruggegrepen en is de informatie ook voor de collega's uit de praktijk toegankelijk. Een patroon in de klachten en symptomen, of juist het ontbreken daarvan, zal dan sneller duidelijk worden. Soms kiest een huisarts voor een cryptische omschrijving als geheugensteun bij een nog niet bevestigd vermoeden. Het is de vraag of dit zinvol is, aangezien een patiënt niet alleen recht heeft op inzage in het eigen dossier, maar ook op uitleg over zo'n cryptische omschrijving. Wel zou een niet bevestigd vermoeden als 'persoonlijke werkaantekening' genoteerd kunnen worden, dus een notitie die alleen toegankelijk is voor de huisarts zelf en niet voor de patiënt, collega's of praktijkassistentes. De huidige HIS'en bieden nog niet de mogelijkheid om dergelijke aantekeningen te maken.

Indien een vermoeden van misbruik of mishandeling aan de orde is gesteld, maar de patiënt dit ontkent, kan toch worden overwogen te noteren dat dit onderwerp is besproken, maar dat het vermoeden niet door de patiënt is bevestigd. Voor een collega uit de praktijk kan dit belangrijke informatie zijn. Adequate hulpverlening en onterechte stigmatisering moeten tegen elkaar worden afgewogen.

Wanneer patiënten over daden van familieleden en andere mensen uit hun omgeving vertellen, is het in verband met eventuele juridische gevolgen van belang om in de notities duidelijk te maken waar de patiënt geciteerd wordt en wat de interpretatie van de huisarts is.

Soms vraagt een patiènt om 'het niet verder te vertellen'. Dan moet worden nagegaan of de patiënt collega's of assistentes in de praktijk bedoelt, of de familieleden van de patiènt zelf. Dit heeft consequenties voor het wel of niet noteren van het besprokene. 
Als de patiënt niet wil dat iets in het dossier komt, kan uitleg worden gegeven over het belang van het noteren in verband met hulpverlening in de toekomst. Mocht de patiênt desondanks voet bij stuk houden, dan moet worden overwogen of de hulpverlening wordt belemmerd door geen aantekening te maken. Indien dit zo is, kan de huisarts overwegen de gebeurtenis toch te noteren.

\section{Overdracht aan collega's buiten de praktijk}

Als een patiënt zelf verzoekt een bepaald gedeelte uit de voorgeschiedenis weg te laten of te verwijderen, dan bespreekt de huisarts de nadelen hiervan: een volgende collega ontbeert dan gegevens die bijdragen tot een goede hulpverlening, of kan zo onvoldoende rekening houden met bepaalde gevoeligheden van de patiënt.

Soms doet zich een situatie voor waarin vermoedens over mishandeling of misbruik in het gezin nog niet zijn besproken op het moment dat het gezin naar een andere praktijk verhuist. Het is dan verleidelijk om de vermoedens mondeling over te dragen aan de collega. Dit is echter een schending van het beroepsgeheim en dus af te raden.

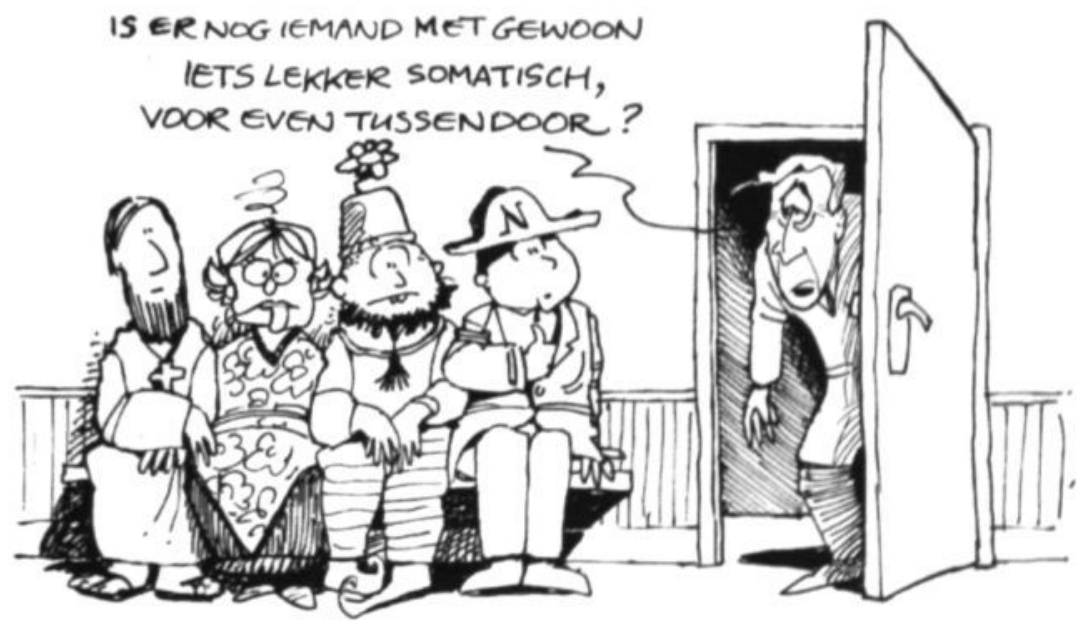


In het voorgaande is veel gezegd over de ingrijpende gebeurtenissen die uw patiënten kunnen hebben meegemaakt en wat goede manieren zijn om daarmee om te gaan. Onderstaand is geprobeerd de belangrijkste adviezen voor u samen te vatten.

\section{Vraag actief naar ingrijpende gebeurtenissen.}

Huisartsen zijn vaak niet op de hoogte van de gebeurtenissen die hun patiènten hebben meegemaakt. Symptomen die op verwerkingsproblemen wijzen, zijn soms weinig specifiek. Het is goed uw vermoeden te bevestigen door actief navraag te doen naar ingrijpende gebeurtenissen. U zult dan wel een enkele keer een nietslachtoffer 'beledigen', maar de voordelen wegen hier vermoedelijk tegenop.

\section{Stel in een kennismakingsgesprek een algemene vraag over ingrijpende ge-} beurtenissen in het verleden.

Een van de manieren om patiënten duidelijk te maken dat ingrijpende gebeurtenissen goed kunnen worden besproken met de huisarts, is door ernaar te vragen in een kennismakingsgesprek, of het op te nemen in de schriftelijke vragenlijst voor nieuwe patiënten. Als uit het dossier van een nieuwe patiënt blijkt dat er ingrijpende ervaringen zijn geweest, kan het aankaarten ervan in het kennismakingsgesprek de boodschap overbrengen dat u openstaat voor bespreking van dergelijke gebeurtenissen.

Neem patiënten die vertellen over nare ervaringen serieus, geef steun en toon begrip.

Patiënten die aarzelen om over ingrijpende gebeurtenissen te vertellen, gooien soms een balletje bij u op om te kijken hoe u reageert. Als $u$ hier dan niet serieus op ingaat, zal de patiënt een dergelijk onderwerp niet gemakkelijk nog eens aansnijden. Realiseer u dat patiënten diverse redenen kunnen hebben om niet met hun verhaal op de proppen te komen.

Maak patiënten duidelijk dat wat zij u vertellen vertrouwelijk behandeld zal worden.

Als ook de dader patiënt is in uw praktijk, aarzelen slachtoffers soms om te vertellen over hun ervaringen. Ze zijn bang dat het de dader via de praktijk ter ore zal komen. Vertel hun dat uw beroepsgeheim ook hun partner of familieleden betreft. 
Bouw bij het vragen naar ervaringen waarop een taboe rust uw openingszinnen op van minder naar meer concreet.

Wanneer u de manier van vragen opbouwt en gaandeweg steeds concreter wordt, zal de anamnese zo soepel mogelijk verlopen. De patiënt zal niet al te zeer schrikken, en beide partijen weten waarover ze het hebben. Een weinig concrete vraag is bijvoorbeeld: 'Bij sommige mensen met uw soort klachten komt het voor dat ze vervelende ervaringen hebben... Kan dit ook bij u aan de hand zijn?' Een meer concrete vraag is: 'Bent u ooit geslagen?'

Stel, als het om partnermishandeling gaat, uw doelen niet te hoog. Verwacht niet dat $\mathrm{u}$ het voor elkaar zult krijgen een vrouw weg te krijgen bij haar mishandelende partner, want dat zal zelden lukken. Het is voor patiënten vooral van belang om steun te krijgen, zodat hun zelfvertrouwen wordt vergroot. Dit is een voorwaarde voor het door de patiënt zelf nemen van adequate beslissingen rond de mishandeling.

Neem, als het verhaal is verteld en u de patiënt heeft laten blijken het 'gehoord' te hebben, de regie van het consult weer over.

Als patiënten in de spreekkamer over hun nare ervaringen vertellen, geeft dit vaak een machteloos gevoel. Hoe kunt $u$ de patiënt nu in het korte tijdsbestek van een consult helpen? Dit zal meestal ook niet lukken. Daarom is het van belang om, samen met de patiënt, een plan van aanpak te maken. Dat is úw expertise. En het geeft u ook weer greep op het consult.

Wees alert op reacties als angst en dissociatie tijdens lichamelijk onderzoek bij mensen die gevangen hebben gezeten, of zijn gemarteld, mishandeld of seksueel misbruikt.

Leg uit wat u precies gaat doen en geef aan of dit pijn zal doen. Geef de patiënt indien mogelijk 'invloed' op wat er gebeurt. U kunt bijvoorbeeld een patiènte vragen of zij wil meekijken bij speculumonderzoek. Ook kunt u een patiènt vragen welke houding hij of zij prefereert bij een rectaal toucher.

Leg bij nog niet bevestigde vermoedens van mishandeling of seksueel misbruik de anamnese en de bevindingen bij lichamelijk onderzoek toch tamelijk precies vast. Zo zal voor u en uw collega's een eventueel patroon sneller duidelijk worden.

Sla een voor de patiënt als ingrijpend ervaren gebeurtenis niet alleen op in uw hoofd, maar ook in het dossier.

Neem de gebeurtenis ook op in de problemenlijst en gebruik waar mogelijk ICPCcodes, zodat de informatie op lange termijn toegankelijk blijft. Soms geven ingrijpende gebeurtenissen pas na jaren problemen, en dan bent u ze misschien vergeten of niet langer de huisarts van de patiënt. 
Benadruk dat herbeleving, vermijding en prikkelbaarheid normale reacties zijn op een ingrijpende gebeurtenis.

Mensen die net een ingrijpende gebeurtenis hebben meegemaakt, zijn vaak bang dat ze gek aan het worden zijn, of dat ze onbeheersbaar agressief worden, of dat het huilen nooit zal stoppen als zij daar eenmaal aan toegeven. Het is belangrijk om uit te leggen dat deze gevoelens gewoon zijn; in de loop van de tijd zullen de flashbacks, het huilen en de prikkelbaarheid vanzelf afnemen.

\section{Stimuleer sociale steun van de directe omgeving van de patiënt.}

Steun van familie en vrienden is belangrijk voor een goede verwerking. De huisarts kan hierover voorlichting geven, eventueel ook aan de gezinsleden. Verder kan de patiënt zelf worden gestimuleerd om diens sociale netwerk zoveel mogelijk te mobiliseren. Denk ook aan verwijzing naar een vrijwilliger van het Buro Slachtofferhulp (via de politie).

Leg aan patiènten uit dat het belangrijk is om een balans te vinden tussen vermijding en herbeleving.

De patiënt moet aan de ene kant elke dag wat tijd nemen om met het voorval bezig te zijn en aan de andere kant de normale dingen zoveel mogelijk weer oppakken. Overigens kan een advies om de confrontatie aan te gaan door bijvoorbeeld de plek van de overval op te zoeken of weer zelf te gaan autorijden, hard overkomen. Breng dat dus voorzichtig.

Wijs patiënten op de nadelige effecten van middelen die gevoelens dempen (kalmeringsmiddelen en alcohol, maar ook drugs als hasj en XTC). Het dempen van gevoelens heeft op de lange termijn nadelige gevolgen voor de verwerking. Aan mensen die heel slecht slapen kan voor enkele dagen een slaapmiddel worden voorgeschreven.

Als klachten van herbeleving, vermijding en prikkelbaarheid lang blijven aanhouden, moet de patiënt worden verwezen.

De genoemde klachten kunnen wijzen op een posttraumatische stress-stoornis. Bij klachten die langer duren dan een maand, is de prognose matig, maar een deel van de patiënten zal dan nog spontaan herstellen. Klachten die langer dan drie maanden duren, zijn reden tot verwijzing naar een Riagg.

Wees bij kinderen terughoudend met het afnemen van een gedetailleerde anamnese.

Kinderen zijn suggestibel. Het afnemen van een gedetailleerde anamnese kan bij een verwijzing de beoordeling door en het beleid van gespecialiseerde hulpverleners beïnvloeden. 


\section{Oefenstof *}

In dit cahier heeft u informatie gekregen over de consultvoering met mensen die een ingrijpende gebeurtenis hebben meegemaakt. Daarbij is belicht welke voorkeuren patiënten hebben voor de manieren waarop de huisarts hiermee omgaat. Ook zijn de knelpunten van huisartsen besproken, en mogelijke oplossingen hiervoor. In onderstaande oefenstof kunt u stilstaan bij de manier waarop u zelf omgaat met deze problematiek.

\subsection{Oefenstof voor de individuele huisarts}

\section{Casus 1}

Haal een patiënt voor de geest die u consulteerde na een ingrijpende gebeurtenis. Dit kan van alles zijn, behalve voortgaand geweld in het gezin. Voorbeelden zijn: een ongeval, beroving, brand, mishandeling op straat, aanranding of verkrachting, marteling, vluchtsituatie, oorlog, vredesmissies.

(Indien u geen patiënt voor de geest kunt halen, ga dan door naar vraag 9 en 10.)

1. Wat dacht u toen de patiënt over de gebeurtenis vertelde?

2. Heeft u zelf ooit een dergelijke gebeurtenis meegemaakt? Zo ja, hoe bent u daar destijds mee omgegaan?

- U kunt in aanmerking komen voor accreditering door het Toetsblad in te vullen en naar het NHG op te sturen. Wanneer u de 'Oefenstof' samen met anderen doorneemt, is accreditering van de bijeenkomst van uw huisartsen- of toetsgroep mogelijk: neem voor meer informatie hierover contact op met uw DHV. 
3. Heeft u de patiënt voorlichting gegeven? Zo ja, welke?

4. Vindt $u$ de voorlichting zoals weergegeven in het cahier relevant?

5. Had $u$ het idee dat de patiënt zelf (met behulp van familie of vrienden) de gebeurtenis in de komende weken tot maanden zou verwerken? Zo ja, wat gaf u dat idee?

6. Wat heeft u genoteerd over deze gebeurtenis (onder welke ICPC-code), en heeft u deze in de problemenlijst opgenomen?

7. Wat was uw oordeel over de wijze waarop u dit consult gevoerd heeft?

8. Zijn er punten waarop $u$ anders gehandeld zou hebben, nu u dit cahier heeft doorgenomen?

Onderstaande twee vragen zijn alleen bedoeld voor degenen die geen eigen casus konden bedenken.

9. Wat zouden redenen kunnen zijn dat u geen patiënt voor de geest kon halen? 
10. Lees de casus uit de 'Warming-up' nog eens door en beantwoord vervolgens vraag 1, 2, 4 , en 6.

\section{Casus 2}

Haal een patiënt voor de geest waarvan u zelf het vermoeden had dat deze thuis mishandeld en/of seksueel misbruikt werd.

(Indien u geen eigen casus kunt bedenken, beantwoord dan alleen vraag 19.)

11. Heeft u dit vermoeden ter sprake gebracht? Zo nee, waarom niet? (Ga door naar vraag 19.) Zo ja, weet u nog welke formulering u daarvoor gebruikte?

12. Hoe specifiek/concreet vindt u deze manier van vragen?

13. Hoe reageerde de patiënt op uw vraag?

14. Werd uw vermoeden bevestigd door de patiënt?

15. Hoe voelde u zich bij dit antwoord?

16. Heeft $u$ uw vermoeden/de gebeurtenis genoteerd? Zo ja, hoe en waar? 
18. Zijn er punten waarop $u$ anders gehandeld zou hebben, nu u dit cahier heeft doorgenomen?

De volgende vraag is alleen voor degenen die geen eigen casus konden bedenken of die vraag 11 ontkennend hebben beantwoord.

19. Wat zouden redenen kunnen zijn dat u geen patiënt voor de geest kon halen? Of, indien $u$ vraag 11 ontkennend heeft beantwoord, wat kan daarvan de reden zijn?

\subsection{Oefenstof voor in een groep huisartsen}

Ter bespreking van de stof uit dit cahier met collega's volgen hier twee oefeningen.

Dit kan het best worden gedaan in een kleinere groep (maximaal vijftien huisartsen).

1. Beantwoord de vragen uit de oefenstof voor de individuele huisarts en neem de antwoorden in tweetallen door.

Neem hiervoor twintig minuten de tijd.

2. Hiernaast zijn enkele stellingen opgenomen over ingrijpende gebeurtenissen. Verzoek de deelnemers bij iedere stelling aan te geven of ze het ermee eens of oneens zijn.

Bespreek de beweringen als volgt:

- vraag de deelnemers die het met een bewering eens zijn hun hand op te steken;

- vraag vervolgens degenen die het niet eens zijn met de bewering om hun hand op te steken;

- vraag twee van de deelnemers met tegengestelde meningen hierover in discussie te gaan;

- benadruk dat het gaat om het krijgen van inzicht in de achtergronden van de opvattingen en emoties;

- bespreek, indien relevant, hoe de deelnemers een conflict tussen taakopvatting en emoties hanteren.

Neem hiervoor dertig minuten de tijd. 
Ik denk bij elke klacht van een vluchteling met geweldservaringen aan een mogelijk verband met die ervaringen.

Ik heb er genoeg van mij in klachten die het gevolg zijn van een whiplash te verdiepen.

Het zou goed zijn voor patiěnten die fysieke klachten zoals hoofdpijn of buikpijn hebben na een ingrijpende gebeurtenis als zij begrijpen dat hun klachten daarmee samenhangen.

Ik durf niet naar geweld in het gezin te vragen als ik niet heel zeker ben van mijn zaak. Stel je voor dat het niet zo is.

Ik weet niet of ik de emoties kan hanteren van iemand van mijn eigen leeftijd die door een gezinslid wordt mishandeld.

Kinder- en vrouwenmishandeling komt met name voor in de lagere sociale klassen.

Bij vrouwenmishandeling denk ik vaak: ze blijft toch zelf bij deze man.

Als ik geweld in het gezin signaleer, moet ik er vervolgens ook iets mee, en dat vind ik niet gemakkelijk.

Bij partnermishandeling ben ik bang om met de dader te maken te krijgen.

Kinderen bedenken soms dat ze misbruikt zijn om aandacht te krijgen.

Sommige van de verhalen die ik hoor van vluchtelingen over martelingen zijn zo gruwelijk dat ik ze niet kan geloven. Ik kan me niet voorstellen dat mensen elkaar dat aandoen.

Als ik over een ingrijpende gebeurtenis begin, gat dat veel tijd kosten. Daarvoor heb ik het te druk.

Ik kan niet al te zeer op haar ervaringen doorgaan, want ze zegt dat haar vader de pleger is. Hij is ook patiènt bij mij.

Als ze niet zelf beginnen over geweld in het gezin, vraag ik me af of het wel mijn taak is me met die gezinszaken te bemoeien. 


\section{Leestips}

\section{Geraadpleegde en aanbevolen literatuur}

1. Anonymus. Factsheet Seksueel Misbruik. Utrecht: TransAct, 1998.

2. Mol SSL, Dinant GJ, Metsemakers JFM, Knottnerus JA. Incidentieverschillen van (gewelddadige) ingrijpende gebeurtenissen in landelijke registratiesystemen, enquêtes in de bevolking en onderzoek onder huisartsen; een literatuuroverzicht. Nederlands Tijdschrift Geneeskunde 1999;143(25):1308-14.

3. Frenken J. Seksueel misbruik van kinderen: aard, omvang, signalen, aanpak. Den Haag: Ministerie van Justitie, 2001.

4. Van der Velden PG, Eland J, Kleber RJ. Handboek voor opvang na rampen en calamiteiten. Utrecht: Thema, 1997.

5. Mol SSL, Dinant GJ, Vilters-van Montfort PAP, Metsemakers JFM, Van den Akker M, Arntz A, Knottnerus JA. Traumatic events in a general practice population: the patient's perspective. (Geaccepteerd voor publicatie in Family Practice.)

6. Boland G. Hulpverleners over seksueel geweld: moet ik er dan direct naar vragen? Utrecht: Stichting Tegen Seksueel Geweld, 1988.

7. Kersten-van Beek A, Vink J. Huisarts en seksueel geweld. Utrecht: Bunge, 1996.

8. Herman J. Trauma en herstel, de gevolgen van geweld, van mishandeling thuis tot politiek geweld. Amsterdam: Wereldbibliotheek, 1999.

9. Wolzak A. Kindermishandeling. Signaleren en handelen. Utrecht: NIZW, 2001. 


\section{Colofon}

Aan dit cahier werkten de volgende mensen mee:

Auteur:

Saskia Mol

Redactie:

Ron Helsloot

Liesbeth van der Jagt

Ans Stalenhoef

Kees in 't Veld

Ontwerp cahiers:

Studio Bassa, Culemborg

Illustraties:

Marcel Jurriëns (tekeningen)

Hans van der Voort (tekst)

Opmaak:

Léon Morselt

Deze uitgave zou niet tot stand zijn gekomen zonder de deskundige inbreng van enkele referenten, waarvoor onze hartelijke dank. 
De kwaliteit en het resultaat van het hindelen van huisartsen worden sterk bepaald door hun vermogen goed me patiënten en collega's te communiceren. Patiènten geven keer op keer aan vooral een huisarts te willen die luistert, zich inleeft in hun situatie en Jegrip heeft voor wat een klacht, een aandoening of ongerustheid voor henbetekent. Bovendien blijken patiênten grote behoefte aan voldoende en jiste informatie te hebben.

Dit alles vraagt om de nodige commuicatieve vaardigheden en een 'open' houding van de huisarts. In de beroepopleiding is hiervoor al wel aandacht, maar in de nascholing nog relaief weinig.

In de reeks 'Huisarts en patiênt; cahies over communicatie en attitude'

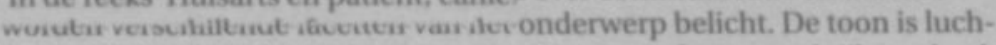
ting en onnodig getheoretiseer is vermeden. Een of meer praktijkvoorbeelden vormen steeds het uitgangspunt.

Na de 'warming-up' komen wetenswaardigheden over het betreffende onderwerp aan de orde. Vervolgens worden hints en adviezen gegeven om het beschrevene in praktijk te kunnen brengen.

leder cahier bevat oefenstof en leestips. De oefenstof leent zich voor individueel gebruik, maar kan ook samen met collega's worden doorgenomen. De cahiers zijn elk voor anderhalf uur nascholing geaccrediteerd.

De inhoud van de cahiers is ongetwijfeld voor iedere huisarts nuttig en wil stimuleren tot verder nadenken en nascholen.

Nederlands Huisartsen Genootschap

Lomanlaan 103

Postbus 3231

3502 GE Utrecht

$030-2881700$ 


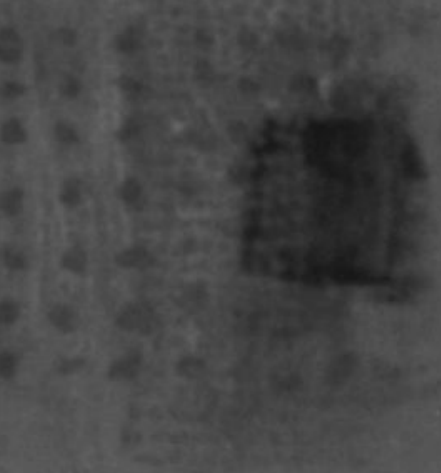

